\title{
ANÁLISE EXPLORATÓRIA DE DADOS: IDENTIFICACÃO DE UM ÚNICO "OUTLIER" EM DADOS DE EXPERIMENTOS DELINEADOS EM BLOCOS CASUALIZADOS
}

ANA BEATRIZ COSTA CZERMAINSKI

Orientador: Prof. Dr. ANTONIO FRANCISCO IEMMA

Dissertação apresentada à Escola Superior de Agricultura "Luiz de Queiroz", da Universidade de São Paulo, para obtenção do título de Mestre em Agronomia. Área de Concentração: "Estatística $\theta$ Experimentação Agronômica".

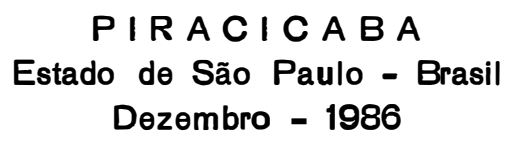




\section{AGRADECIMENTOS}

Ao Prof. Dr. Antonio Francisco lemma pela orientação.

Ao Corpo Docente do Departamento de Matemática e Estatística da ESALQ/USP, pelos ensinamentos recebidos.

Aos : colegas do Departamento de Matemática e Estatística da Universidade Federal de Pelotas pelo apoio e oportunida de de realização do Curso.

Ao colega Eng? Agr? Lusbi Herrera Sandoval pelas valiosas su gestões e apoio recebidos na realização deste trabalho.

Ao colega Eng? Agro João Riboldi pela colaboração e troca de idéias.

Ao meu esposo, Eng? Agr? Paulo Ricardo Dias de 01 iveira pelo constante incentivo e participação em todos os momentos.

A todos que, direta ou indiretamente, colaboraram para a realização desta dissertação. 
$\mathbf{i} \mathbf{i} \mathbf{~}$

INDICE

Pàgina

RESUMO $\ldots \ldots \ldots \ldots \ldots \ldots \ldots \ldots \ldots \ldots \ldots \ldots \ldots \ldots \ldots \ldots$

SUMMARY $\ldots \ldots \ldots \ldots \ldots \ldots \ldots \ldots \ldots \ldots \ldots \ldots \ldots \ldots \ldots \ldots \ldots$ vi

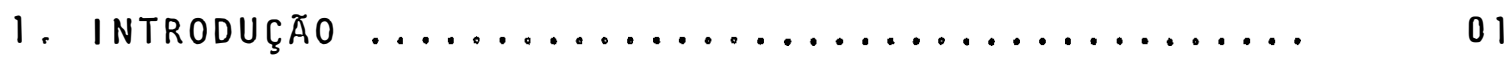

2. REVISATO DE LITERATURA .......................... 04

2.1. Aspectos da teoria dos "outliers" ........ 04

2.2. "Outliers" em delineamentos experimentais. 12

2.3. O modelo de Gauss-Markov e os resíduos .... 19

2.4. Residuos nos ensaios com dois fatores .... 27

2.5. A deteç̧ão de um valor discordante ........ 31

2.5.1. Gráficos de probabilidade normal ... 34

2.5.2. Os métodos propostos por GENTLEMAN e WILK (1975a, 1975b) ............ 46

2.6. Um teste de discordância para um único "outlier" ....................... 50

2.7. Homogeneidade de variâncias e aditividade 2.7.1. Homogeneidade de variâncias ....... 54

2.7.2. Aditividade ................ 56

2.8. Procedimentos remediadores na presença de uma observação aberrante ............ 58

3. MATERIAL E METOdOS ........................ 61

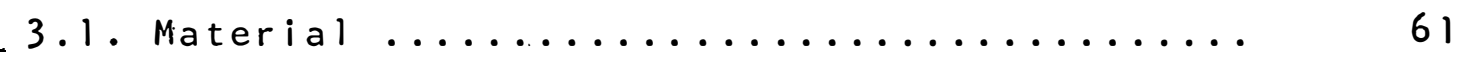

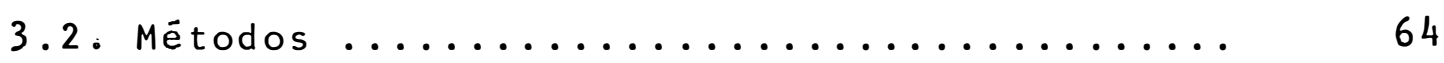

3.2.1. Obtenção dos resíduos e suas correla

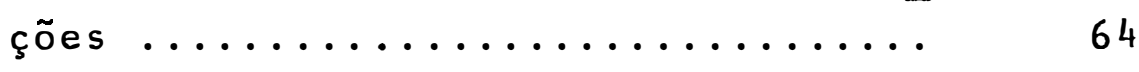

3.2.1.1. Modelo linear ........... 64

3.2.2.2. Matriz de projeção e correlações entre resíduos ..... 
3.2.2. Escolha de uma estratégia para a ana lise exploratóría dos dados ........

3.2.2.1. Avaliação do padrão geral dos dados ................

3.2.2.2. Identificação de um valor

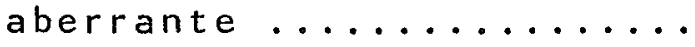

3.2.2.3. Verificação da homogeneidade de variancias de tratamentos e da aditividade do $\operatorname{modelo} \ldots \ldots \ldots \ldots \ldots \ldots$

3.2.3. Anālise da variância $\ldots \ldots \ldots \ldots$

4. APRESENTAÇÃO DE EXEMPLOS $\ldots \ldots \ldots \ldots \ldots \ldots \ldots$





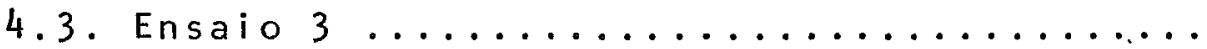

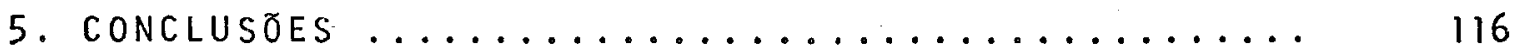

6. LITERATURA CITADA $\ldots \ldots \ldots \ldots \ldots \ldots \ldots \ldots \ldots \ldots$

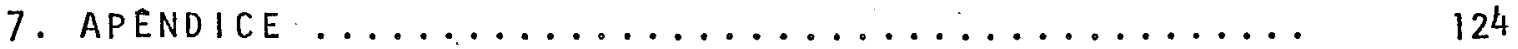




\section{AnÁlise Exploratória de Dados: Ident ificacão de UM Único "Outlier" em Dados de Experimentos Delineados em BLOCOS CASUALIZADOS}

\section{Autora: ANA BEATRIZ COSTA CZERMAINSKI}

Orientador: Prof. Dr. ANTONIO FRANCISCO IEMMA

\section{RESUMO}

A análise exploratória de dados é hoje consi. derada uma etapa imprescindível e simultânea às análises conclusivas, que têm por base modelos usuais em anālise de dados. A moderna anālise da variância, sem dúvida, envolve o cálculo e avaliação de resíduos. Dentre os aspectos comumente considerados em uma análise de residuos, situa-se o reconhecimento e avaliação de "outliers". No entanto, em delinea mentos experimentais, esse reconhecimento é feito, geralmente, através de métodos informais. Isto se deve ao fato de que, com raras e felizes exceções, o desenvolvimento do estudo dos "outliers" disponível na bibliografia tem estado basicamente preso aos modelos de regressão ou às amostras isoladas.

Este estudo visou apresentar uma sequência de procedimentos que levam à identificação de um ünico "outlier" e promover sua adaptação, atravēs do modelo linear de Gauss- 
vi .

Markov, aos delineamentos em blocos casualizados, tão úteis na pesquisa agropecuāria.

$$
\text { Apresentou-se tambēm a anālise exploratōria de }
$$
dados, bem como um procedimento remediador, para dados de exem plos numēricos, buscando evidenciar algumas das sequelas causadas pela presença de um único valor aberrante e, à medida do possível, como amenizà-las. 
vi i .

EXPLORATORY DATA ANALYSIS: IDENTIFICATION OF A SINGLE OUTLIER IN EXPERIMENTS DESIGNED IN RANDOMIZED BLOCKS

\author{
Author: ANA BEATRIZ COSTA CZERMAINSKI \\ Adviser: Prof. Dr. ANTONIO FRANCISCO IEMMA
}

SUMMARY

The exploratory data analysis today is considered a simultaneous and indispensable phase to a conclusive analysis that has as base usual models in data analysis. The modern analysis of variance, without question, envolves the calculation and evaluation of residuals. Among the commonly considered aspects in a residuals analysis, one can find the reconnaissance and evaluation of outliers. However, in experimental designs the reconnaissance is done, generally, through informal methods. This occurs because, with rare and successful exceptions, the development of the outliers study, available in the literature, has been basically connected to the regression models and to isolated samples.

This study aimed to show a series of procedures that lead to the identification of a single outlier and promote its adaptation, through Gauss-Markov's linear model, to the randomized blocks designs, very useful on the agriculture research. 
Exploratory data analysis was also presented, as well as a helpful procedure, for numerical examples data, seeking to show some of the effects caused by the presence of a single outlier and, as much as possible, how to undermine them. 


\section{INTRODUS.ÃO}

Sem dūvida, o modelo linear de Gauss - Markov $y=x \theta+\varepsilon$, nas suas mais diversas caracterizações, tem sido a ferramenta básica para a análise de dados na pesquisa agropecuāria, bem como em muitas outras āreas do saber. Este fato pode estar justificado na estrutura simples dos erros exigida pelo modelo.

No entanto, em geral, os dados experimentais podem apresentar estruturas mais complexas para a matriz de covariâncias e, nesse caso, os resultados de inferências obtidas com base no modelo $1 \sigma^{2}$ são seriamente comprometidos. Sob esse aspecto, as técnicas da anālise de resíduos têm sido fun damentais para detectar violações e sugerir procedimentos remediadores.

Para muitos autores (por exemplo, GENTLEMAN e WILK, 1975b), a moderna anālise da variância envolve o cálculo e anälise dos resíduos, no sentido de verificar se pelo menos aproximadamente, $\varepsilon \sim N\left(\Phi, 1 \sigma^{2}\right)$. 
De fato, a maioria dos procedimentos em anälise exploratöria de dados considera resíduos como o reflexo natural da impropriedade das pressuposições básicas da anälise da variância. De modo geral, isso significa verificar se os erros são homocedásticos, se säo independentes e, ainda, se têm distribuição normal. Além disso, outro aspecto a ser levantado è a presença de dados aberrantes ou "outliers".

A preocupação com dados aberrantes é da māxima importância, pois muitos autores, dentre eles ANSCOMBE e TUKEY (1963), WILK e GNANADESIKAN (1968) e BARNETT e LEWIS, (1978, 1984), referem-se à influência destes dados, particularmente, em processos para se verificar ausência de normalidade, não -aditividade removivel e heterogeneidade de variancias. De fa to, COOK e WEISBERG (1982) recomendam que procedimentos para constatar a ocorrência de observações discrepantes sejam apli cados antes de ser testada qualquer outra hipótese, pois a sua presença afetará todos os testes formais que utilizam residuos.

Além de não ser de rotina na pesquisa em geral, considerar a ocorrência de "outlier", quando isso é feito, é comum o uso de métodos informais na sua deteç̧ão. Isso se justifica, talvez, porque os métodos de reconhecimento e avaliação de "outliers" são inümeros, porém tendem a aparecer dispersos na literatura. Com raras exceções, cite-se, por exemplo, o texto de BARNETT e LEWIS (1978, 1984), a grande maioria dos mētodos disponíveis aplicam-se ao estudo de re 
gressão e de amostras isoladas e sãoraros para casos de delineamentos experimentais (modelo de análise de variancia). Não obstante, existe razoável disponibilidade de métodos para o modelo linear geral.

Pretende-se apresentar aqui um levantamentodos métodos mais significativos da teoria dos "outliers", visando sua divulgação entre profíssionais da pesquisa agropecuá ria, e uma sequência de procedimentos que levam ao reconheci mento de um único valor aberrante, procurando adequá-los aos modelos de experimentos delineados em blocos casualizados, tão ūteịs a tais pesquisadores. 


\section{REVISÃO DE LITERATURA}

\subsection{Aspectos da teoria dos "OUtliers"}

o interesse por observações aberrantes è tão antigo quanto a tentativa de basear conclusões em um conjunto de dados estatisticos. Segundo BECKMAN e COOK (1983), comentärios de Bernoulli, registrados em 1777 , indicam que a prátí ca de descartar dados aberrantes era comum há mais de duzentos anos. Os primeiros esforços para desenvolver métodos estatisticamente objetivos para lidar com "outliers" foram relatados por volta de 1850 (BECKMAN e COOK, 1983). Nesse senti do, BARNETT e LEWIS (1984) citam Chauvenet, 1863.

Entretanto, consideraçōes, de diversos autores ilustram que o conceito de "outlier" é subjetivo e, a despeito da vasta literatura disponível, existem divergências em re lação a conceitos básicos e à pröpria nomenclatura.

BECKMAN e COOK (1983). apontam que devido à ên- 
fase dada a modelos nos ültimos anos, o termo "outlier" está sendo usado por alguns autores para indicar qualquer observação que não provenha da população alvo. Contudo, na maioria dos trabalhos falta até mesmo uma definição informal. BECKMAN e COOK (1983), considerando ser a terminologia dominante nos ültimos vinte anos, adotam as seguintes noções:

- "discordant observation": qualquer observação que pareça surpireendente ou discrepante para o pesquisa dor;

- "contaminant": qualquer observação que não é uma realização da população alvo;

- "outlier": termo geral para fazer referência a qualquer dos anteriores.

A tradução literal para a lingua portuguesados dois primeiros termos sãoobservação discordante e contaminante, res pectivamente. O termo "outlier" significa "estranho", "foras teiro", "... a parte do lote principal".

BARNETT e LEWIS (1978) usam o termo "outlier" e "discordant observation" onde BECKMAN e COOK (1983) usam, respectivamente, "discordant observation" e "contaminant". Na terminologia de BARNETT e LEWIS (1978) uma"discordant observation" não aparece necessariamente como um "outlier".

Aqui serão usados os termos "valor", "dado" ou "observação" acompanhados de "aberrante" ou "discrepante" (ís to é, "valor aberrante", etc.) com o sentido geral empregado 
por BECKMAN e COOK (1983) ao usarem o termo "outlier", podendo ser usado o próprio.

Historicamente, métodos objetivos que tratam de dados aberrantes são empregados somente após serem rotulados como "valores suspeitos" através de uma inspeção visual dos da dos.

BARNETT (1978) e BARNETT e LEWIS (1978) distin guem quatro procedimentos básicos para lidar com "outliers":

(a) acomodação: diz respeito ao uso de métodos robustos de análise de dados ou inferências, ou seja, métodos que não sejam afetados pe la presença de valores aberrantes;

(b) incorporação: é a substituição do modelo adotado por outro no qual nenhuma observação pareça discrepante;

(c) identificação: um "outlier" pode servir pa ra indicar, por si só, a presença de fatores experimentais de importância prática, podendo levar o pesquisador a estabelecer um modelo alternativo ou voltar sua atenção especificamente sobre o novo fator, inclusive com novo experimento baseado no modelo apropriado para a população que pro duz os contaminantes;

(d) rejeição: esta regra está limitada a casos onde o modelo inicial é inviolável.e a 
alternativa é descartar o valor discordante e tratar apropriadamente o restante dos dados.

Para BARNETT e LEWIS (1978), um processo de de teç̧ão deve ser empreendido como um pré-requisito dos procedimentos acima, sendo indispensável a todos exceto ao processo de ajustamento de valores, ou seja, à acomodação. Um teste estatístico, chamado por estes autores de teste de discordância, deve decidir se o "valor discordante" detectado ("outlier" na terminologia de BARNETT e LEWIS) pode ser considerado como um membro da população principal de onde se obteve a amostra. O diagrama apresentado na Figura l constitui um resumo, esquematicamente, dos diferentes interesses e princípios a respeito de observações discordantes, conforme BARNETT e LEWIS (1978).

BECKMAN e COOK (1983) distinguem dois procedimentos amplos para lidar com a possibilidade de ocorrência de "outliers". O primeiro método refere-se à sua identificação, para posterior estudo. O segundo método diz respeito à adaptação ou acomodação desses dados por modificações convenien tes do modelo ou dos métodos de análise: Para esses autores, a identificação é mais importante, sendo que pode levar a:

(a) sua subsequente rejeição;

(b) nova e importante informação contida em va riáveis concomitantes que teriam sido omitidas; 


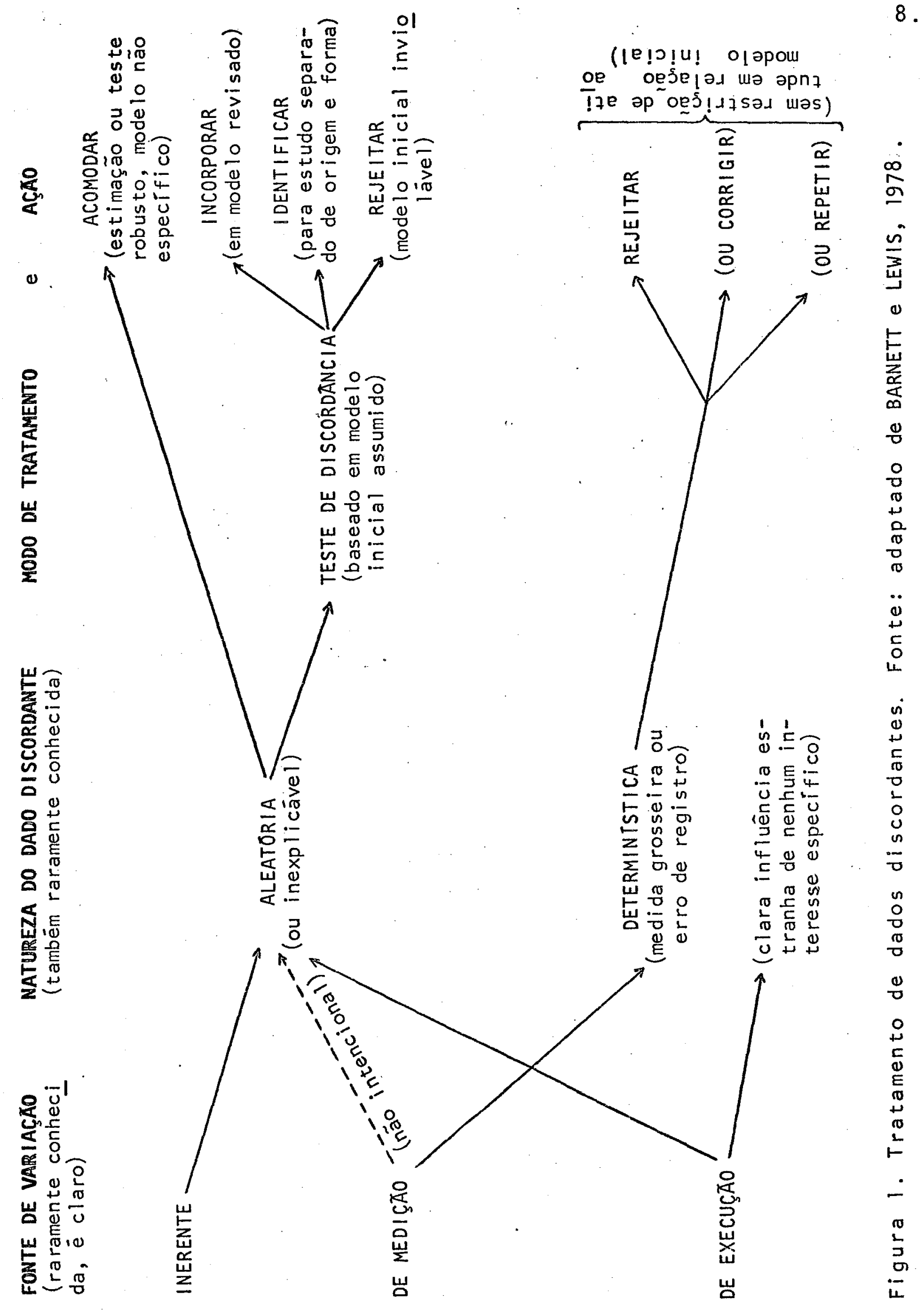


(c) sua incorporação at ravēs de uma revisão do modelo;

(d) um reconhecimento da fragilidade inerente dos dados, levando a experimentos adicionais.

E de se observar que BECKMAN e COOK

utilizam o termo identificação para designar a fase em que se constata a ocorrência da observação discordante e a sua carac terização, ou não, como sendo um contaminante. ROSADo* refe re-se a três fases na identificação de "outliers": a detecção, a escoliha do modelo de discordância e o teste de discordân cia.

A escolha do modelo de discordância diz respe to ao estabelecimento das hipóteses nula e alternativa a serem examinadas no teste de discordância. Neste teste estatistico, a hipótese nula ou hipótese de trabalho expressa o mode lo probabilístico bàsico que gera todos os dados. A hipótese alternativa expressa o modo em que o modelo pode ser modifica do para incorporar ou explicar prováveis contaminantes. Em BARNETT e LEWIS (1978) está detalhada uma variedade de diferentes formas de hipótese alternativa lou modelos de geração de "outliers").

*ROSADO, F.F. (Universidade de Lisboa, Lisboa). Comunicação pes soal, 7\%. S.INAPE, Campinas, SP, 1986. 
0 tipo mais comum de hipótese alternativa como um modelo para a geração de "outliers" é aquele referido em BARNETT e LEWIS (1978) como a alternativa de deslizamento("slip page alternative"l). Nesse caso, todas as observações, exceto um pequeno nümero $k$, são independentemente obtidas de um modelo inicial $F$ com parámetro de posição $\mu$ e de dispersäo $\sigma^{2}$; as $k$ observações restantes são independentes e surgem de uma versão modificada de $F$ em que o valor de $\mu$ ou de $\sigma^{2}$ está alte rado. Na maioria dos trabalhos publicados Fé uma distribuição normal (BARNETT e LEWIS, 1978).

Embora Ferguson (1961), segundo BARNETT e LEWIS (1978), tenha dado uma expressão mais geral à alternat i va de deslizamento normal, a formulação dos modelos misturados para explicar a presença de "outliers" é anterior. DIXON (1950) sugeriu dois típos de modelos de contaminação em amostras de população normal com média $\mu$ e variância. $\sigma^{2}$ :

A. Uma ou mais observações de $N\left(\mu+\lambda \sigma, \sigma^{2}\right), \lambda \neq 0$

B. Uma ou mais observações de $N\left(\mu, \lambda^{2} \sigma^{2}\right), \lambda^{2}>1$

A representa a ocorrência de um "erro" no valor da mëdia. B representa a ocorrência de um. "lerroll originado por uma população com a mesma média, mas com uma variância maior que a da amostra.

$\mathrm{Na}$ terminologia de COOK et alii (1982) e BECK MAN e COOK (1982), $\underline{\text { A }}$ é o modelo de média modificada ("mean- 
shift model"') e indica a mistura de elementos $N\left(\mu, \sigma^{2}\right)$ e $N\left(\mu+\lambda \sigma, \sigma^{2}\right), \lambda \neq 0, e$ B $\bar{e}$ o modelo de variancia inflacionada ou modificada ("variance-inflation model") ou, ainda, modelo de deslizamento da variância ("variance-slippage model") para a mistura de $N\left(\mu, \sigma^{2}\right)$ e $N\left(\mu, \lambda^{2} \sigma^{2}\right), \lambda^{2}>1$.

Muitos trabalhos sobre métodos de identificação de dados aberrantes referem-se à situação em que o pesqui sador deseja obter uma amostra aleatória univariada de populaçäo normal (por exemplo, QUESENBERRY e DAVID, 1961). Ou seja, o analista deseja uma amostra de população não contamina da, de modo a não violar as hipóteses básicas de processos de inferência.

Vários caminhos tem sido propostos para estender a metodologia referente à "outliers" em amostras simples ao acaso para situações com dados estruturados, isto é, os da dos disponíveis são valores de uma variāvel-resposta que sofre a influência de outras variāveis (independentes) ou de diferentes fatores qualitativos. 0 primeiro caso, suscita um estudo de modelos de regressão. 0 segundo caso, diz respeito, é claro, aos delineamentos experimentais analisados sob um modelo linear através de técnicas de anälise de variância (ANOVA).

A literatura referente ao estudo de "outliers" em regressão é vasta. Citam-se aqui TIETJEN et ali i (1973), DACHS e CARVALHO (1984), COOK (1979), DRAPER e JOHN (1981), COOK e WEISBERG (1982), dentre outros. 
Não é objeto desse trabalho o estudo dos valores discrepantes em modelos de regressão.

\section{2. "Outliers" em Delineamentos experimentais}

"Intuitivamente, a provável integridade de uma observação è refletida pela sua conexão com outras observações obtidas sob.condições similares" (BECKMAN e COOK, 1983). Nesse sentido, o analista conta com o fator "surpresa"; o impacto que um dado discordante causa em relação aos restantes.

BARNETT e LEWIS (1978) chamam a atenção para uma distinção crucial na ocorrência de dados discordantes: em uma amostra univariada ordenada, uma inspeção visual pode levar à deteç̧ão de um valor discordante pois que ele estará ví sivel no final da amostra. Essa identificação subjetiva não é confiāvel em dados estruturados. Nesse caso, o provável "outlier" não é um simples valor extremo, mas ele rompe um padrão geral dos dados.

$$
\text { BROSS (1961) e BARNETT e LEWIS (1978, 1984) con- }
$$

sideram um exemplo, anteriormente apresentado por Daniel (1960), para discutir a dificuldade de identificação do valor discordante. A Tabela 1 apresenta as produções hipotéticas de um certo produto em diferentes níveis de dois fatores químicos $A$ e $B$. 
Tabela 1. Produções hipotéticas.

\begin{tabular}{llllll}
\hline & \multicolumn{3}{c}{ Niveis de B } & Total \\
\hline Niveis & 35 & 32 & 37 & 40 & 144 \\
de A & 29 & 29 & 34 & 36 & 128 \\
& 25 & 29 & 30 & 20 & 104 \\
& 19 & 25 & 25 & 35 & 104 \\
& 22 & 20 & 29 & 29 & 100 \\
\hline TOTAL & 130 & 135 & 155 & 160 & 580 \\
\hline
\end{tabular}

Fonte: BROSS (1961).

Se as vinte observações constituissem uma amos tra, os valores extremos $(19$ e 40$)$ seriam candidatos a aberrantes. E, ainda, a linha onde está o valor 40 (primeiro nível de Al poderia ser uma sub-amostra discrepante, porém esse é um efeito esperado no esquema de anâlise e que não serve de base para que.se suspeite da integridade dos dados. Por outro lado; a observação 20 na última coluna dos dados, é relativamente mais extrema dentro da coluna (e da linha) que qual quer outra. Ela parece romper um padrão geral de resultados onde os valores decrescem com os niveis de $A$ e crescem com os niveis de $B$.

Com base em avaliações desse tipo sobre o arranjo dos dados experimentais, BROSS (1961) estabelece uma de 
finição de um "outlier" em um experimento padronizado como sen do uma observação isolada que rompe, em algum sentido, o padrão de interrelação nos dados.

Além da dificuldade de detecção, um outro problema básico referente a "outliers" em resultados de experimento, apontado por BARNETT e LEWIS (1978), è a sua influêncía na anạlise da variância. O efeito na análíse da variância pode ser no sentido de encobrir efeitos significantes ou exibir efeitos aparentes, os quais não surgiriam em condições normais.

o efeito combinado do "outlier'e das têcnicas de anâlise de variância é salientado em BROSS (1961). Ele ressalta que a "contaminação" se expande, atingindo a linha, a coluna e a média geral, influenciando estimativas e testes de significância, 0 mesmo autor refere-se ao efeito do surgimento de significância ("star burst") especialmente no tado em experimentos fatoriais: a inclusão de determinada observação pode levar a uma análise da variância com efeitos principais e interações estatisticamente significantes.

Para ilustrar a distorção na anâlise da variân cia causada pela presença de "outliers" em dados experimentais, considere-se o exemplo apresentado por GENTLEMAN e WILK (1975a). Eles apresentam as anālises da variância dos dados de um ensaio de dois fatores $(8 \times 5)$, sem e com dois "outliers" introduzidos artificialmente. Na Tabela 2 estão os dados do exemplo, com os valores aberrantes entre parênteses. 
Tabela 2 .

\begin{tabular}{rrrrrr}
\hline & 1 & 2 & 3 & 4 & 5 \\
\hline 1 & 8,4883 & 11,3327 & 10,1865 & 8,5163 & 8,4653 \\
2 & 7,6039 & 11,6601 & 8,6973 & 7,7149 & 7,5774 \\
& & & & & $(10,3199)$ \\
3 & 7,6158 & 11,2652 & 8,2592 & 7,6454 & 7,5694 \\
4 & 7,4900 & 10,8051 & 8,8186 & 7,5517 & 7,4407 \\
& 7,5310 & 9,8628 & 8,2441 & 7,5251 & 7,4512 \\
6 & 7,4466 & 10,4725 & 8,1391 & 7,4697 & 7,3914 \\
7 & 7,3658 & 9,8933 & 7,7354 & 7,3356 & 7,2556 \\
8 & 7,8594 & 8,8630 & 7,9570 & 7,8906 & 7,8320 \\
\hline
\end{tabular}

Fonte: GENTLEMAN e WILK'(1975a)

Tabela 3. Anälise da variancia referente aos dados da Tabela 2.

\begin{tabular}{|c|c|c|c|c|c|c|c|}
\hline \multirow{2}{*}{$\begin{array}{l}\text { Fonte de } \\
\text { variação }\end{array}$} & \multirow{2}{*}{$\mathrm{GL}$} & \multicolumn{3}{|c|}{ Dados originais } & \multicolumn{3}{|c|}{ Dados com "outl iers" } \\
\hline & & SQ & $Q M$ & $F$ & $S Q$ & $Q M$ & $F$ \\
\hline Linhas & 7 & 7,6132 & 1,0876 & 5,50 & 13,1785 & 1,8826 & 2,42 \\
\hline Colunas & 4 & 48,9065 & 12,2266 & 61,88 & 40,5506 & 10,1376 & 13,03 \\
\hline Interação & 28 & 5,5337 & 0,1976 & & 21,7922 & 0,7783 & \\
\hline TOTAL & 39 & 62,0534 & - & . & 75,5214 & - & \\
\hline
\end{tabular}

Fonte: adaptada de GENTLEMAN e WILK (1975a) 
GENTLEMAN e WILK (1975a) consideram que o efe to mais dramätico ocorre na soma de quadrados da interação que cresce quase quatro vezes em relação a dos dados originais. Além disso, se fixado um $\alpha=0,01$ para testar o efeito de linhas, teremos significância com os dados originais e não significân cla na anälise com os dois "outliers", pois o teste $F$ para linhas cai de 5,5 (significativo a $\alpha=0,001$ ) para 2,42 (significativo para $\alpha \fallingdotseq 0,05)$, respectivamente.

Retomando-se o exemplo da Tabela 1 , pode se ve rificar a alteração na análise da variâncía quando se considera os dados originais da Tabela 1 e com o valor 20 substituido pela correspondente estimativa de minimos quadrados cujo valor ê 35 . A Tabela.4 contém os resultados das anälises de variância das duas situações.

Tabela 4. Anālise da variancia referente aos dados da Tabela 1 .

\begin{tabular}{|c|c|c|c|c|c|c|c|c|}
\hline \multirow{2}{*}{$\begin{array}{l}\text { Fonte de } \\
\text { variação }\end{array}$} & \multirow[b]{2}{*}{$\mathrm{GL}$, } & \multicolumn{3}{|c|}{ Dados originais } & \multicolumn{4}{|c|}{ Com a estimativa } \\
\hline & & SQ & $\mathrm{OM}$ & $F$ & $G L$ & SQ & QM & $\mathrm{F}$ \\
\hline Fator A & 4 & 368 & 92 & $5,47 * *$ & 4 & 323 & 80,75 & $13,26 * *$ \\
\hline Fator B & 3 & 130 & 43,33 & 2,57 & 3 & 253,75 & 84,58 & $13,89 * *$ \\
\hline Resíduo & 12 & 202 & 16,83 & - & 11 & 67. & 6,09 & - \\
\hline TOTAL & 19 & 700 & - & & 18 & 643,75 & - & \\
\hline
\end{tabular}


Naturalmente, a soma de quadrados residual fica diminuida, tendo-se substituído uma parcela pela estimativa de mínimos quadrados correspondente. Porêm, cabe salientar que essa redução é bem mais drästica com a substituição acima do que em qualquer outra parcela, na qual o valor original é substituido pela estimativa correspondente.

A maioria das técnicas para detecção de pontos discordantes ou para testar sua discordancia utiliza os residuos em relação ao modelo linear ajustado, como uma medida bạ sica da importância das observações individuais (BARNETT e LEE WIS, 1978).

Seguindo com os dados da Tabela 1 para ilustração, BROSS (1961) E BARNETT E LEWIS (1978). Obtiveram os residuos associados às observações, à partir do modelo linear aditivo

$$
y_{i j}=\mu+\alpha_{i}+\beta_{j}+\varepsilon_{i j}, \quad i=1, \ldots, 5 ; j=1, \ldots, 4
$$

ajustado aos dados, de modo que $\sum_{i=1}^{5} \alpha_{i}=\sum_{j=1}^{4} \beta_{j}=0$.

A tabela de residuos è a que segue (Tabeía 5).

Tabela 5. Resíduos ordinários associados aos dados da Tabela 1.

\begin{tabular}{lrrrr}
\hline \multicolumn{5}{c}{ Niveis de B } \\
\hline \multirow{2}{*}{ Niveis de A } & 2 & -2 & -1 & 1 \\
& 0 & -1 & 0 & 1 \\
& 2 & 5 & 2 & -9 \\
& -4 & 1 & -3 & 6 \\
\hline
\end{tabular}

Fonte: BROSS (1961). 
o residuo associado à observação de valor 20 na ültima coluna da Tabela 1 é o mais distante da média zero de todo o conjunto de residuos.

Segundo BECKMAN e COOK (1983), a idéia geral existente por trás dos mētodos para identificar um ünico "out lier" é associar os dados a um conjunto de $n$ estatisticas univariadas, uma para cada observação, que são inspecionadas visualmente ou, em alguns casos, usadas para construir testes de significância.

Para BRoSS (1961), o uso de resíduos não constitui uma base fidedigna para decidir se existem ou não valores discordantes em resultados de experimentos padronizados. A partir da idéia de efeito combinado entre contaminante e análise da variancia, ele considera que todos os residuos são afe tados por um "outlier", alêm das desvantagens de serem correlacionados e serem calculados sob um modelo nulo especificado previamente. BROSS (1961) sugere que a identificação de um "outlier" deve ser feita relativamente a um padrão percebido no arranjo dos dados ao invēs de um modelo especificado a prio ri. No entanto, BECKMAN e COOK (1983) consideram que isso parece impossivel de ser generalizado de um modo prático. "Outliers" devem ser julgados com algum modelo em mente e a sua presença indicará que o modelo considerado ou os dados estão inadequados. Também GENTLEMAN e WILK (1975b) consideram que existe um "outlier" relativamente a um modelo ou teoria préespecificados. 


\subsection{0 modelo de Gauss-Markov e os Residuos}

Seja. o modelo linear de Gauss-Markov

$$
{ }_{n} y_{1}=n_{n}{ }^{\theta}{ }_{1}+n^{\varepsilon_{1}}
$$

onde, $y$ è um vetor de realizações de variáveis aleatörias;

$X$ é uma matriz conhecida com posto $r[X]<\min \{n, p\}$;

$\theta$ é um vetor de parâmetros desconhecídos;

$\varepsilon$ è um vetor de variāveis aleatórias não observāveis, tal que $\varepsilon \sim N\left(\phi ; 1 \sigma^{2}\right)$.

Ao adotar-se o modelo (2.3.1) pressupõem-se as seguintes hipóteses básicas:

i) os diversos efeitos são aditivos;

ii) a esperança do vetor aleatório $\varepsilon$ é nula, is to $\bar{e}, E\left(\varepsilon_{i}\right)=0, i=1, \ldots, n$;

iiil as componentes de $\varepsilon$ têm variância constante e não são correlacionadas, ou seja, $\operatorname{var}\left(\varepsilon_{i}\right)=\sigma^{2}$ e $\operatorname{cov}\left(\varepsilon_{i}, \varepsilon_{j}\right)=0, i \neq j ;$

iv) a distribuição de $\varepsilon_{i}, i=1, \ldots, n$, é normal.

A condição (i) é imposta pelo modelo, sendo que os efeitos variam conforme o delineamento usado. E, naturalmente, as hipôteses (iii) e (iv) implicam que os $\varepsilon_{i}$ 's são independentes. 
Nesse contexto, a teoria geral fornece o sistema de equações normais $x^{\prime} x \theta^{\circ}=x^{\prime} y$, sempre consistente. As soluções usuais de mínimos quadrados para $\theta$ podem ser obtidas de

$$
\theta^{0}=(x \cdot x)^{G} x^{\prime} y
$$

onde $\left(X^{\prime} X\right)^{G}$ indica qualquer inversa generalizada de $X^{\prime} X$.

Assim, a aproximação de mínimos quadrados para o vetor $y$, que é a projeção ortogonal de y no espaço gerado pelas colunas de $X, \bar{e}$ obtida por

$$
\hat{y}=x \theta^{\circ}=x\left(x^{\prime} X\right)^{G} X^{\prime} y=H y
$$

invariante para qualquer $\theta^{\circ}$ solução das equações normais ou, equivalentemente, para qualquer escolha de $\left(X^{\prime} X\right)^{G}$.

A representação geomētrica da aproximação de mínimos quadrados para y está na Figura 2 .

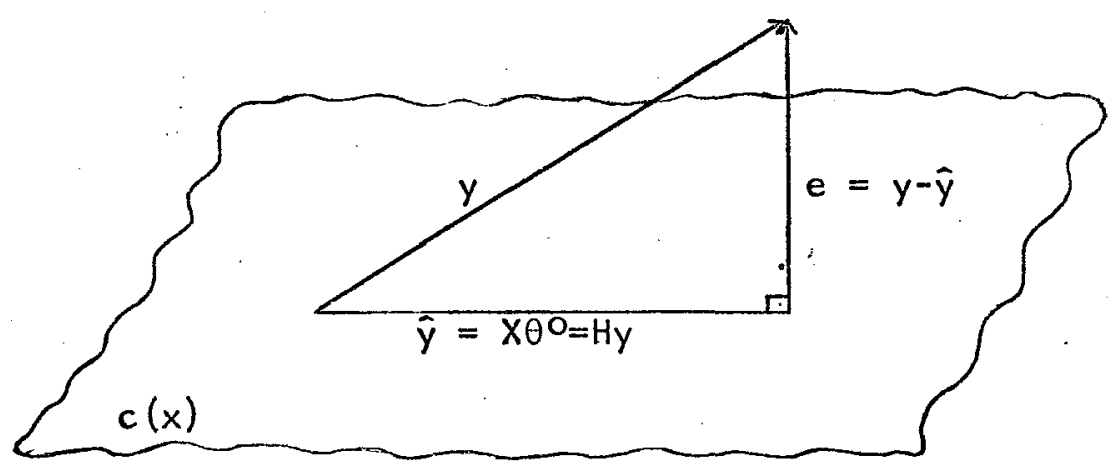

'Figura 2. Representação geomētrica do ajuste de mînimos quadrados. 


$$
H=X\left(X^{\prime} X\right)^{G} X^{\prime} \text { é a matriz de: projeção de } y \text { no }
$$
espaço-coluna de $X$ ou matriz chapēu (segundo HOAGLIN e WELSCH (1978), o termo matriz chapéu - "hat matrix" - foi introduzi do por John Tukey).

H é invariante para qualquer inversa generalizada $\left(X^{\prime} X\right)^{G}$, e como é simétrica e idempotente tem-se que:

$$
V(\hat{y})=H \sigma^{2}
$$

o vetor de resíduos ordinärios é dado por

$$
e=y-\bar{y}
$$

Logo,

$$
e=y-x \theta^{0}=(1-H) y
$$

A relação entre e e $\underline{\varepsilon}$ é encontrada substituindo-se y por $x \theta+\varepsilon$ em $(2.3 .2)$

$$
e=(1-H)(X \theta+\varepsilon)
$$

portanto,

$$
e=(1-H) \varepsilon
$$

\section{A identidade $(2.3 .3)$ demonstra claramanteque} a relação entre e e $\varepsilon$ depende somente da matriz chapēu, $H$. COOK e WEISBERG (1982) chamam a atenção para a importância do comportamento de $H$ : se as suas componentes são suficientemente pequenas, e servirá como um substituto razoãvel de $\underline{E}$; ca so contrārio, a utilidade de $\underline{e}$ pode ser limitada. 
Importantes discussões sobre as propriedades de He, especialmente, sobre os elementos de sua diagonal são apresentados em HOAGLIN e WELSCH (1978), DACHS e CARVALHO (1984) e COOK e WEISBERG (1982).

A esperança de e ë nula e a matriz de variâncias e covariancias è

$$
V(e)=(1-H) \sigma^{2}
$$

Logo, a variância de um resíduo particular é $\left(1-h_{i j}\right) \sigma^{2}$ e a covariância entre $e_{i} e e_{j} ; i \neq j$, é $\left(-h_{i j}\right) \sigma^{2}$. ou seja, mesmo quando os erros são de variāncia constante e nâo-correlacionados, tem-se resíduos de variâncias diferentes e correlacionados (DACHS e CARVALHO, 1984).

A correlação entre $e_{i}$ e e $\mathbf{j}, \mathbf{i} \neq j$, é dada por

$$
\rho_{i j}=\frac{-h_{i j}}{\left[\left(1-b_{i j}\right)\left(1-h_{j j}\right)\right] 1 / 2}, i \neq j, i=1, \ldots, n ; j=1, \ldots, n \text {. }
$$

A performance de diversos testes de discordâncla na identificação de "outliers" depende da estrutura de correlação entre os resíduos (BECKMAN e COOK, 1983).

A soma de quadrados de residuos usual è e'e. Comio $s^{2}=y^{\prime}(1-H) y \mid(n-p)$ é um estimador não tendencioso de $\sigma^{2}$, então

$$
\hat{v}(e)=(I-H) s^{2}
$$

Segundo BECKMAN e COOK (1983), muitos traba- 
Ihos sobre observações aberrantes em modelos lineares estão baseados, algumas vezes de modo implícito, no modelo de mēdia mod if icada

$$
y=x \theta+D \gamma+\varepsilon
$$

onde $\gamma$ è um vetor de $k$ parâmetros desconhecidos; Dô uma matriz $n \times k$ com colunas $u_{i}\left(u_{i 1}, u_{i 2}, \ldots, u_{i k}\right)$ nas quais aparece 1 na íésịma posição e zeros nas restantes. As demais quantidades foram definidas anteriormente.

Supondo que apenas um valor, digamos o i-ësimo caso, é suspeito de ser aberrante, admite-se o modelo

$$
y=x \theta+D_{i} \gamma+\varepsilon
$$

onde $D_{i} \bar{e}$ um vetor $n$ dimensional com o $i$-ésimo elemento igual a 1 e todos os outros iguais a zero (COOK e WEISBERG, 1982).

Sob o modelo de variância inflacionada, o vetor $y$ tem a seguinte representação (COOK et alii, 1982):

$$
y=x \theta+z
$$

onde $X$ e $\theta$ são como em $(2.3 .1)$ e $Z$ e um vetor de erros aleató rios de dimensão $n$, sendo $z=\pi \cdot \varepsilon$, onde $\pi$ é uma matriz desconhe cìda, $\varepsilon$ tem distribuição multinornal com média zero e matriz de covariâncias

$$
\sigma^{2}\left[\begin{array}{ll}
W & 0 \\
0 & 1(n-1)
\end{array}\right]
$$


$\operatorname{com} \sigma^{2}>0$ e $W>1$. Ou seja, o modelo homocedāstico $y=x \theta+\varepsilon$ é verdadeiro para todos menos um caso desconhecido com varian cia $w \sigma^{2}, \forall>1$.

Segundo BECKMAN e COOK (1983), o modelo de mé dia modificada é mais adequado quando hä interesse em identificação ao invês de acomodação de dados discrepantes.

CoOK et alii (1982) demonstram que a posição estimada do possível contaminante não é necessariamente a mes ma para ambos os modelos: a identificação de um dado discre pante depende da forma do modelo de discordancia ("outlier model"L assumido ao operar os dados. Porém, sob os dois mode los, a posição estimada será a mesma quando o maior resíduo studentizado corresponde ao maior resíduo ordinärio. E isso será verificado em delineamentos experimentais balanceados, on de todos os resíduos têm a mesma variância (BARNETT e LEWIS, 1978 ; COOK et ali $\mathrm{i}, 1982$; BECKMAN e COOK, 1983).

Diversas transformações dos residuos ordinārios têm sido sugeridas, visando obter estatísticas que tenham distribuição nula independente de qualquer quartidade, jẩ que os resîduos ordinârios têm distribuição dependente de $\sigma^{2}$ e de $h_{i j}$.

A nomenclatura para os värios resíduos que podem ser derivados dos residuos ordinärios, $e_{i}$, é infelizmente confusa (VELLEMAN e WELSCH, 1981; ATKINSON, 1981 ).

Segundo COOK e WEISBERG (1982), o termo studen tịzação serve para descrever a divisão de uma estatística de- 
pendente em escala, por exemplo U, por uma estimativa do parâ metro de escala, T, resultando numa estatistica independente $S=U / T$. Uma distinção entre studentização interna e studentização externa diz respeito a serem U e T dependentes (se T foi obtida dos mesmos dados) ou independentes, respectivamen te.

Assim, os residuos studentizados internamente são definidos por

$$
\begin{gathered}
r_{i}=\frac{e_{i}}{\left[\nabla_{m}\left(e_{i}\right)\right]^{1 / 2}}=\frac{e_{i}}{s \cdot\left(1-h_{i}\right)^{1 / 2}}, \\
i=1, \ldots, n
\end{gathered}
$$

onde $s^{2}=e^{\prime} e /(n-p)$ é a soma de quadrados de residuos. Para COOK e WEISBERG (1982) e DACHS e CARVALHO (1984), a distribui ção de $r_{i}$ não é exatamente uma $t$ de student porque as variáveis do numerador e denominador não são independentes.

os residuos studentizados externamente são de-

finidos por:

$$
t_{i}=\frac{e_{i}}{s_{(i)}\left(1-h_{i i}\right)^{1 / 2}}, i=1, \ldots, n
$$

onde $s^{2}(i)$ é um estimador de $\sigma^{2}$ que é independente de $e_{i}$, ou seja, é obtido sem o i-èsimo caso (COOK e WEISBERG, 1982; DACHS e CARVALHO, 1984). DACHS e CARVALHO (1984) apresentam uma ma neira de calcular cada $s^{2}(i)$ da fórmula (2.3.8) sem precisar 
fazer cada ajuste apōs a retirada do i-ésịmo ponto:

$$
s^{2}(i)=\frac{n-p}{n-p-1} s^{2}+\frac{e_{i}^{2}}{(n-p-1)\left(1-h_{i i}\right)}, i=1, \ldots, n
$$

Sob normalidade $s^{2}(i)$ e $e_{i}$ são independentes e $t_{i}$ tem distribuição $t$, de Student, com n-p-l graus de liber dade.

DRAPER e SMITH (19.66) e NETER e WASSERMAN (1974), dentre outros, utilizam a forma

$$
d_{i}=\frac{e_{i}}{s}, i=1, \ldots, n
$$

onde $s^{2}=$ QMRes, sendo chamados de residuos padronizados ou standartizados. Esta definição baseia-se em que, sob a hipótese de que $\varepsilon_{i} / \sigma \sim N(0,1), i=1, \ldots, n$, cerca de $95 \%$ dos $e_{i} / s$, $i=1, \ldots, n$, pertencem ao intervalo $[-2,2]$.

COOK e WEISBERG (1982) reservam o termo residuo studentizado para referirem-se a (2.3.7), tal como em LUND (1975), COOK e PRESCOTT (1981) e BARNETT E LEWIS (1984). DACHS e CARVALHO (1984), atribuem o termo aos residuos studentizados externamente (forma 2.3.8), assim como em HOAGLIN et alii (1983), no qual a forma (2.3.7) representa os residuos padronizados. Aqui, serä adotado o termo resíduo studentizado para a forma $(2.3 .7)$.

os residuos studentizados são muito usados para detectar observações discordantes sob um determinado mode- 
lo linear. Usualmente, é dada atenção especial à observação com o maior resíduo absoluto studentizado e esta é considerada a mais provāvel de ser um contaminante. Para cook e PRESCOTT (1981), o teste estatístico básico para um ünico "outlier" no modelo linear de Gauss-Markov envolve o resíduo studentizado absoluto māximo, $\max \left|r_{\mathbf{i}}\right|$. Esta estatistica é usualmente associada à alternativa do deslizamento da mêdia, isto é, (2.3.1) está correto exceto pelo fato de que a esperança de uma observação desconhecida está modificada, ou que a esperança de um elemento de $\varepsilon$ é diferente de zero.

\subsection{Residuos nOS ENSAIOS COM DOIS FATORES}

o modelo linear para ensaios de classificação dupla com uma observação por casela ("two-way layouts") ê lar gamente utilizado para ilustrar a aplicação de métodos de diagnóstico atravês. de resíduos em delineamentos experimentais (BARNETT e LEWIS, 1978; COOK e WEISBERG, 1982). Notadamente, mëtodos de deteç̧ão e avaliação de dados discordantes para ensaios com dois fatores tem sido discutidos mas tendem a aparecer dispersos na literatura (GENTLEMAN e WILK, 1975a, 1975b; DANIEL, 1978; JOHN E DRAPER, 1978; STEFANSKY, 1971).

Para COOK e WEISBERG (1982) desde o aparecimento do teste de aditividade de Tukey (1249), essa gama de métodos tem sido desenvolvida valendo-se da vantagem da estrutu- 
tura especial das tabelas de dois fatores e que podem, frequen temente, ser generalizados para "layouts" de maior dimensão.

o modelo aditivo linear usual para experimentos de classificação dupla, assumindo que não existe interação entre os dois fatores $A$, com $r$ niveis, $e B$, com $c$ niveis, é caracterizado da seguinte forma:

$$
\gamma_{i j}=\mu+\alpha_{i}+\beta_{j}+\varepsilon_{i j}, \quad i=1, \ldots, c ; j=1, \ldots, r
$$

onde, $y_{i j}$ é. a observação resultante da parcela que recebeu 0 nivel $i$ do fator $A$ e o nivel $j$ do fator $B$. Sob as restrições paramétricas $\sum_{i=1}^{c} \alpha_{i}=0$ e $\quad \sum_{j=1}^{r} \beta_{j}=0, \mu$ è a média ge ral do experimento; $\alpha_{i}$ é o efeito do nível i do fator $A_{;} \beta_{j} \hat{e}$ o efeito do nivel $j$ do fator $B$ e $\varepsilon_{i j}$ é o erro experimental as sociado a $y_{i j}$.

$$
\begin{aligned}
& \text { Com as restrições citadas, tem-se que } \\
& \hat{\mu}=\bar{y}_{\ldots} \\
& \bar{\alpha}_{\mathbf{i}}=\bar{y}_{\mathbf{i}}-\bar{y}_{\ldots}, \quad \mathbf{i}=1, \ldots, \mathrm{c} \\
& \bar{B}_{\mathbf{j}}=\bar{y}_{\mathbf{j}}-\bar{y}_{\ldots}, \quad \mathbf{j}=1, \ldots, r
\end{aligned}
$$

logo, os resíduos ordinärios serão obtidos do seguinte modo

$$
e_{i j}=y_{i j}-\bar{y}_{i .}-\bar{y}_{\cdot j}+\bar{y}_{\ldots,} \quad i=1, \ldots, k, \ldots, c ; j=1, \ldots, 1, \ldots, r .
$$

Neste caso, sob balanceamento, $n=c r$ e $p=r+c-1$ e a matriz chapēu, H, terá como componentes (HOAGLIN e WELSCH, 1978):

$$
h_{i j, i j}=(r+c-1) / c r=p / n
$$


29.

$$
\begin{aligned}
& h_{i j, i l}=(c-1) / c r, \quad l \neq j \\
& h_{i j, k j}=(r-1) / c r, k \neq i \\
& h_{i j, k l}=-1 / r c, \quad k \neq i, \quad l \neq j
\end{aligned}
$$

Portanto, de $(2.4 .1)$ vê-se que todos os elemen tos da diagonal de H são iguais, o que ocorre em todos os experimentos balanceados.

A variancia dos residuos é dada por

$$
\operatorname{Var}\left(e_{i j}\right)=\left(1-\frac{r+c-1}{r c}\right) \sigma^{2}=\left(1-\frac{p}{n}\right) \sigma^{2}, i=1, \ldots, c ; j=1, \ldots, r
$$

Logo, a distribuição de um residuo individual será a normal com média 0 e variância $(r-1)(c-1) \sigma^{2} / r c$.

As covariâncias são:

$$
\begin{aligned}
& \operatorname{Cov}\left(e_{i j}, e_{i 1}\right)=-(c-1) \sigma^{2} / c r, \quad 1 \neq j \\
& \operatorname{Cov}\left(e_{i j}, e_{k j}\right)=-(r-1) \sigma^{2} / c r, \quad k \neq i \\
& \operatorname{Cov}\left(e_{i j}, e_{k l}\right)=\sigma^{2} / c r, \quad k \neq i ; 1 \neq j
\end{aligned}
$$

Assim, tem-se nos ensaios com dois fatores ape nas três valores diferentes para as correlações entre residuos:

$$
\begin{aligned}
\rho_{i j, i l}= & -1 /(r-1), 1 \neq j \text {, entre residuos correspondentes a } \\
& \text { observações com o mesmo nivel (tratamento) i do fa- } \\
& \text { tor } A .
\end{aligned}
$$


$\rho_{i j, k j}=-1 /(c-1), k \neq i$, entre residuos correspondentes a ob servações com o mesmo nivel (tratamento) j do fator B.
$\rho_{i j, k l}=1 /(c-1)(r-1), k \neq i, l \neq j$, entre residuos corres- pondentes a observações de diferentes níveis de $A$ e de. B .

Como as variâncias dos resíduos são iguais em um ensaio de classificação dupla, não existe dístinção essencial entre os resíduos ordinärios e os studentizados.

o modelo para ensaios de dois fatores com único "outlier", admitindo a alternativa de deslizamento da mëdia, é expressado por BARNETT e LEWIS (1978) pela forma

$$
y_{i j}=\mu+\alpha_{i}+\beta_{j}+a_{i j} \sigma+\varepsilon_{i j}, i=1, \ldots, c ; j=1, \ldots, r
$$

onde $a_{i j} \neq 0$ para exatamente um par $(i, j)$ e è zero para os de mais.

GENTLEMAN e WILK (1975a) e COOK e WEISBERG (1982) mos tram o padrão de valores esperados de resíduos, quando um va$\operatorname{lor} \lambda$ for adicionado à observação $(1,1)$. Os valores esperados caem em quatro categorias: (a) a cela que contēm o "outlier"; (b) aquelas celas não na mesma linha ou coluna do "out liner"; (c) celas na mesma linha e (d) celas na mesma coluna que o "outlier". Generalizando as expressões, isto é, para qualquer posição $(i, j)$ onde se adicione o valor $\lambda$ tem-se que:

$$
E\left(e_{i j}\right)=\lambda(c-1)(r-1) / c r
$$




$$
\begin{aligned}
& E\left(e_{i l}\right)=-\lambda(c+1) / c r, \quad 1 \neq j \\
& E\left(e_{k j}\right)=-\lambda(r+1) / c r, k \neq i \\
& E\left(e_{k l}\right)=\lambda / c r, k \neq i ; 1 \neq j
\end{aligned}
$$

Portanto, se $\lambda>0$, o residuo correspondente à observação aumentada $y_{i j}$ ficará aumentado de um valor $\Delta_{i j}=\lambda(r-1)(c-1) / c r$ assim como todos os residuos $e_{k l}, k \neq i$, $1 \neq \mathbf{j}$ ficarão acrescidos de $\Delta_{k l}=\lambda / c r$. Os residuos das observações da mesma linha e da mesma coluna que $y_{i j}$ diminuirão. Se $\lambda<0$, a observação $y_{i j}$ sofrerá um decrēscimo; o seu residuo bem como os de observações em outras linhas e colunas serão reduzidos. Os resíduos das observações na mesma linha ou na mesma coluna que $y_{i j}$ ficarão aumentados. Evidentemente, que a variância dos residuos per manece inalterada.

\title{
2.5. A DETECGÃO DE UM VALOR DISCORDANTE
}

\begin{abstract}
ANSCOMBE O TUKEY (1963) e BARNETT P LEWIS
(1978) alertam que quase todos os procedimentos de análise de residuos são sensiveis à presença de valores aberrantes ou contaminantes. Particularmente, os testes para detectar ausência de normalidade, para não-aditividade removivel e heterogeneidade de variâncias geram indicações de comportamento discrepante de uma ou mais observações. No entanto, o uso
\end{abstract}


destes testes com o objetivo de detectar prováveis "outliers" poderia gerar confusão, uma vez que seu resultado poderá ser devido a esses dados ou ao verdadeiro propósito do teste.

Para ANSCOMBE e TUKEY (1963) os processos gräficos são os menos afetados pela presença de dados aberrantes.

Uma variedade de métodos gräficos tem sido usa da para investigar a validade das vārias hipóteses básicas da anālise da variância de dados obtidos sob um delineamento experimental. Para BARNETT e LEWIS (1978), mais frequentemente estão sob investigação as hipōteses de normalidade, aditividade ou homocedasticidade, porém as performances dos gráficos são sensiveis à presença de valores aberrantes. Nessa situação, é dificil distinguir, especificamente, que hipótese bâsịca não está satisfeita e está causando o comportamento ina ceitâvel do gráfico. Porém, algumas vezes o método é maís sen sivel a um aspecto do que outro e isso deve ser levado em consideração na avaliação grāfica.

Entretanto, existem procedimentos gräficos dirigidos especificamente a exibir ou examinar valores discordantes (BARNETT e LEWIS, 1978). NETER e WASSERMAN (1974) recomendam a construção do gräfico dos residuos padronizados (na forma 2.3 .9 ) contra os $y$ estimados, no qual o resíduo correspondente ao "outlier" apresenta o comportamento mostrado na Figura 3 . 


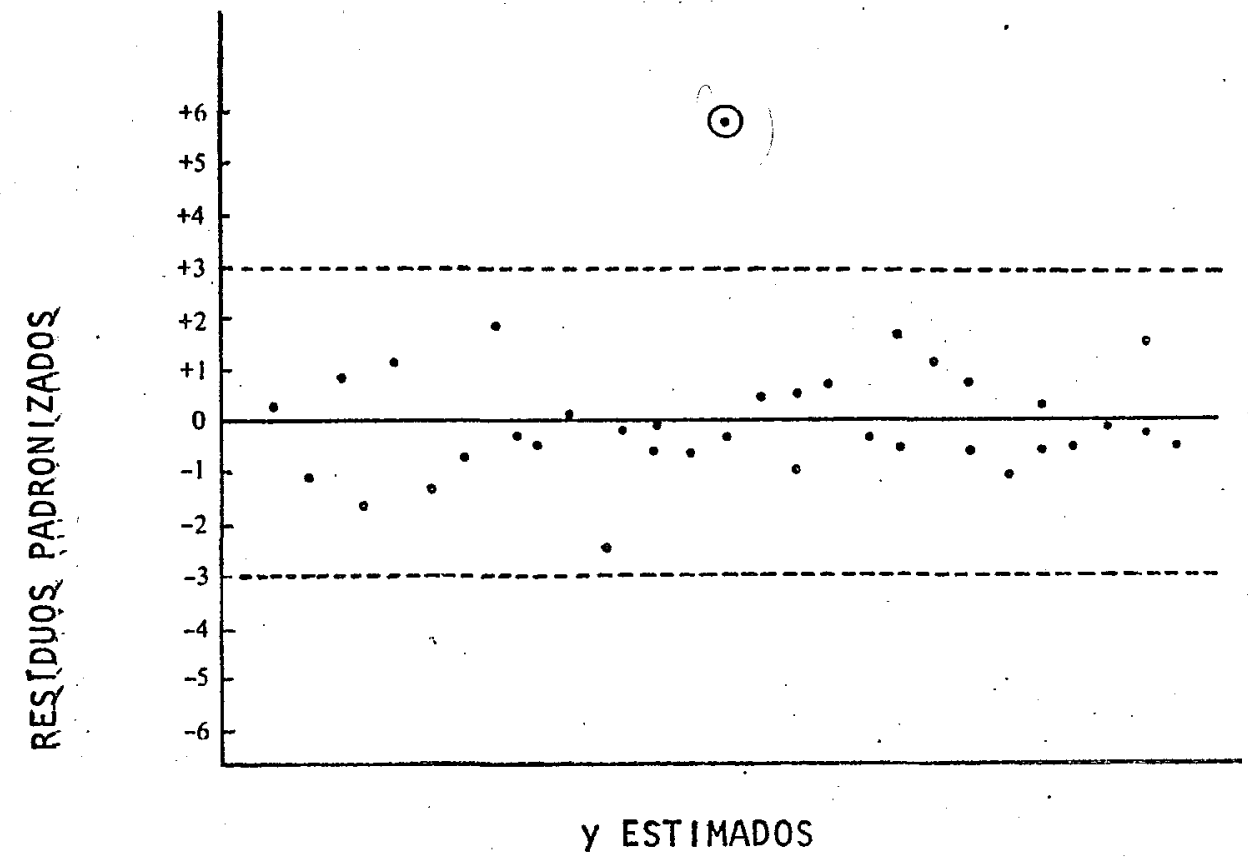

Figura 3. Grâfico dos residuos padronizados contra y estimados, caracterizando a presença de um "outlier". Fonte: Adaptado de NETER e WASSERMAN (1974).

Diversos autores como WILK e GNANADESIKAN (1968), SEBER (1977), BARNETT e LEWIS (1978), DANIEL e WOOD (1980), COOK e WEISBERG (1982) admitem a utilidade de gräficos de pro babilidade na detecção de um valor discordante em amostrasuni variadas.

Para DANIEL e WOOD (1980) tanto o gräfico de residuos contra valores y ajustados como o gráfico de proba bilidade normal dos residuos são necessários para detectar um ponto discordante. Para ilustração do comportamento dos gráficos, os autores apresentam os dois tipos construidos para um conjunto de 58 residuos com um "outlier" (Figuras 4 e 5 ). 
34.

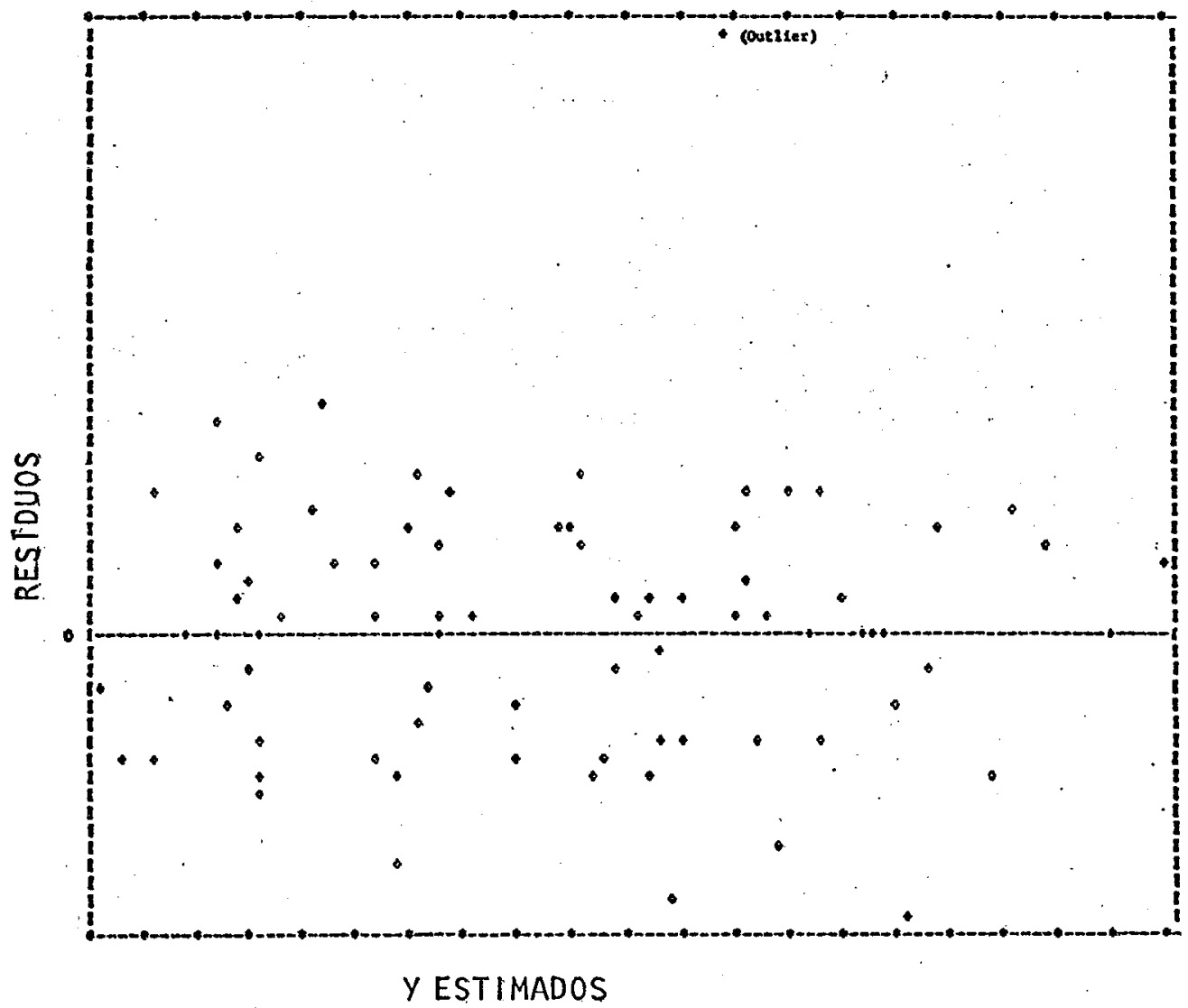

Figura 4. Gräfico dos resíduos ordinários contra y estimados. Fonte: Adaptado de DANIEL e WOOD (1980).

Em gráficos de probabilidade normal, o elemento discordante da "amostra" situa-se em um dos extremos do gräfico, enquanto os demais pontos tendem a uma linha reta (SE BER, 1977; DANIEL e WOOD, 1980; COOK e WEISBERG, 1982).

2.5.1. GRAFICOS DE PROBABILIDADE NORMAL

Os grấficos de probabilidade são usados comumente, como um complemento de um teste estatistico formal da 


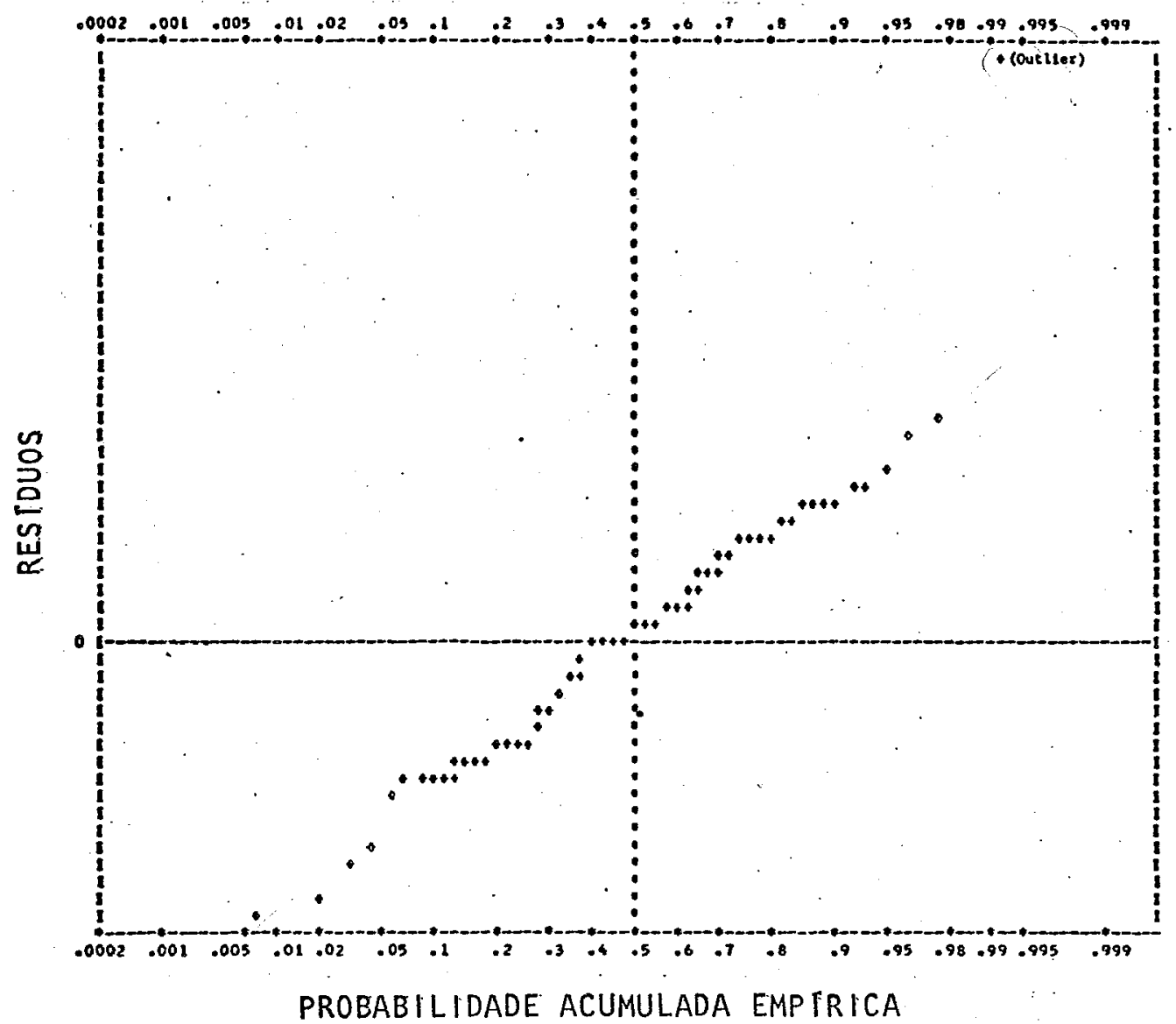

Figura 5. Gráfico de probabilidade normal de residuos ordinarios, cáracterizando a presença de um "outlier". Fonte: Adaptado de DANIEL e WOOD (1980).

hipótese distribucional. A idéia de complementar o teste escolhido não tem o sentido de confirmar ou colocar em dūvida a conclusão obtida do teste, mas simapenas visualizar melhor essa conclusão.

LOONEY e GULLEDGE (1985) sugerem o exame do grä fico probabilístico antes de ser efetuado um teste de hipótese formal, ao contrārio da idéia de ser um teste "aumentado" pelo gráfico. 
KIMBALL (1960) aponta très tipos de objetivos ao se usar um gráfico de probabilidade:

i) verificar se a amostra disponivel é oriunda de determinada população;

ii) obter estimativa do parâmetro de dispersão da distribuição que originou os dados;

iii) detectar valores discrepantes.

Esses objetivos podem sobrepor-se.

DANIEL e WOOD (1980) e COOK e WEISBERG

fazem referência à utilidade dos gráficos probabilísticos com os objetivos (i) e ( $i$ i i) acima.

De acordo com WILK e GNANADESIKAN (1968), a es sência de um grä́fico de probabilidade está em localizar os va lores amostrais ordenados contra alguns valores representativos, à partir de uma presumida distribuição nula padrão.

0 fundamento geral da construção de grä́icos de probabilidade normal é que se os valores de uma amostra dą da forem de uma população normal, então sua função de distribuição acumulada empírica deve estar "próxima" de $\Phi(x)$ na Figura 6 , para qual tem-se:

$$
\begin{aligned}
\Phi(x) & =\frac{1}{\sqrt{2 \pi}} \int_{-\infty}^{x} \exp \left\{-z^{2} / 2\right\} d z, \begin{array}{l}
\text { onde } z \text { è uma variävel } \\
\text { aparente, }
\end{array} \\
\text { e } \Phi\left(x_{0}\right) & =P\left(-\infty<x<x_{0}\right) .
\end{aligned}
$$




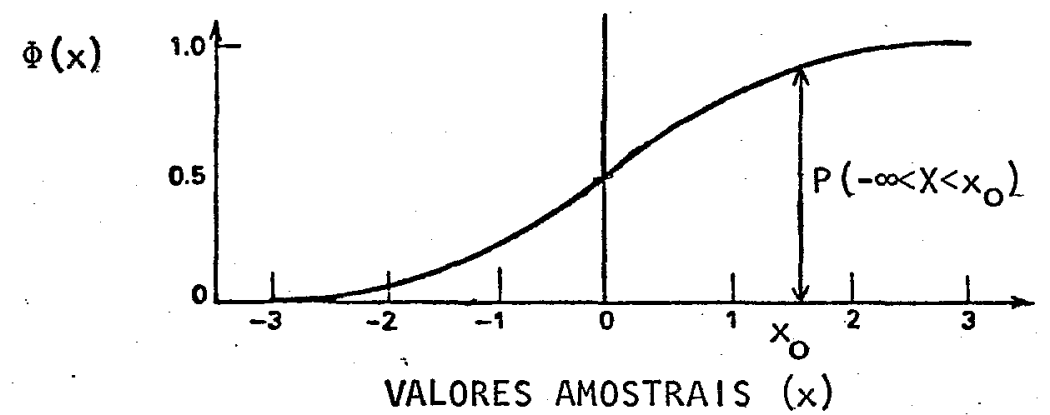

Figura 6. A função de distribuição normal.

A avaliação da proximidade à $\Phi(x)$ é facilitada pelo uso do papel normal de probabilidade cuja escala é tal que os valores da $\Phi(x)$ (teórica) formam uma linha reta. Ou se ja, a escala vertical do gráfico da figura 6 è transformada não uniformemente como mostra a Figura 7. Em papel de probabilidade normal, ográfico de $100 . \Phi(x)$ contra valores da variável $X \sim N(0,1)$ é uma linha reta.

Se $X \sim N\left(\mu, \sigma^{2}\right)$ o gräfico correspondente à $\mathrm{Fi}$ gura 7 será ainda uma linha reta, porém com diferente declividade e posição (SEBER, 1977).

$$
\text { Assim, sejam } x(1), x_{(2)}, \ldots, x_{(n)} \text { as estatisti }
$$

cas de ordem de uma amostra cuja função de distribuição (acumulada) é supostamente da forma $\Phi[(x-\mu) / \sigma]$, onde $\mu$ e $\sigma$ são os parãmetros de posição e dispersão, respectivamente. Para se construir um gräfico de probabilidade em papel normal de 


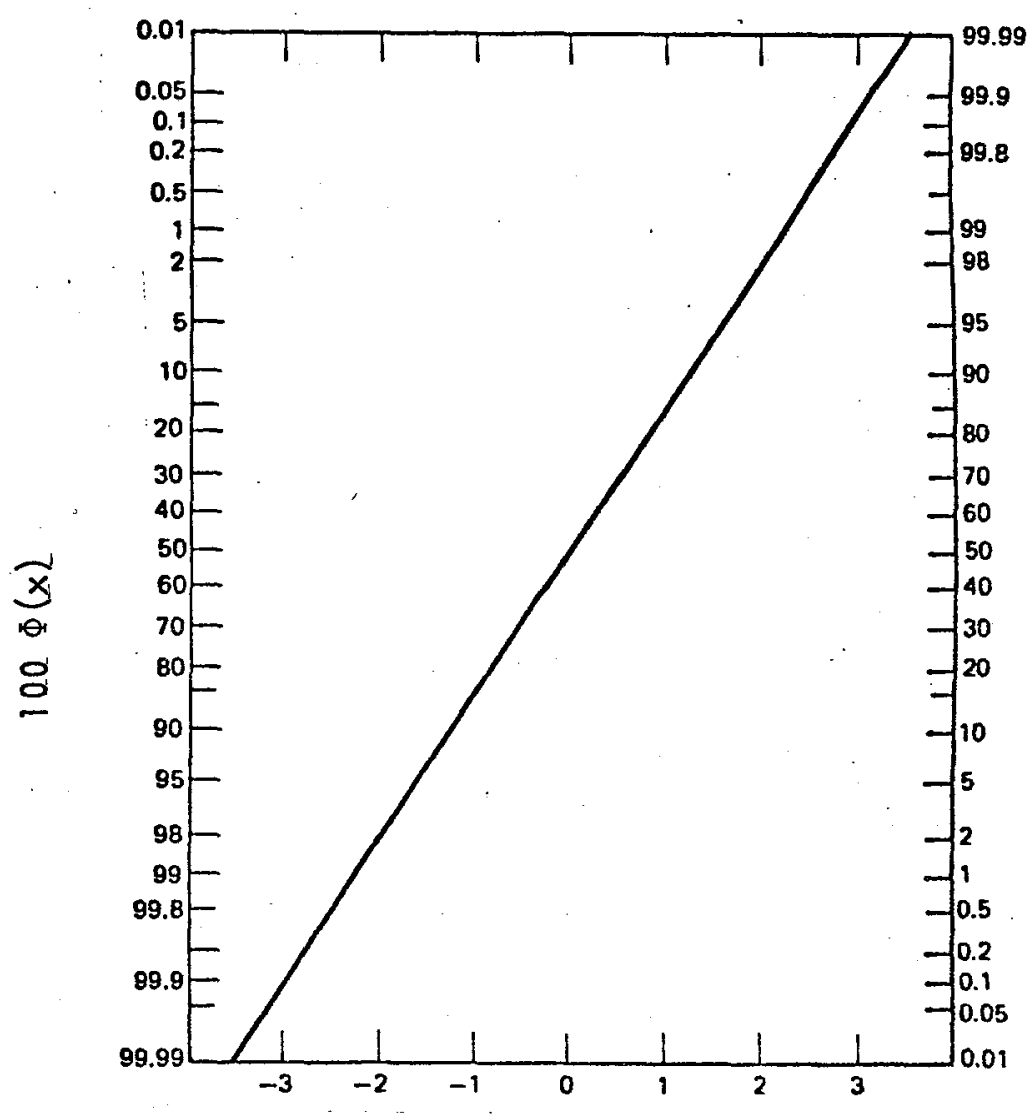

VALORES AMOSTRAIS $(x)$

Figura 7. A função de distribuição normal em papel de probabi lidade normal.

Fonte: adaptado de SEBER (1977).

probabilidade, a amostra de estatísticas de ordem $x_{(k)}$ é loca lizada no eixo de escala: linear (geralmente horizontal) contra $p_{k}$, no eixo de escala não linear, onde $p_{k}$ è uma estimativa. de $\Phi[(x(k)-\mu) / \sigma]$, isto é, é uma função de distribuição (acu mulada) empírica. Essa estimativa da probabilidade, $p_{k}$, é chamada posição de "plot" ("plotting position") e existem diversas fórmulas propostas para sua obtenção como será abor- 
dado. Sob a hipótese de que os $x_{k}{ }^{\prime} s$ formam uma amostra identicamente distribuida, $N\left(\mu, \sigma^{2}\right)$, espera-se um comportamento linear dos pontos rio papel de probabilidade.

Outra maneira de se construir um gráfico probabilístico normal pode ser obtida localizando-se o vetor observado de estatisticas de ordem, $x_{(1)}, x_{(2)}, \ldots, x_{(n)}$, contra o vetor esperado de estatísticas de ordem obtido com base na função de distribuição acumulativa, $F_{0}$, da variāvel padronizada $(X-\mu) / \sigma(L L O Y D, 1952)$. Nesse caso, ë dispensado o uso do papel normal de probabilidade. Espera-se uma relação $1 \mathrm{i}$ near entre os dois vetores de estatisticas de ordem, caso $x$ seja normal.

Para COOK e WEISBERG (1982), a construção do gräfico sem o papel de probabilidade pode ser dificultada pela inviabilidade de se obter valores exatos para as estatisti cas de ordem esperadas. Nesse caso, aproximações adequadas são obtidas de $\Phi^{-1}\left(p_{k}\right)$. Essas aproximações são quantis norma is correspondentes à k-ésima observação ordenada, isto é, se $p_{\grave{k}}$ é a estimativa de $\Phi[(x(k)-\mu) / \sigma]$, então o k-ēsimo quan ti 1 será $\Phi^{-1}\left(p_{k}\right)$.

Adequadamente, WILK e GNANADESIKAN (1968) denominam gräficos $Q-Q$ ("Q-Q plot"), de quantil "versus" quantil, a esses gräficos probabilísticos. De fato, localiza-se cada "quantil amostral", $x_{(k)}$, contra um correspondente "quan til teörico padrão", $\Phi^{-1}\left(p_{k}\right)$.

o problema da escolha da posição de "plot" tem 
sido discutido por muitos autores, dentre eles HARTER (1961), FILLIBEN (1975), CUNNANE (1978) e HOAGLIN et alii(1983) atribuem a Blom (1958) a proposta de aproximar a estimativa da probabilidade acumulada por meio da fórmula

$$
p_{k}=\frac{k-c}{n-2 c+1}
$$

onde $k=1, \ldots, n, e ́$ a ordem da observação na amostra ordenada de tamanho $n ; c$ è uma função de $n, 0 \leqslant c<1$.

ou seja, a k-ēsima estatística de ordem para uma amostra de tamanho $n$ será aproximada por

$$
E(X(k))=\Phi^{-1}\left(\frac{k-c}{n-2 c+1)}\right)
$$

Na prática os autores simplificam o uso da expressão (2.5.1) assumindo um valor constante para c (MAGE, 1982).

MAGE (1982), seguindo o estudo de KIMBALL (1960) sobre a escolha de $P_{k}$, apresenta nove diferentes convenções ob servadas na literatura estatística, conforme a Tabela 6.

$$
\text { CUNNANE (1978) e LOONEY e GULLEDGE (1985) atri }
$$
buem as fórmulas 1 e 8 , respectivamente,a Weibull (1939) e Hazen (1914), afirmando serem as mais usadas. Observa-se, de fato, que autores como WILK e GNANADESIKAN (1968), SEBER (1977) e DANIEL e WOOD (1980) fazem uso da fórmula 8 da Tabela 6. 
41.

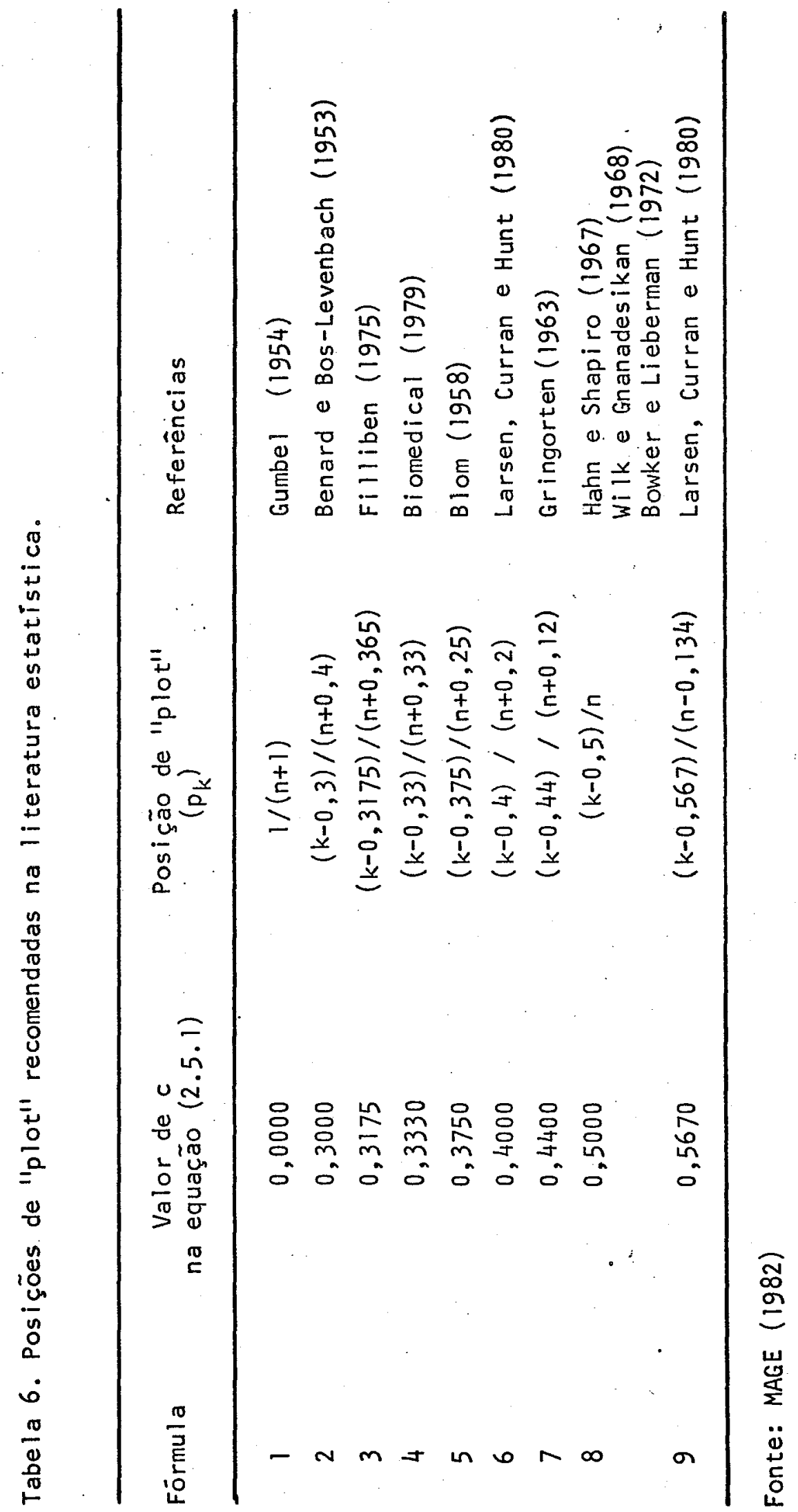


Segundo HARTER (1961); Blom investigou o valor de c que resultaria no valor correto de $E\left(x_{(k)}\right), k=1, \ldots,(n / 2)$, quando $n=2(2) 10(5) 20$. Blom teria observado que os valores de c crescem quando $n$ cresce, permanecendo no intervalo $(0,33$, $0,50)$. Ele sugeriu o uso de $c=3 / 8$ como o valor mais adequa do para aproximar estatisticas de ordem normais em (2.5.2).

Embora HARTER (1961) considere o valor de $c=3 / 8$ baixo, exceto para pequenos valores de n, KIMBALL (1960) e CUNNANE (1978) recomendam a aproximação de Blom (fórmula 5 da Tabela 6). E, ainda, para LOONEY e GULLEDGE (1985) essa posição de "plot" tem sido a mais aceita atualmente, inclusive sendo usada nos gräficos de probabilidade produzidos pelo Sistema de Anālise Estatística (SAS - Statistical Analysis Sís tem).

HARTER (1961) apresenta a tabela de valores es perados das k-ésimas maiores estatísticas de ordem normais, $E\left(X_{(k)}\right), k=(n / 2+1), \ldots, n(n$ par $)$ ou $k=(n / 2+0,5) \ldots, n$ ( $n$ impar), para $n=2(1) 100(25) 250(50) 400$ obtidas de:

$$
\begin{aligned}
& E\left(X_{(k)}\right)=k\left(\begin{array}{l}
n \\
k
\end{array}\right) \int_{-\infty}^{\infty} x[1 / 2-\Phi(x)]^{k-1}[1 / 2+\Phi(x)]_{\phi(x) d x}^{n-k} \\
& \phi(x)=(2 \pi)^{-1 / 2} e^{(-1 / 2) x^{2}} \text { e } \Phi(x)=\int_{0}^{x} \phi(y) d y .
\end{aligned}
$$


ções gräficas resultantes são similares ao serem usados quantis aproximados ou valores esperados como posição de "plot!" Porém, consideram mais conveniente, conceitualmente e para efeito de cálculo, empregar quantis ao invēs de valores esperados.

Após ter sido escolhida a posição de "plot" e construído o gräfico de probabilidade normal, um critērio for mal para interpretar ográfico é necessārio. Existe maior preocupação com o julgamento do gräfico em relação à hipótese distribucional de normalidade (objetivo (i) de KIMBALL. (1960)). MAGE (1982) cita como desvantagem dos gräficos de probabilidade a falta de regras para traçar a linha reta que melhor se ajusta aos pontos e de maneiras objetivas simples para julgar quão bem está esse ajustamento. Segundo o autor, o exame da literatura não aponta um processo único acei to para traçar a linha reta no papel probabilístico, sendo, geralmente, traçada "a olho", porēm, Bowker e Lieberman (1972), citados por MAGE (1982), dizem que o método de mínimos quadra dos pode ser usado. E, ainda, o julgamento de um grä́ico não è uniforme quando feito por diversas pessoas, pois, em geral, é usado um critērio subjetivo, isto é, de avaliação visual.

Julgar a adequação de um grāfico probabilístico exige experiência (COOK e WEISBERG, 1982). SEBER alerta para que gräficos probabilisticos sejam tratados com cautela: deve ser considerada a "forte evidência não estatísticall e o nümero total de observações, n. Para esse autor, 
"quando $n$ è pequeno è quase impossivel dizèr se uma única observação é um verdadeiro 'outlier':".

DANIEL e WOOD ( 1980$)$ apresentam diversos exemplos de gräficos probabilísticos normais com n variando de 8 a 384 . Os autores concluem que conjuntos de tamanho 8 quase nada dizem sobre normalidade, conjuntos de 16 mostram muitas oscilações, conjuntos de 32 são visivelmente melhor comportados, conjuntos de 64 aparecem lineares na região central, mas flutuam'nas extremidades, e conjuntos de 384 são está veis a não ser por poucos pontos nas extremidades.

SEBER (1977) faz referência aos gräficos citados acima e recomenda que $n$ seja pelo menos 20 e, prefer $\underline{i}$ velmente, maior que 50 .

MAGE (1982) propõe um mētodo objetivo para trạ çar a linha reta de modo a obter o menor valor para a estatís tica $D_{n}=\max \left|F(x)-S_{n}(x)\right|$, de Kolmogorov-Smirnov. Compara-se o $D_{n}$ obtido do gráfico com o valor tabelado por Lilliefors (1967), para concluir se a linha reta é uma adequada representação da distribuição do conjunto de dados.

Outro procedimento para avaliar gráficos de probabilidade normal é o teste proposto por SHAPIRO e WILK (1965). A estatística do teste, $W, \dot{e}$ essencialmente a razão entre dois estimadores de $\sigma^{2}$ : o quadrado do melhor estimador li near do parâmetro de dispersão e a variância amostral (FILLIBEN, 1975 e LOONEY e GULLEDGE, 1985). A estatística W. é definida por 


$$
w=\frac{w^{2}}{s^{2}}
$$

$$
[n / 2]
$$

oride $w=\sum_{k=1} a_{n-k+1}\left(x_{(n-k+1)}-x_{k}\right)$, para $n$ par, $n=2 t$, sen do $a_{n-k+1}$ valores tabelados (Tabela $A 3$ do Apêndice). Se $n$ é impar, $n=2 \underline{t}+1$, o cālculo é idêntico, porèm com $a_{t+1}=0$. En contra-se então

$$
\left.w=a_{n}\left(x_{(n)}-x_{n}\right)\right)^{\prime}+a_{n-1}\left(x_{(n-1)}-x_{(2)}\right)+\ldots+a_{t+2}\left(x_{(t+2)}-x_{(t)}\right) .
$$

$s^{2}$ è a soma de quadrados dos desvios $\left(x_{k}-\bar{x}\right)$.

Calculado o valor de $W$, compara-se com o valor tabelado correspondente ao $n$ e ao nivel de significância, $\alpha$, desejado. Pequenos valores de $W$ säo significantes (Tabela $A 4$ do Apêndice), is to è, indicam não normalidade (SHAPIRO e WILK, 1965).

BARNETT e LEWIS (1984) consideram a estatistica $W$ de relevancia para testar dados discordantes sendo este teste referido como um teste bilateral para a presença de um nümero indefinido de contaminantes em amostra normal com $\mu$ e $\sigma^{2}$ desconhecidos.

FILLIBEN (1975) sugere o uso do coeficiente de correlação de Pearson como medida da linearidade do gräfico de probabilidade. A estatistica do teste è o coeficiente de correlação entre as observações ordenadas, ${ }_{(k)}$, e quan tis correspondentes da $N(0,1), M_{k}=\Phi^{-1}\left(p_{k}\right)$, onde $p_{k} \bar{e}$ dado por

$$
P_{k}=\left\{\begin{array}{l}
1-P_{n}, \quad k=1 \\
(k-0,3175) /(n+0,365), k=2,3, \ldots,(n-1) \\
(0,5) 1 / n, \quad k=n
\end{array}\right.
$$


0 coeficiente de correlação para ogräfico probabilistico nor mal entre $x_{(k)}$ e $M_{k}$ é então definido por:

$$
r=\frac{\sum_{k}^{n}\left(x_{k}-\bar{x}\right)\left(M_{k}-\bar{M}\right)}{\left[\sum_{k}^{n}\left(x_{k}-\bar{x}\right)^{2} \cdot \sum_{k}^{n}\left(M_{k}-\bar{M}\right)^{2}\right]^{1 / 2}}
$$

0 mesmo autor apresenta diversas propriedades da estatística $r$ e a tabela de valores críticos (minimos) para $r$ quando $n=3(1) 50(5) 100$ e diversos niveis de significância. Para LOONEY e GULLEdGe (1985) técnicas como a de MAGE (1982) e de SHAPIRo e WILK (1965) não avaliam a linea ridade do gráfico probabilístico tão diretamente como o coefi ciente de correlação. Seguindo, então, a idéia de FILLIBEN (1975), eles avaliaram o uso do coeficiente de correlação em gráfico de probabilidade normal, concluindo que o teste do coeficiente de correlação é um teste mais poderoso que o teste de Shapiro-Wilk, quando utiliza-se a posição de "plot" da fórmula 5 da Tabela. 6, proposta por Blom. A Tabela A5 do Apên dice apresenta os limites mínimos para o $r$ calculado originados empiricamente por LOONEY e GULLEDGE (1985).

\subsubsection{OS METODOS PROPOSTOS POR GENTLEMAN E WILK} $(1975 a ; 1975 b)$

Gráficos de probabilidade são usados numa bateria de métodos de deteç̧ão de dados discordantes descritos por GENTLEMAN e WILK (1975a; 1975b). 
No primeiro trabalho, GENTLEMAN e WILK (1975a) examinam resíduos oriundos de tabelas de classificação dupla (experimentos com dois fatores), admitindo aditividade de $1 i$ nhas e colunas. Eles examinam gráficos de probabilidade normal, e meio-normal confirmando sua utilidade na detecção de um valor discordante, e que, no caso de não haver "outliers", os resíduos comportam-se aproximadamente como uma amostra nor mal, especialmente para grandes configurações.

Quando dois ou mais valores discordantes estão presentes, GENTLEMAN e WILK (1975a) demonstram, que ocorrem "efeitos compensadores" e o gráfico de probabilidade tem pouco valor.

Para o julgamento parcial dos gráficos probabilísticos de residuos, GENTLEMAN e WILK (1975a) usaram a estatistica W, de SHAPIRO e WILK (1965), que consideraramser uma medida sensível à näọ-normalidade e que responde à presença de um "outlier". Isso foi comprovado através de gräficos da função de distribuição acumulada empírica de $W$, obtida de resíduos, contra a função de distribuição acumulada de W para amostras normais. Se as duas funções fossem as mesmas, isto é, se resíduos comportam-se próximos a uma amostra normal, então seria obtida uma linha reta passando pela origem e de declividade 1. Foram feitos os gräficos para várias configuraçōes da tabela de dados com "resíduos nulos" (sem "outlier") e com um "outlier" de magnitude $5 \sigma$ introduzido no conjunto de dados. 
Entre as conclusões de GENTLEMAN e WILK (1975a) tem-se que, no caso de não haver "outliers" em dados de ensaios com dois fatores, os resíduos comportam-se de modo muito semelhante a uma amostra de população normal, e tendem a apresentar "super-normalidade" para pequenas configurações. Quando um dado aberrante está presente, o uso direto de resíduos proporciona uma base completa para sua deteção, especialmen te através do uso de gräficos probabilísticos. Quando estão presentes dois valores aberrantes, porém, os resíduos resultantes não demonstram, em geral, peculiaridades, seja através da avaliação visual do gräfico probabilístico, seja através da estatística W.

$$
\text { No segundo trabalho, GENTLEMAN e WILK }
$$
levam em consideração a redução na soma de quadrados de resídugs causada pela omissão de $K$ valores do conjunto de dados. Resumindo a metodologia proposta pelos autores, o processo con siste na escolha de um valor $K$ como o nūmerómāximo razoável de prováveis "outliers" ( $K<(n-p))$; calcular para todas as possiveis $\left(\begin{array}{l}n \\ k\end{array}\right)$ partiçōes dos dados o valor de $Q_{K}$, sendo

$$
Q_{K}=e^{\prime} e^{-} e^{\prime} e^{e} *
$$

onde ée é a soma de quadrados de residuos para os dados originais e $e^{\prime} e_{\star} \vec{e}$ a soma de quadrados de "resíduos revisados" que resultam do ajuste do modelo bāsico para o restante dos da dos após a omissão do subconjunto de $K$ valores. A maior $Q_{K}$ ' representada por $Q_{K}^{*}$, indica os $K$ valores mais provāveis de se . rem aberrantes. 
Para julgar se a magnitude de $Q_{K}^{*}$ é "suficientemen te grande" em relação aos demais $Q_{K}$ 's necessitar-se-ia conhecer sua distribuição nula. Como esta é desconhecida, são usa dos métodos informais para avaliar a significância de $Q_{K}$, que consistem de duas formas de gráficos probabilísticos: o gráfi co dos maiores $Q_{K}{ }^{\prime} s$ para os dados sob análise contra "valores típicos" desses, obtidos (presumivelmente por simulação) sob o modelo nulo na mesma configuração; e o gráfico de probabili dade normal para os residuos normalizados (forma 2.3.6).

Se conclui-se que $Q_{K}^{*}$ não é estatisticamente aber rante, considera-se, então, sucessivamente um nümero $k$ - 1 , K - $2, \ldots$ de prováveis dados aberrantes até um conjunto discrepante significante ser detectado.

Embora sejam apresentadas fórmulas de cálculo para simplificação do processo para delineamentos de linhas e colunas, a bateria de cālculos é bastante grande (BARNETT e LEWIS, 1978). GENTLEMAN e WILK (1975b) concordam que é um pro cesso pesado em termos de cálculos, mas argumentam que computadores o tornam relativamente simples e rápido para valores razoáveis de K (tal como 3) e de n (tal como 100).

$$
\text { GENTLEMAN e WILK (1975b) e JOHN e DRAPPER (1978) }
$$

consideram que o método é bastante aplicável para $K=1$. Nesse caso, cada $Q_{1}$ é proporcional ao quadrado do resíduo normalizado e será estatisticamente equivalente ao resíduo absoluto para o caso onde todos os resíduos têm igual variância, ou seja, em ensaios balanceados. E nesse caso, também o grä́fi- 
co probabilistico normal dos resíduos é equivalente ao gräfico dos $Q_{1}$, quando, de fato, somente um "outlier" está presente.

Na obtenção de $Q_{1}$, a soma de quadrados dos residuos revisados pode ser obtida inserindo-se a estimativa de minimos quadrados em lugar da observação suspeita e calculando-a então, do reajuste do modelo a todas as $n$ observações (GENTLEMAN, 1980).

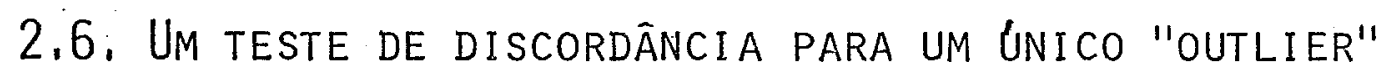

Após a detecção de uma observação discordante atravēs de um processo informal, um teste estatistico adequado deverá confirmar sua inaceitabilidade. Só então pode se afirmar que existe um valor aberrante no conjunto de dados experimentais, tendo por base um modelo inicial especifica do (BARNETT e LEWIS, 1978).

os residuos studentizados (forma 2.3.4) desempenham um papel central nos testes de discordancia para um ünico valor discrepante ẹm um modelo linear normal (BARNETT e LEWIS, 1978; BECKMAN e COOK, 1982). Para BARNETT e LEWIS (1978) existe quase total preocupação com o resíduo studentizado máximo (positivo, negativo ou absoluto) como estatística teste que indicará a observação discrepante se for "suficientemente grande". Assim, para o teste bilateral rejeita-se a 
hipōtese bäsica de que o modelo (2.3.1) é correto em favor de uma hipótese que postule um único valor aberrante se

$$
\max \left|r_{i}\right|>h_{\alpha}
$$

onde, para um nível de significância $\alpha$, o valor crítico $h_{\alpha}$ é tal que

$$
P\left[\max \left|r_{i}\right| \geqslant h_{\alpha} \mid H_{0}\right]=\alpha
$$

ou seja, sob o modelo $(2.3 .1)$, o modelo alternativo (2.3.5) ou (2.3.6) ocorre com probabilidade a (ELLENBERG, 1976; BARNETT e LEWIS, 1978; DOORNBOS, 1981). A observação que produz - valor máximo de $r_{i}$ será ou não declarada como aberrante.

Não ë comum a preocupação em estabelecer o modelo alternativo, isto é, o modelo de discordancia que caractrize a hipōtese alternativa do teste (BARNETT e LEWIS, 1978). BECKMAN e COOK (1982) e COOK e PRESCOTT (1951) admitem que, para dados estruturados sob o modelo de Gauss-Markov, é comumente adotado, ainda que não explicitamente, o modelo de desli zamento da média (2.3.5). De fato, em ELLENBERG (1976), BARNETT e LEWIS (1984) e DOORNBOS (1981) a hipótese a ser testada é a de que o modelo $(2.3 .1)$ é correto, contra um modelo al ternativo para o qual existe um $y_{i}$, onde $i$ é um valor qualquer desconhecido, com esperança diferente de $x^{\prime}{ }_{i} \star^{\theta}, \quad$ onde $x_{i *}^{\prime} \bar{e}$ a $i$-ẽsima linha de $x$.

Muitos trabalhos tem sido desenvolvidos sobre - problema de determinar valores críticos para os resíduos stu- 
dentizados (BARNETT e LEWIS, 1984; BECKMAN e COOK, 1983). A princípio, a determinação desses valores críticos envolveria a distribuição da estatística-teste. Como a distribuição exa ta de max. $\left|r_{i}\right|$ sob $H_{0}$, tal como (2.6.1), é de difícil determinação, ELLENBERG (1973) sugeriu estabelecer os valores críticos para o resíduo máximo à partir do uso iterativo da desigualdade de Bonferroni. A desigualdade de Bonferroni, apli cada ao evento $\left|r_{i}\right|>r_{0}$, onde $\left|r_{i}\right|$ é o valor absoluto do iésimo resíduo studentizado, fica (BARNETT e LEWIS, 1984):

$$
\sum_{i=1}^{n} P\left(\left|r_{i}\right|>r_{0}\right)-\sum_{i<j} P\left(\left|r_{i}\right|>r_{0},\left|r_{j}\right|>r_{0}\right) \leqslant P\left(\max \left|r_{i}\right|>r_{0}\right) \leqslant \sum_{i=1}^{n} P\left(\left|r_{i}\right|>r_{0}\right)
$$

Alēm disso, ELLENBERG (1973) determinou a função de densidade conjunta para os resíduos studentizados (2.3.7) divididos pela raiz quadrada dos graus de liberdade desses re siduos, ou seja, $r_{i}^{*}=r_{i} /(n-p)^{1 / 2}$.

LUND (1975), à partir da função de densidade marginal para $r_{i}^{*}$ e empregando a desigualdade de primeira-ordem de Bon ferroni (o lado direito de (2.6.2)), construiu tabelas de valores críticos superiores para os residuos studentizados $r_{i}$, em modelos lineares, ao nível $\alpha=0,10,0,05$ e 0,01 e para $\mathrm{n}=5(1) 10(2) 20(5) 50(10) 100$ e $\mathrm{p}=1(1) 6(2) 10,15,25$. BARNETT e LEWIS (1984) consideram a mais ütil tabulação atual e DANIEL e WOOD (1980) tambëm, abordam o teste viabilizado pela tabela de LUND (1975). Esta tabela está reproduzida no Apêndice (Tabela A6). 
Como a tabela de LUND (1975) foi baseada na de sigualdade de primeira-ordem de Bonferroni, ela possibilita um teste para um ünico valor discordante com nível de significância igual ou menor que o estabelecido. DOORNBOS (1981) e COOK e PRESCOTT (1981) consideram toda a desigualdade (2.6.2), isto é, também a desigualdade de segunda-ordem (o lado esquer do de (2.6.2)), de modo a obter um limite inferior para o ní vel de significância do teste para um "outlier" em modelos li neares. DOQRNBOS (1981) mostra que, quando as correlações en tre residuos são menores, em valor absoluto, que um certo valor tabelado, ou seja

$$
\max \left|\rho_{i j, k l}\right| \leqslant g_{\alpha}, \quad k \neq i \text { ou } \quad l \neq j
$$

então o uso do valor tabelado ro leva a um teste para o qual

$$
\alpha-\frac{1}{2} \alpha^{2}<P\left(\max \left|r_{i}\right|>r_{0}\right)<\alpha \quad(2.6 .3)
$$

No mesmo estudo, DOORNBOS (1981) propõe o teste para $r_{i} /(n-p)^{1 / 2}$, que é, basicamente, o mesmo teste de LUND (1975), apenas com os residuos studentizados divididos por $(n-p)^{1 / 2}$. DOORNBOS (1981) encontrou alguns erros de uma unidade na ültima casa decimal na tabela de LUND (1975) (Tabela A6 do Apêndice) e refere-se a uma extensa tabela produzida em Doornbos (1980). A Tabela A7 do Apêndice traz os valores crí ticos para o coeficiente de correlação máximo entre resíduos, $g_{\alpha}$, extraídos de DOORNBOS (1981). 


\subsection{Homogeneidade de VARIÂNCIAS E adit IVIDADE}

Como já citado no item 2.5., além da ausência de normalidade, tanto a falta de homogeneidade de variâncias como a não-aditividade dos dados sob o modelo adotado podem ter como causa a ocorrência de um ou mais valores aberrantes entre os dados experimentais. A metodologia até aqui aborda da está intimamente ligada à verificação da hipótese distribü cional da normalidade, marcadamente no item 2.5.1.

Visando aplicações nos capitulos seguintes, apre senta-se aqui uma rápida abordagem sobre a problemática da he terogeneidade de variâncias e da não-aditividade.

\subsubsection{HOMOGENEIDADE DE VARIANCIAS}

Diversos testes formais estão disponiveis para estudar a homocedasticidade de dados para os quais tenha sido adotado o modelo ANOVA. Citam-se, por exemplo, o teste de Bartlett e. o teste de Hartley, abordados por NETER e WASSERMAN (1974). Entretanto, para experimentos de dois fatores ou de um fator e uma restrição na casualização, a aplicação desses testes não é direta, pois as variâncias amostrais não são independentes. Alēm disşo, os dois testes são extremamente sensiveis à ausência de normalidade (NETER e WASSERMAN, 1974).

Considerando as restrições acima, IEMMA (1985)

utiliza o teste proposto por BoX $(1949 ; 1950)$ para verificar. 
55.

a uniformidade da matriz de covariáncias. Esse teste, de caräter mais geral que ós de Bartlett, de Hartley e congêneres, apresenta a vantagem de considerar possíveis correlações entre parcelas que por ventura possam existir. Procedimentos nes sa linha de conduta estão descritos em KIRK (1968), HUYHN e FELDT (1970) e GILL (1978).

Então, no contexto de BoX $(1949 ; 1950)$, considere-se o seguinte, para $v$ niveis ou tratamentos,

$$
\begin{aligned}
& \text { 1. } \rho \sigma_{12}^{2}=\rho \sigma_{13}^{2}=\ldots \rho \sigma^{2}(v-1) v \\
& \text { 2. } \sigma_{1}^{2}=\sigma_{2}^{2}=\ldots=\sigma_{v}^{2}
\end{aligned}
$$

isto é, as covariâncias populacionais entre pares de tratamen tos são iguais e as variâncias das populações dos $v$ níveis são homogêneas. Se 1 e 2 são verdadeiras a matriz de va riâncias e covariâncias

$$
v=\left[\begin{array}{ccccc}
\sigma_{1}^{2} & \rho \sigma_{12}^{2} & \rho \sigma_{13}^{2} & \cdots & \rho \sigma_{1 v}^{2} \\
\rho \sigma_{12}^{2} & \sigma_{2}^{2} & \rho \sigma_{23}^{2} & \cdots & \rho \sigma_{2 v}^{2} \\
\rho \sigma_{13} & \rho \sigma_{23}^{2} & \sigma_{3}^{2} & \cdots & \rho \sigma_{3 v}^{2} \\
\ldots & \ldots & \cdots & \ldots & \ldots \\
\rho \sigma_{1 v} & \rho \sigma_{2 v} & \rho \sigma_{3 v}^{2} & \cdots & \sigma_{v}^{2}
\end{array}\right]
$$

é uniforme. Assim, para o teste de

$$
\begin{aligned}
& H_{0}: V=U \\
& H_{a}: V \neq U
\end{aligned}
$$


onde $U$ é a matriz uniforme

$$
\dot{U}=\left[\begin{array}{cccc}
1 & \rho & \cdots & \rho \\
\rho & 1 & \cdots & \rho \\
\cdots & \cdots & \cdots & \\
\rho & \rho & \cdots & 1
\end{array}\right] \sigma^{2}
$$

o procedimento consiste em se obter

$$
\ddot{X}_{c}^{2}=(1-E) M
$$

onde

$$
M=-(b-1) \ln \frac{|v *|}{|\bar{v} *|} ; \quad E=\frac{v(v+1)^{2}(2 v-3)}{6(b-1)(v-1)\left(v^{2}+v-4\right)}
$$

e $|V *|$ é o determinante da matriz amostral de covariâncias; $|\bar{V} *|$ é o determinante da matriz uniforme obtida do polimento de $V^{*}$, sendo $\bar{V} *=\left(v_{i j}\right)$ onde $v_{i}$ é a mēdia.das variâncias amos trais e $v_{i j}, i \neq j, e \bar{e}$ a média das covariāncias que estão em $v *$ e b é o tamanho das amostras.

Sob $H_{0},(1-E) M$ tem distribuição aproximada de $x^{2}$ com $\left(v^{2}+v-4\right) / 2$ graus de liberdade.

\subsubsection{ADITIVIDADE}

0 modelo de efeitos aditivos descritós em 2.4., $y_{i j}=\mu+\alpha_{i}+\beta_{j}+e_{i j}$, não considera,pela pröpria natureza, 
a interação entre os efeitos dos fatores $\alpha$ e $\beta$. No entanto, em situações práticas a interação pode estar presente mesmo que imperceptivel ou inexplicável para o pesquisador.

Um teste adequado para a verificação da suposição de aditividade do modelo é proposto por TUKEY (1949). Este teste é sensível à existência de interação como causa da não-aditividade.

0 teste consiste basicamente em se verificar as hipóteses:

$$
\begin{aligned}
& H_{0}: \text { o modelo é aditivo } \\
& H_{a} \text { : o modelo não é aditivo. } \\
& \text { o procedimento do teste segue com a obtenção }
\end{aligned}
$$
da soma de quadrados da interação por

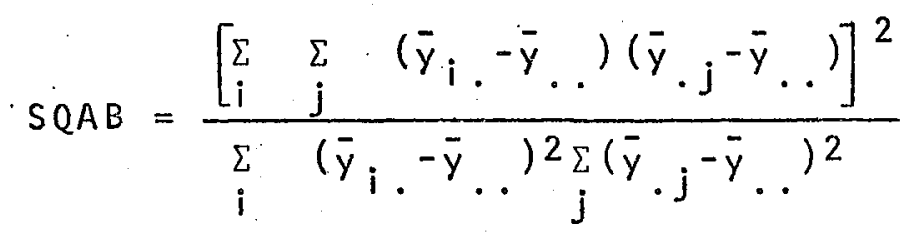

Obtida SQAB, esta é subtraída da soma de quadrados do resíduo, sendo obtida a soma de quadrados do erro puro

$$
\text { SQEP = SQRESiduO - SQAB }
$$

cujos graus de liberdade são (g.l.resíduos - 1), que para o caso de ensaio de dois fatores será $(r-1)(c-1)-1$. A seguir obtêm-se a estatística do teste: 


$$
F_{\tilde{N} A}=\frac{\operatorname{SQAB}}{\operatorname{SQEP} /(r c-r-c)}
$$

Sob $H_{0}$, SQAB e SQEP são independentemente distribuidos e F $\tilde{N}_{A}$ tem distribuição $F(1, r c-r-c)$.

\subsection{PROCEDimentos Remediadores nA PRESENG.A DE UMA OBSERVACÄO ABERRANTE}

Embora os procedimentos remediadores não cons-

tituam o objetivo formal deste estudo, juigou-se que a discus são dos exemplos no capitulo 4, ficaria enriquecida através de sua apresentação. Desse modo, apresentam-se aqui algumas idéias básicas sobre o assunto.

Ficando constatada a presença de "outliers" no conjunto de dados em estudo, a indagação que surge é como rea gir a eles. Em BARNETT e LEWIS $(1978$; 1984) esta questão è discutida amplamente tendo por base os procedimentos gerais que se pode observar na figura 1, de 2.1. As possiveis ações em relação a dados aberrantes devem ser consideradas em conform dade com sua origem (quando for possivel assegurar qual a sua causa) e com o propósito da anälise estatística (ANSCOMBE e TUKEY, 1963; BARNETT E LEWIS, 1984; BECKMAN e COOK, 1983).

A presença de "outliers" num conjunto de dados obtidos sob um modelo linear pode ser um indicativo de especificações inadequadas da estrutura de erros ou do próprio mo: 
delo básico. Neste sentido, torna-se bastante importante o estudo de origem e forma, isto é, a "identificação" com a co notação dada por BARNETT e LEWIS (1978).

Quando se suspeita que um dado discrepante è uma observação correta de um fenômeno pouco comum, ele pode ser modificado, atribuindo-se um peso menor, ou eliminado da análise de variáncia e avaliado separadamente. Outra possibilidade é a transformação de todas as observações a fim de se efetuar a ạnälise de variância usual, ou, ainda, o uso de aná lise não-paramētrica (ANSCOMBE e TUKEY, 1963).

Autores como ANSCOMBE e TUKEY (1963), NETER e WASSERMAN (1974) e BARNETT e LEWIS (1984) concordam em que se existem evidencias de medição mal feita ou erro de registro como origem de um dado aberrante, se não for possível cor rigílo, causa menos problema descartá-lo do que utilizá-lo na condução da anälise. Naturalmente, este procedimento é mais simples em amostras univariadas do que em dados estruturados, para os quais métodos formais de rejeição ou de acomodação es tão menos desenvolvidos (BARNETT e LEWIS, 1984).

No contexto de experimentos balanceados, úma alternativa viável para contornar o problema da ocorrência de um ünico dado aberrante é substituí-lo pela estimativa de míminos quadrados, procedendo-se a anālise conclusiva, como se aquela observação fosse perdida. Esta possibilidade está implícita em BARNETT e LEWIS (1984) e è sugerida em DODGE (1985), em especial para quando a observação aberrante è admitida ser 
de natureza determinística e não se tem como corrigir ou recu perar o verdadeiro valor.

Cabe ressaltar que esta alternativa é sensata, dependendo de uma variedade de fatores relativos ao interesse do pesquisador na situação prātica. A garantia de que a causa do "outlier" é um erro de registro ou medição ou uma influência estranha de nenhum interesse prätico é relativa à confiança no modelo adotado. Por sua vez, considerar um modelo inicial como inviolável, pressupõe um planejamento rigoroso do experimento, um conhecimento seguro do material experimental e um bom controle local das condições experimentais. Através da Figura 1, pode-se cogitar outros procedimentos remediadores, tais como acomodação, incorpora ção e identificação (no sentido do estudo separado de origem e formal. Estes procedimentos não serão aqui abordados. 
61

\section{MATERIAL E MÉTODOS}

\subsection{Material}

A fim de ilustrar a metodologia abordada no item 2, são mostrados exemplos numéricos de ensaios em blocos casualizados. Os exemplos são compostos de dados hipotēticos, sendo que o primeiro deles constitui o chamado ensaio nulo, isto é, näo contendo dados discordantes ou aberrantes. os exemplos subsequentes resultam da contaminação dos dados do ensaio nulo, obtida por adição de um valor arbitrado $\lambda_{i j}$ a uma observação de posição $(i, j)$, de modo a constituirem exem plos de ensaios que possibilitem aplicar e discutir a metodologia abordada, caracteristicamente, com a presença de um valor aberrante dentre os dados experimentais. Este procedimen to foi usado seguindo GENTLEMAN e WILK (1975a; 1975b), conforme descrito em 2.5.2.

E importante ressaltar que os exemplos obtidos 
a partir do ensaio nulo não constituem situações que poderiam ser consideradas absurdas na prātica. Antes, são dados que, "a primeira vista" de um pesquisador podem ser perfeitamente razoāveis, isto é, sem qualquer valor inadequado no conjunto. Apenas optou-se por este caminho, isto é, de contaminação de um ensaio nulo, de modo a se ter um referencial na discussão dos efeitos da ocorrência de um único "outlier".

outrossim, cabe observar que, obviamente, outras inúmeras situações poderiam ter sido obtidas com a adição de diferentes $\lambda_{i j}{ }^{\prime}$ s a diferentes observações, melhorando ou rompendo o padrão geral de dados.

a) Ensaio 1: ensaio nulo

Tabela 7. Valores observados do ensaio 1.

Tratamentos

Blocos

$\begin{array}{llll} & \text { B } & \text { C } & \text { D }\end{array}$

\begin{tabular}{rrrrr}
\hline 1 & 7,54 & 8,48 & 8,73 & 9,33 \\
11 & 9,97 & 10,82 & 10,88 & 11,31 \\
111 & 7,97 & 10,21 & 9,61 & 11,06 \\
IV & 8,06 & 9,96 & 9,38 & 10,42 \\
VI & 8,71 & 9,56 & 8,94 & 9,44 \\
\hline
\end{tabular}


b) Ensaio 2: $\lambda_{21}=3$

Tabela 8. Valores observados do ensaio 2.

\begin{tabular}{rrrrr}
\hline & \multicolumn{4}{c}{ Tratamentos } \\
\cline { 2 - 4 } Blocos & A & \multicolumn{1}{c}{ B } & \multicolumn{1}{c}{ C } & \multicolumn{1}{c}{ D } \\
\hline 1 & 7,54 & 8,48 & 8,73 & 9,33 \\
11 & 12,97 & 10,82 & 10,88 & 11,31 \\
111 & 7,97 & 10,21 & 9,61 & 11,06 \\
$1 V$ & 8,06 & 9,96 & 9,38 & 10,42 \\
$V$ & 8,71 & 9,56 & 8,94 & 9,44 \\
VI & 9,21 & 8,70 & 9,81 & 10,10 \\
\hline
\end{tabular}

c) Ensaio 3: $\lambda_{24}=-3,5$

Tabela 9. Valores observados do ensaio 3.

\begin{tabular}{rrrrr}
\hline & \multicolumn{4}{c}{ Tratamentos } \\
\cline { 2 - 4 } Blocos & A & \multicolumn{1}{c}{ B } & C & D \\
\hline 1 & 7,54 & 8,48 & 8,73 & 9,33 \\
11 & 9,97 & 10,82 & 10,83 & 7,81 \\
I11 & 7,97 & 10,21 & 9,61 & 11,06 \\
IV & 8,06 & 9,96 & 9,38 & 10,42 \\
V & 8,71 & 9,56 & 8,94 & 9,44 \\
VI & 9,21 & 8,70 & 9,81 & 10,10 \\
\hline
\end{tabular}




\subsection{MÉTODOS}

Apresenta-se aqui, dentre outras, uma sequência de procedimentos a ser aplicada aos três exemplos referidos em 3.1. Após a obtenção dos residuos são efetuados proce dimentos peculiares da análise exploratória de dados. A seguir é feita a añise da variancia para os dados do ensaio sem que sejam considerados os resultados da anālise explorató ria, isto é, estando ou não satisfeitas as pressuposições bäsicas da análise da variância. Pretende-se com isso, chamar a atenção sobre os riscos de conclusões erróneas na presença de um ünico"outlier".

Cabe salientar que aqui está se considerando a identificação de um ünico possivel valor aberrante, derivado de perturbações aditivas e relativo a um modelo especificado, neste caso o modelo para experimentos com um fator e uma restrição na casualização aqui caracterizado como o de blocos casualizados.

3.2.1. OBTENÇÃ̈O DOS RESTDUOS E SUAS CORRELAÇÕES

3.2.1.1. Modelo linear

0 modelo linear usual para os ensaios em blocos casualizados, com b blocos e v tratamentos, é caracterizado por:

$$
y_{\mathbf{i} \mathbf{j}}=\mu+\beta_{\mathbf{i}}+\boldsymbol{t}_{\mathbf{j}}+\varepsilon_{\mathbf{i} \mathbf{j}}
$$

onde, para $i=1, \ldots, b$ e $j=1, \ldots, v$, 
$Y_{i j}$ é a observação do bloco i que. recebeu o tratamento j;

$\beta_{i}$ è o efeito do bloco i;

$t_{j}$ é o efeito do tratamento j;

$\varepsilon_{\mathbf{i j}}$ é o erro experimental não-observāvel associado a $y_{\mathbf{i j}}$, tal que $\varepsilon_{i j} \sim N(0, \sigma 2)$;

com as restrições usuais $\sum_{i} \beta_{i}=0$ e ${ }_{j} \sum_{j}=0, \mu$ é a média ge-ral.

Considerando o modelo linear na sua forma matricial $y=x \theta+\varepsilon$ descrito em 2.3, y sérä um vetor bvxl, ou seja:

$$
y^{\prime}=\left[y_{11} \cdots y_{1 v} ; y_{21} \cdots y_{2 v} ; \cdots ; y_{b 1} \cdots y_{b v}\right]
$$

$b v X_{1+b+v}$ é a matriz conhecida do delineamento, de posto $b+v-1$ e que tem a forma:

$$
X=\left[\begin{array}{c:cccc:cccc}
1 & 1 & 0 & \ldots & 0 & 1 & 0 & \ldots & 0 \\
1 & 1 & 0 & \ldots & 0 & 0 & 1 & \ldots & 0 \\
\cdots & \ldots & \ldots & \ldots & \ldots & \ldots & \ldots & \ldots & \ldots \\
1 & 1 & 0 & & 0 & 0 & 0 & \ldots & 1 \\
1 & 0 & 1 & \ldots & 0 & 1 & 0 & \ldots & 0 \\
\ldots & 0 & 1 & \ldots & 0 & 0 & 1 & \ldots & 0 \\
1 & 0 & 1 & \ldots & 0 & 0 & 0 & \ldots & 1 \\
\ldots & \ldots & \ldots & \ldots & \ldots & \ldots & \ldots & \ldots & \ldots \\
1 & 0 & 0 & \ldots & 1 & 1 & 0 & \ldots & 0 \\
\ldots & 0 & 0 & \ldots & 1 & 0 & 1 & \ldots & 0 \\
1 & 0 & 0 & \ldots & 1 & 0 & 0 & \ldots & 1
\end{array}\right]
$$


66.

$1+b+v^{\theta} e^{e}$ um vetor de paràmetros desconhecidos, tal que

$$
\theta=\left[\begin{array}{c}
\mu \\
\beta \\
\tau
\end{array}\right] \quad ; \quad \beta=\left[\begin{array}{c}
\beta_{1} \\
\ldots \\
\beta_{b}
\end{array}\right] \quad ; \quad \tau=\left[\begin{array}{c}
t_{1} \\
\ldots \\
t_{v}
\end{array}\right]
$$

bv ${ }^{\varepsilon}{ }_{1}$ é um vetor de variāveis aleatórias não-observáveis, tal que $\varepsilon \sim N\left(\Phi, 1 \sigma^{2}\right)$.

3.2.2.2. Matriz de projeção e correlações entre residuos

o sistema de equações normais será

$$
x^{\prime} x \theta^{\circ}=x^{\prime} y
$$

tendo por solução de mínimos quadrados

$$
\theta^{0}=(x+x)^{G} x \cdot y
$$

onde $\left(X^{\prime} X\right)^{G}$ é uma inversa generalizada de $\left(X^{\prime} X\right)$. Para o sistema irrestrito pode-se tomar, por exemplo, $\left(x^{\prime} x\right)^{G}=\left(x^{\prime} x\right)^{-}$, onde $\left(X^{\prime} X\right)^{-}$pode ser da seguinte forma (SoUzA, 1984):

$$
(x+x)=\left[\begin{array}{c:ccc:ccc}
-1 / b v & 0 & \ldots & 0 & 0 & \ldots & 0 \\
\hdashline 0 & 1 / v & \ldots & 0 & 0 & \ldots & 0 \\
\ldots & \ldots & \ldots & \ldots & \ldots & \ldots & \ldots \\
0 & 0 & \ldots & 1 / v & 0 & \ldots & 0 \\
\hdashline 0 & 0 & \ldots & 0 & 1 / b & \ldots & 0 \\
\ldots & \ldots & \ldots & \ldots & \ldots & \ldots & \ldots \\
0 & 0 & \ldots & 0 & 0 & \ldots & 1 / b
\end{array}\right]
$$


67.

Como

$$
x^{\prime} y=\left[\begin{array}{c}
y_{.} \\
y_{1} \\
y_{2} . \\
\cdots \\
y_{b} . \\
y_{.1} \\
y_{.2} \\
\cdots \\
y_{0} v
\end{array}\right]
$$

com a escolha da inversa condicional $\left(X^{\prime} X\right)^{-}$, a solução obtida para o sistema de equações normais será:

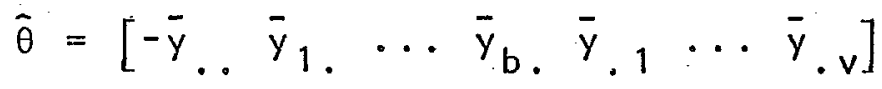

A matriz de projeção ou matriz chapéu é invariante para qualquer escolha de $\left(X^{\prime} X\right)^{G}$ (IEMMA, 1985). Obteve se a forma genérica para a matriz de projeção apresentada a seguir. 


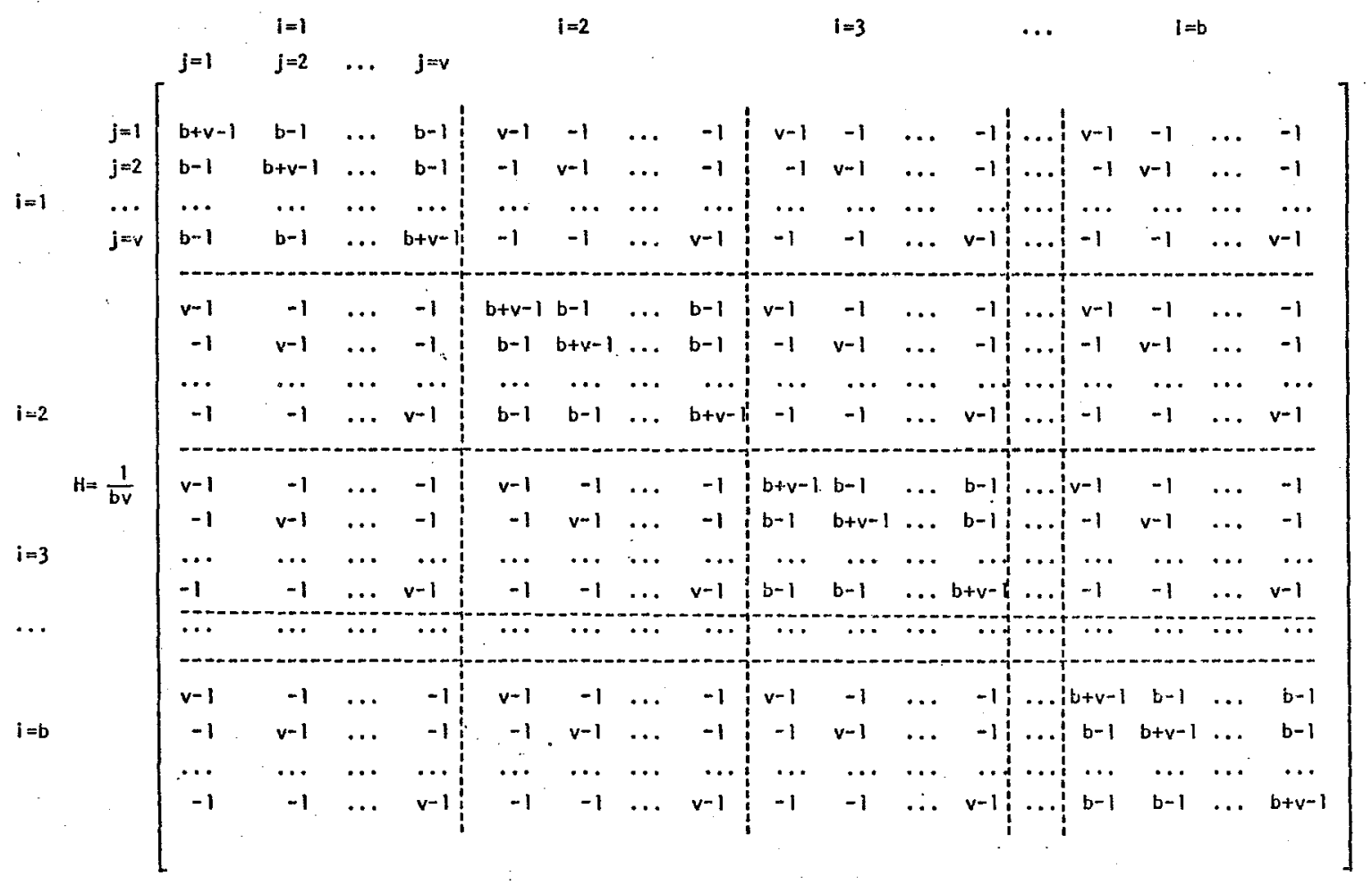

ou seja, $H$ è uma matriz bv $x$ bv com as seguintes componentes:

$$
\begin{aligned}
& h_{i j, i j}=(b+v-1) / b v \\
& h_{i j, i l}=(b-1) / b v, 1 \neq j \\
& h_{i j, k j}=(v-1) / b v, \quad k \neq i \\
& h_{i j, k l}=-1 / b v, \quad k \neq i, 1 \neq j
\end{aligned}
$$


Logo, as componentes do projetor ortogonal são idênticas àquelas mostradas por $(2.4 .1),(2.4 .2),(2.4 .3)$ e (2.4.4) para o modelo de classificação dupla sem interação, apenas com c e $r$ substituídos pelo nümero de blocos (b) e nümero de tratamentos (v), respectivamente.

$$
\text { Da mesma forma, o vetor de resíduos ordinärios }
$$

dado por

$$
e=(I-H) \gamma
$$

terá matriz de variâncias e covariâncias, bem como matriz de correlações, anālogas àquelas abordadas em 2.4, apenas substituidos c por b e $r$ por $v$. Portanto:

$$
\begin{aligned}
& \operatorname{Var}\left(e_{i j}\right)=[1-(b+v-1) / b v] \sigma^{2} \\
& \operatorname{Cov}\left(e_{i j}, e_{i 1}\right)=-(b-1) \sigma^{2} / b v, 1 \neq j \\
& \operatorname{Cov}\left(e_{i j}, e_{k j}\right)=-(v-1) \sigma^{2} / b v, k \neq i \\
& \operatorname{Cov}\left(e_{i j}, e_{k i}\right)=\sigma^{2} / b v, \quad k \neq i, \quad 1 \neq j
\end{aligned}
$$

E as correlações entre resíduos serão:

$$
\begin{aligned}
\rho_{i j, i l}= & -1 /(v-1), \quad 1 \neq j, \text { entre residuos correspondentes } \\
& \text { a observações si tuadas no mesmo bloco; }(3.2 .9) \\
\rho_{i j, k j=}= & -1 /(b-1), \quad k \neq i \text {, entre residuos correspondentes a } \\
& \text { observações que receberam mesmo tratamento } ;(3.2 .10)
\end{aligned}
$$


70 .

$$
\begin{aligned}
\rho_{i j, k\}}= & 1 /(b-1)(v-1), k \neq i, 1 \neq j \text {, entre residuos corres. } \\
& \text { pondentes a observaçöes situadas em blocos diferen } \\
& \text { tes e de tratamentos distintos. }
\end{aligned}
$$

Logo, as correlações entre residuos são fixas para uma determinada configuração de b blocos e $v$ tratamentos.

Com o acréscimo de um valor arbitrado $\lambda$ a uma observação $y_{i j}$ o vetor de observações será:

$$
y^{* 1}=\left[y_{11} y_{12} \cdots y_{1 v^{\prime}} ; \ldots ; y_{i 1} \ldots\left(y_{i j}+\lambda\right) \ldots y_{i v} ; \ldots ; y_{b 1} \cdots y_{b v}\right]
$$

e

$$
x^{\prime} y^{*}=\left[\begin{array}{c}
y_{\ldots}+\lambda \\
-\ldots-. \\
y_{1} \\
\ldots \\
y_{i}+\lambda \\
\dot{y}_{b} \\
\hdashline- \\
y_{.1} \\
\cdots \\
y_{j}^{+\lambda} \\
\cdots \\
y_{\bullet} v
\end{array}\right]
$$

Desse modo, o vetor solução fica:

$$
\begin{gathered}
\hat{\theta}^{* 1}=\left[-\left(\bar{y}_{. .}+\lambda / b v\right)\right. \\
\bar{y}_{1 .} \bar{y}_{2 .} \ldots\left(\bar{y}_{i .}+\lambda / v\right) \ldots \bar{y}_{b .} \bar{y}_{.1} \bar{y}_{.2} \ldots \\
\left.\ldots\left(\bar{y}_{. j}+\lambda / b\right) \ldots \bar{y}_{. v}\right]
\end{gathered}
$$


obtido o vetor $y^{*}=X \hat{\theta}^{*}$, que caracteriza a apro ximação de mínimos quadrados, invariante para qualquer solução das equações normais, o vetor de resíduos, considerando-se o valor $\lambda$, será:

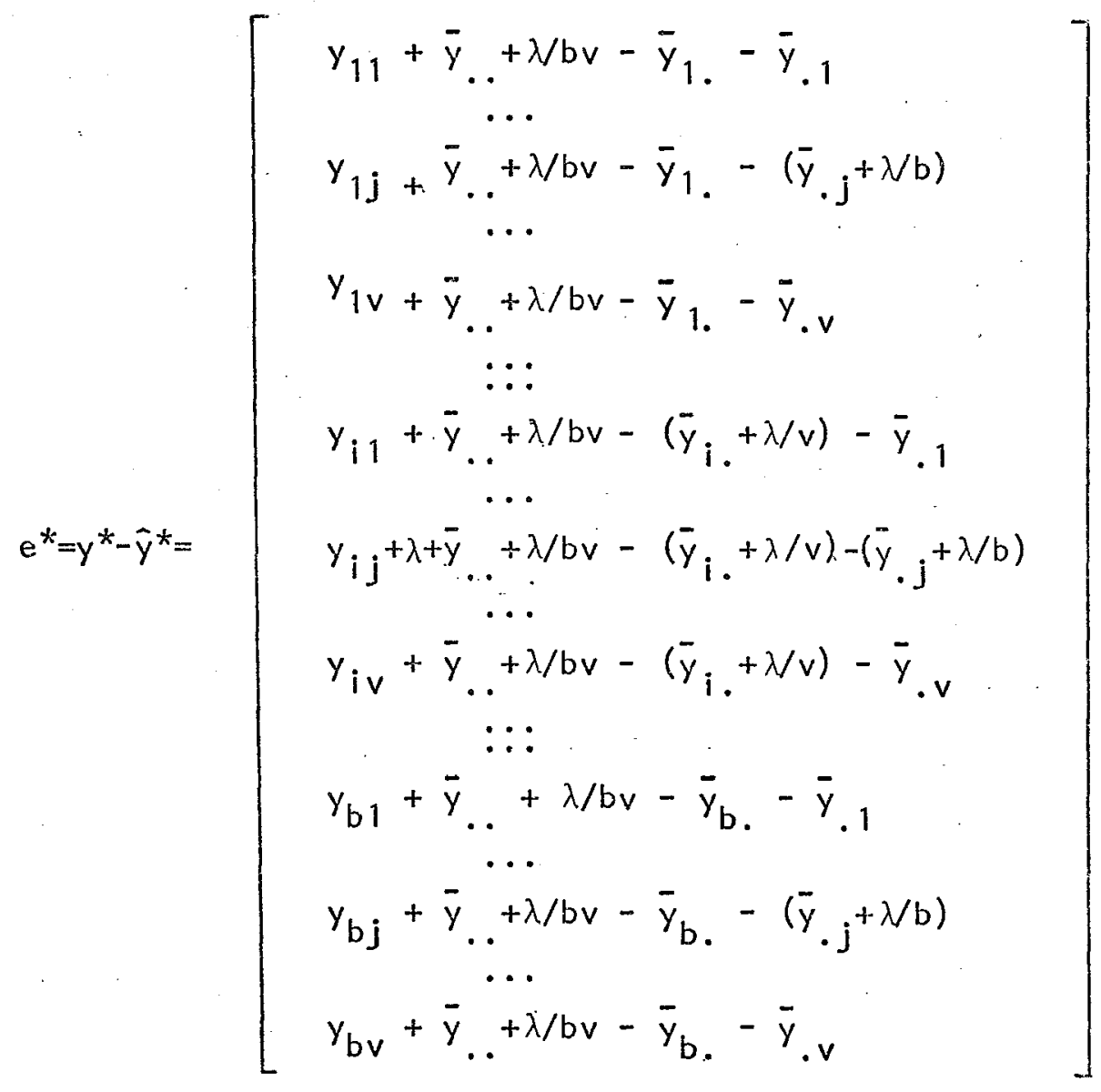

Portanto, o vetor $e^{*}=e+\Delta$, sendo $\Delta=\left(\Delta_{i j}\right)$, onde

$$
\begin{aligned}
& \Delta_{i j}=\frac{\lambda(b-1)(v-1)}{b v} \\
& \Delta_{i 1}=-\frac{\lambda(b-1)}{b v}, \cdot 1 \neq j
\end{aligned}
$$




$$
\begin{aligned}
& \Delta_{k j}=-\frac{(v-1)}{b v}, \quad k \neq i \\
& \Delta_{k l}=\frac{\lambda}{b v}, k \neq i, \quad 1 \neq j
\end{aligned}
$$

A soma de quadrados para os novos residuos, SQR*

serā:

$$
\begin{array}{ll}
e^{*} e^{*}= & (e+\Delta) \cdot(e+\Delta)=e^{\prime} e+2 e^{\prime} \Delta+\Delta^{\prime} \Delta \\
\ddots & S Q R^{*}=S Q R+2 e^{\prime} \Delta+\Delta^{\prime} \Delta \\
\text { ou } & S Q R^{*}=S Q R+S
\end{array}
$$

Como $S$ pode ser maior ou menor que zero, a soma de quadrados de residuos pode sofrer acréscimo ou decréscimo com a adição de um $\lambda$ a uma das observações.

\subsubsection{ESCOLHA DE UMA ESTRATEGIA PARA A ANALLISE} EXPLORATORIA DOS DADOS

3.2.2.1. Avaliação do padrão geral dos dados

Tendo por base as sugestões de BRoss (1961) é observado o padrão geral dos dados dos ensaios, considerandose a ordem decrescente de magnitude das observações dentro da coluna (tratamento) e dentro da linha (bloco). Para facilitar esta apreciação é utilizada uma tabela cujas caselas, cor respondentes a cada observação, trazem dois algarismos onde o 
superior representa a ordem da observação dentro da coluna (tra tamento)e o inferior a ordem na linha (bloco). E, ainda, é apresentado o gráfico de valores observados por bloco, e o grä́fico de valores observados por tratamento. os pontos unidos por linha reta formam uma poligonal que, no primeiro gráfico, constitui o perfil dos tratamentos e, no segundo, o perfil dos blocos. Com estes gräficos, objetiva-se melhorar a visualização do comportamento de tratamentos e de blocos.

3.2.2.2. Identificação de um valor aberrante

A identificação de un ünico valor aberrante é, conforme em 2.1, composta de duas fases: deteç̧ão, onde, aträ vēs da anālise gräfica de resíduos, verifica-se se ocorre um valor discordante, e teste de discordancia, onde verifica-se se - valor discordante detectado $\bar{e}$, de fato, um dado aberrante ou "outlier".

Assim, tem-se três tipos de procedimentos:

a) G.ráficos de resíduos contra y èstimados:

São apresentados grä́ficos de resíduos ordinários contra y estimados, seguindo DANIEL e WOOD (1980) e gráficos de resíduos padronizados contray estimados, seguindo NETER P WASSERMAN (1974).

A avaliação destes gräficos é feita visualmen te e considerando-se o critério informal de NETER e WASSERMAN (1974) em que os resíduos padronizados devem pertencer ao intervalo $(-3,3)$ quando não ocorrem "outliers". 
b) Gráficos de probabilidade normal:

Para cada ensaio considerado, são apresentados gráficos de probabilidade normal dos resíduos padronizados. A probabilidade acumulada empírica foi obtida pela expressão

$$
p_{k}=\frac{k-3 / 8}{n+1 / 4}, k=1, \ldots, n
$$

onde $k$ é a ordem do resíduo no conjunto de resíduos ordenados de forma crescente e $n=b v o$ nümero total de observações. A Tabela Al do Apêndice mostra os valores das posições de "plot" $p_{k}, k=1, \ldots, n$, sendo consideradas algumas das possiveis configurações de experimentos em blocos completos casualizados, desde $n=b v=6$ até $n=b v=50$. Como $p_{k}=1-p_{n-k+1}$, foram tabeliadas as posições de plot $p_{k}$ para $k=(n / 2+1), \ldots, n$ para $n$ par e $k=(n / 2+0,5), \ldots, n$ para $n$ impar.

Foram obtidos os grăficos em papel normal de probabilidade, isto é, localizando residuos ordenados contra a correspondente probabilidade empírica 100.p $p_{k}$ e em escala linear, ou seja, localizando os residuos contra o corresponden te quantil normal $\Phi^{-1}\left(p_{k}\right)$

Na Tabela: A2 do Apêndice estão os quantis normais obtidos para as probabilidades empiricas da Tabela Al, pa ra os mesmos tamanhos de "amostras", $n=b v$. Considerando que $\Phi^{-1}\left(p_{k}\right)=-\Phi^{-1}\left(p_{n-k+1}\right)$, foram tabelados os quantis

$$
\Phi^{-1}[(k-3 / 8) /(n+1 / 4)]
$$


para $k=[n / 2+1], \ldots, n$ quando $n$ è par e para $k=[n / 2+0,5]$, $\ldots, n$ quando $n$ é impar.

A avaliação formal dos grä́ficos probabilisticos normais é efetuada pelo teste $W$ de Shapiro-Wilk e pelo teste do coeficiente de correlação $r$. As hipóteses a serem considera das são:

$$
\begin{aligned}
& H_{0} \text { : os erros têm distribuição normal } \\
& H_{a} \text { : os erros não têm distribuição normal. }
\end{aligned}
$$

A estatistica $W$ foi definida em $(2.5 .3)$ por

$$
w=\frac{w^{2}}{s^{2}}
$$

Como os valores amostrais passam a ser residuos padronizados, no cálculo de w, o numerador de w, tem-se $x_{k}=d_{k}, k=1, \ldots$ bv. E como $\bar{d} \bar{e} i g u a l$ a zero, a não ser por efeitos de arredondamentos, o denominador de $W$ será:

$$
s^{2}=\sum_{k=1}^{b v} d_{k}^{2}
$$

Porēm, como $d_{k}=e_{k} / \sqrt{Q M R}$, conforme definido em (2.3.9), e $Q M R=S Q R /(b-1)(v-1)$, então, $\quad s^{2}=(b-1)(v-1)$, ou seja; é igual ao número de graus de liberdade dos resíduos.

As constantes $a_{n-k+1}$, necessārias para o cálculo de $w$ estão na Tabela $A 3$ do Apêndice. E os valores crí ticos para $W$ estão na Tabela A4 do Apêndice. 
0 coeficiente de correlação associado a grä́ficos de probabilidade está definido por (2.5.4). Ao utilizarem se residuos padronizados e os quantis $\Phi^{-1}\left(p_{k}\right)$, a expressão $(2.5 .4)$ passa a

$$
r=\frac{\sum_{k=1}^{b v} d_{k} \cdot \Phi^{-1}\left(p_{k}\right)}{\left\{\sum_{k=1}^{b v} d_{k}^{2} \cdot \sum_{k=1}^{b v}\left[\Phi^{-1}\left(p_{k}\right)\right]^{2}\right\}^{1 / 2}}
$$

onde $\sum_{k=1}^{b v}\left[\Phi^{-1}\left(p_{k}\right)\right]^{2}$ é constante para um dado $n=b v$. A Tabela A5 do Apêndice contém os valores críticos para $r$.

c) Teste de discordância para o maior residuo studentizado:

Para ser efetuado o teste de discordancia abor dado em 2.6 o procedimento será o que segue:

- obtenção do maior residuo absoluto studentizado

$$
\max \left|r_{i j}\right|=\frac{\max \left|e_{i j i}\right|}{\left[\hat{\operatorname{Var}}\left(e_{i j}\right)\right]^{1 / 2}}
$$

- comparação do max $\left|r_{i j}\right|$ com o valor tabelado por LUND (1975). Os valores tabielados estão reproduzidos na Tabela A6 do Apêndice.

- avaliação da correlação máxima entre residuos por comparação com o valor tabelado por DOORNBOS. (1981) 
(Tabela A7 do Apêndice), a fim de se obter, com maior precisão, o nível de significancia do teste, conforme a desigualdade $(2.6 .3)$.

3.2.2.3. Verificação da homogeneidade de variancias de tratamentos e da aditividade do modelo

A homogeneidade de variancias de tratamentos é verificada pelo teste da uniformidade da matriz de variancias e covariancias de tratamentos, abordado em 2.7.1. A aditividade dos dados sob o modelo descrito em questão é verificada pelo teste de Tukey para não-aditividade descrito em 2.7.2.

\subsubsection{ANALISE DA VARIÂNCIA}

E efetuada a análise da variancia sem levar em consideração os resultados da anàlise explóratória. Embora este não seja um procedimento sensato na rotina da anālise de dados tendo por base o modelo ANOVA, aqui tem o sentido de avaliar, para os exemplos abordados, justamente as consequências da ausência de uma anălise de resíduos.

A seguir, somente para os exemplos 2 e $3, \quad \dot{e}$ apresentada a análise da variância tendo sido substituído o valor aberrante pela estimativa de mínimos quadrados, calculada da maneira usual, como por exemplo em NETER e WASSERMAN $(1974)$ : 


$$
y_{i j}^{o}=\frac{b \cdot y_{i \cdot}^{\prime}+v \cdot y_{\cdot j}^{\prime}-y^{\prime} \cdot}{(b-1)(v-1)}
$$

onde $y_{i}^{\prime}, y^{\prime}$, e $y^{\prime}$. são os totais das observações disponíveis, isto é, aqui, sem a observação aberrante, considerada como per dida.

$$
\text { E, então, obtida a estatística } Q_{1}^{*} \text {, utilizada em }
$$

GENTLEMAN e WILK (1975b), conforme abordado em 2.5.2. Q a $_{1}^{*}$ corresponde à redução na soma de quadrados de resíduos causada pelo ajuste do modelo a $(n-1)$ dados, isto é, omitindo-se o va lor aberrante. 
79.

4. APRESENTACÃO DE EXEMPLOS

4.1. 0 ensaio NULO

Da Tabela 7 , correspondente aos dados do ensaio l ou ensaio nulo, ao considerar-se a ordem decrescente de mag nitude das observaçôes dentro de colunas (tratamentos) e dentro de linhas (blocos), obtém-se:

Tabela 10 .

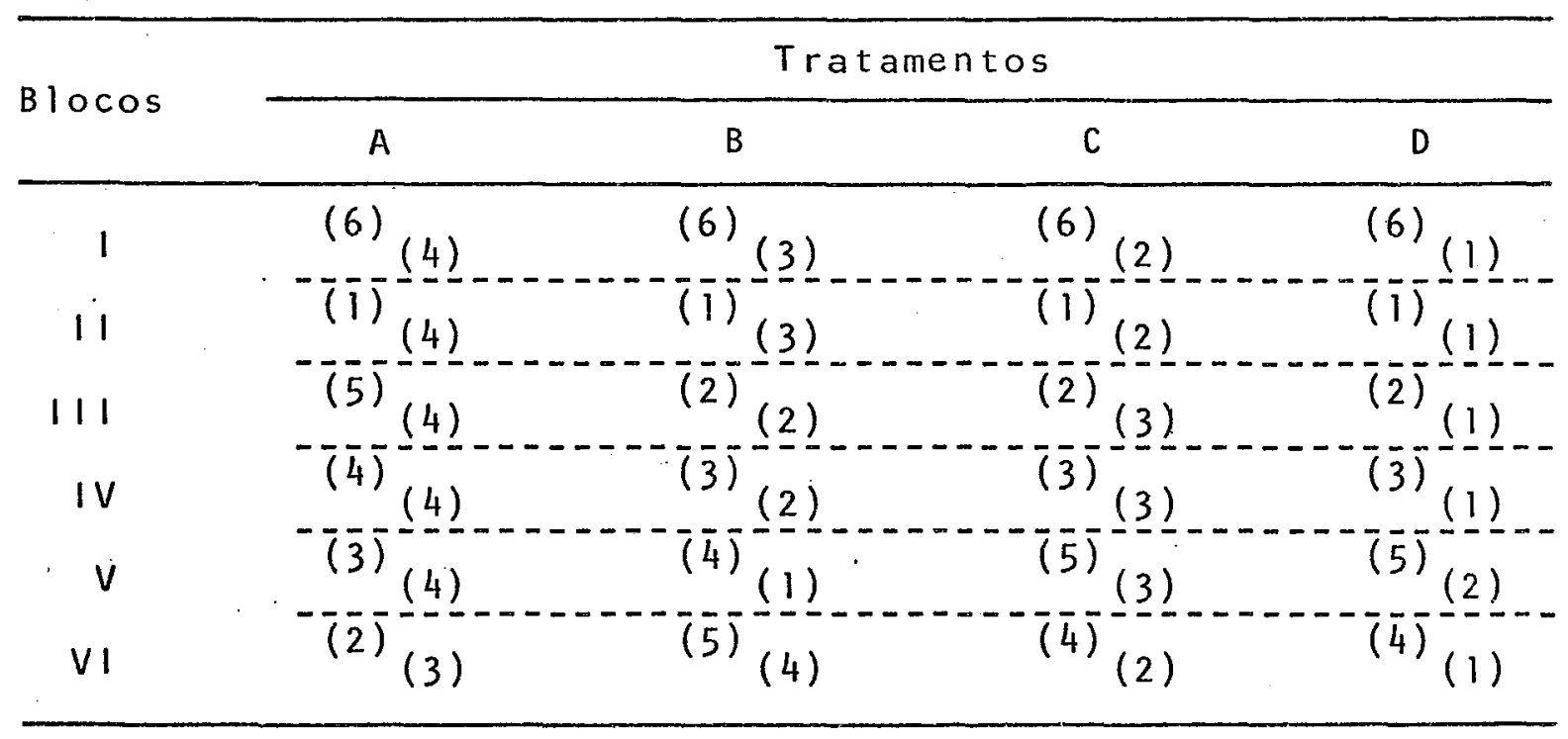


Pela Tabela 10 pode ser observado o padrão geral dos dados. Considerando a ordem das observações dentro de tratamentos (no sentido de colunas, algarismos superiores da Tabela 10) o padrão será avaliado na linha. Assim, nota-se que todos os tratamentos apresentam sua observação mais baixa no blocol e a mais alta no bloco 11 . Dos blocos 111 a VI, - tratamento A rompe o padrão da linha, os tratamentos C e D têm ordens identicas e o tratamento B destoa de C e D apenas pelas ordens. "trocadas" das observações nos blocos V e VI. A Figura 8 mostra o perfil dos tratamentos. Pode-se notarque os tratamentos B, C e D indicam um padrão geral, pois o perfil desses tratamentos são semelhantes, a não ser pela observação no bloco VI do tratamento B. Já o tratamento A, difere mais acentuadamente deste padrão.

Considerando a ordem das observações dentrodos blocos (linhas, algarismos inferiores), nota-se que a observação mais baixa dos blocos 1 a $V$ corresponde ao tratamento A, exceto no bloco Vi que é do tratamento B. Exceto para o bloco V, em todos os demais a observação mais alta corresponde ao tratamento D. A ordem nos blocos, para o tratamento C, é igual a (2) ou (3); o mesmo ocorre no tratamento B, exceto para os blocos V e VI.

A Figura 9 mostra as poligonais que indicam o perfil dos blocos.

Nota-se que os blocos $V$ e VI têm um perfil diferente da maioria formada pelos outros quatro blocos. 




Figura 8. Perfil dos tratamentos no ensaio 1.

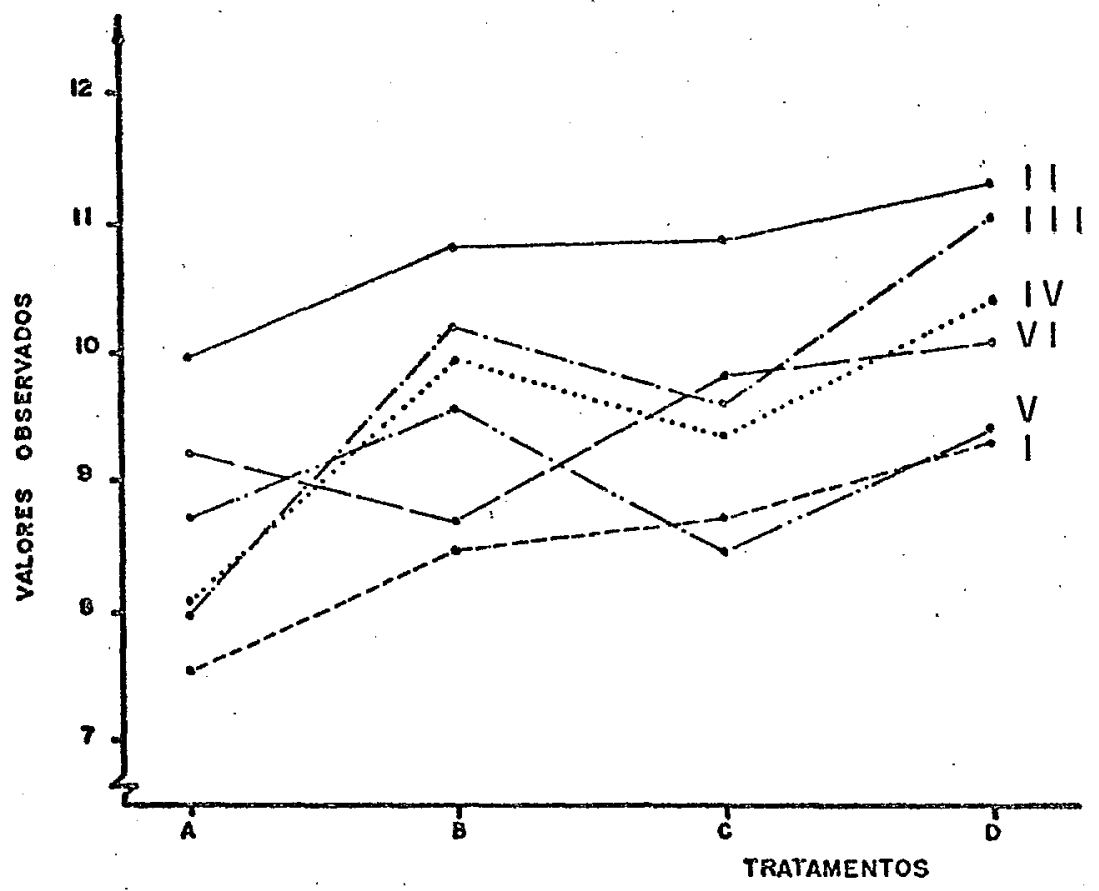

Figura 9. Perfil dos blocos no ensaio 1. 
Na Tabela 11 constam os residuos ordinärios re ferentes aos dados do ensaio nulo. Observa-se que, neste caso, convém apresentar os resíduos sob forma de tabela para se ter a correspondência com a observação.

Tabela 11. Resíduos ordinārios para o ensaio nulo.

$\begin{array}{rrrr}-0,0483 & -0,1533 & 0,1600 & 0,0417 \\ 0,1567 & -0,0383 & 0,0850 & -0,2033 \\ -0,8108 & 0,3842 & -0,1525 & 0,5792 \\ -0,4633 & 0,3917 & -0,1250 & 0,1967 \\ 0,4792 & 0,2842 & -0,2725 & -0,4908 \\ 0,6867 & -0,8683 & 0,3050 & -0,1233\end{array}$

A observação $y_{62}=8,70$ (bloco VI, tratamento B) tem o maior resíduo absoluto do conjunto. De fato, essa observação faz romper o padrão do tratamento $B$, em relação aos tratamentos C e D; e do bloco VI em relação aos demais blocos. No entanto, é de se salientar que $y_{62}$ não é um extre mo dentro do conjunto de observações.

A soma de quadrados de resíduos, dada por $S Q R=e^{\prime} e=\sum_{i=1}^{6} \sum_{j=1}^{4} e_{i j}^{2} \quad \overline{i g} \cdot i g u l$ a $3,673 \operatorname{com}(b-1)(v-1)=15$ graus de 1 iberdade.

Com os resíduos ordinärios e os valores da apro ximação de mínimos quadrados para $y, \hat{y}=x \theta^{0}$. (Tabela 12), ob- 
tem-se o gräfico apresentado na Figura 10. Na Figura 11, vêse o gräfico de resíduos padronizados contra $y_{i j}$ estimados.

Tabela 12. $y_{i j}$ estimados para o ensaio nulo.

\begin{tabular}{rrrr}
7,5883 & 8,6333 & 8,5700 & 9,2883 \\
9,8133 & 10,8583 & 10,7950 & 11,5133 \\
8,7808 & 9,8258 & 9,7625 & 10,4808 \\
8,5233 & 9,5683 & 9,5050 & 10,2233 \\
8,2308 & 9,2758 & 9,2125 & 9,9308 \\
8,5233 & 9,5683 & 9,5050 & 10,2233 \\
\hline
\end{tabular}

As Figuras 10 e 11 não indicam nenhum valor discordante, conforme sugerido pelas Figuras 3 e 4 do capitu10 2. Todos os resíduos padronizados pertencem ao intervalo $(-2,2)$ sendo o maior em módulo, correspondente à observação $Y_{62}$, igual a $d_{62}=-1,7547$. Portanto, pelo critério de NETER e WASSERMAN (1974) não existe "outlier" entre os dados do en saio 1 .

A Tabela 13 traz os resíduos padronizados já ordenados e os correspondentes valores da probabilidade acumu lada empírica ou posição de "plot" $\left(p_{k}\right)$ e do quantil. normal, $\Phi^{-1}\left(p_{k}\right)$, obtidos das Tabelas $A 1$ e $A 2$ do Apêndice, respectivamente, para $n=b \cdot v=24$. 


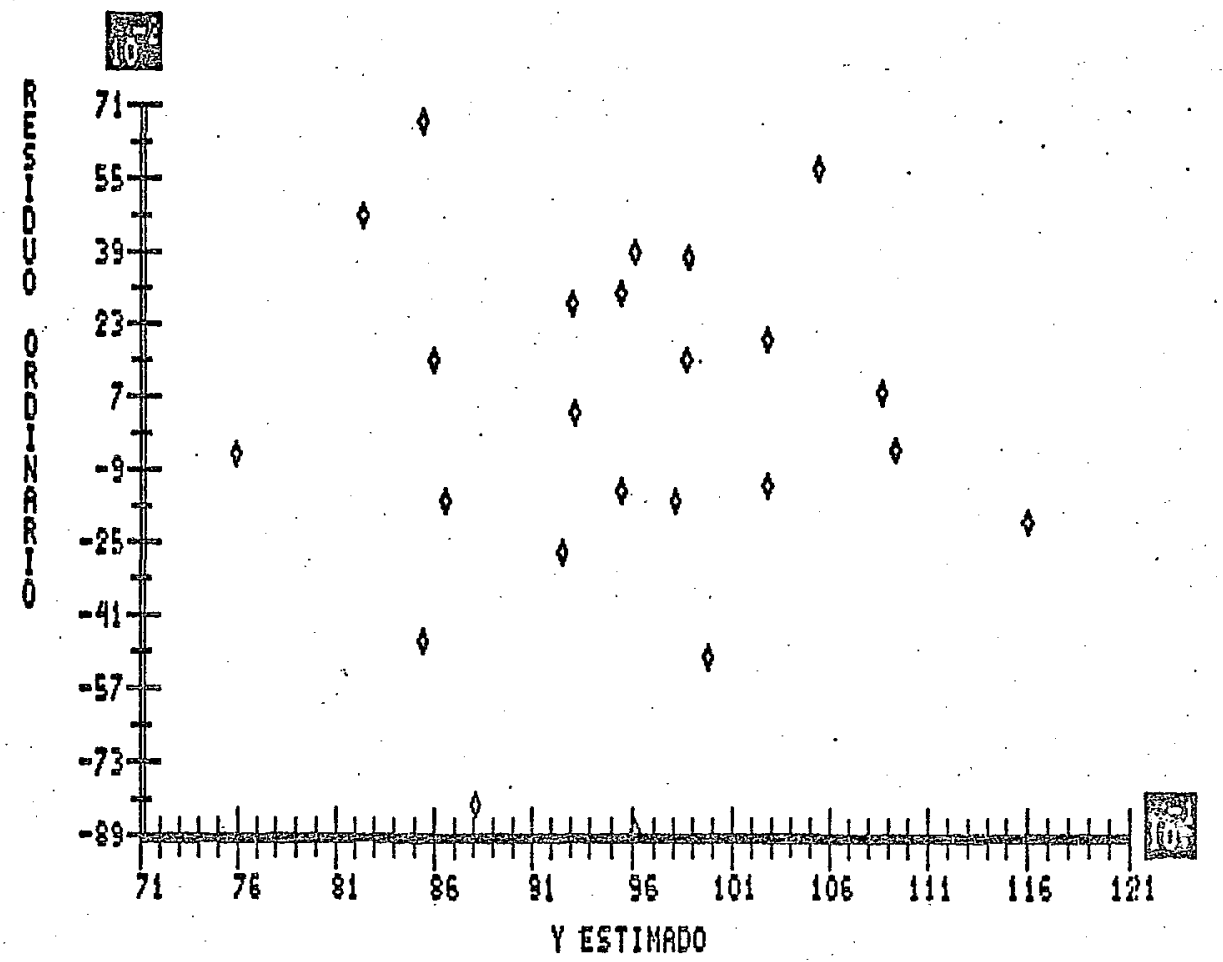

Figura 10. Resíduos ordinārios contra y estimados para o ensaio 1 .

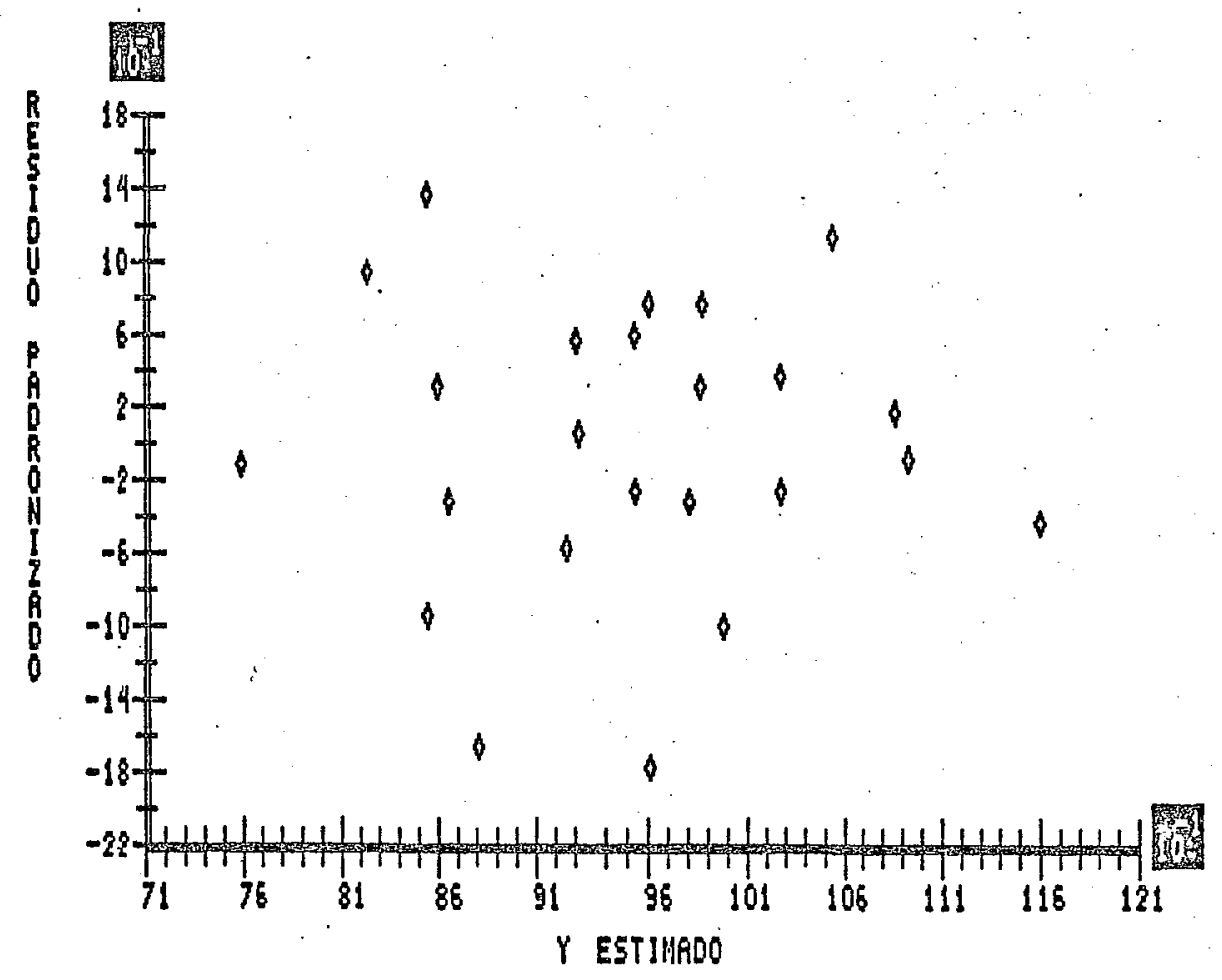

Figura 11. Resíduos padronizados contra y estimados para o ensaio 1 . 
85.

Tabela 13. Residuos padronizados ordenados $\left(d_{k}\right)$, para o ensaio 1 , posições de plot $\left(p_{k}\right)$ e quantis normais $\Phi^{-1}\left(p_{k}\right), k=1, \ldots, 24$.

\begin{tabular}{|c|c|c|c|c|}
\hline $\begin{array}{l}\text { Ordem do } \\
\text { residuo (k) }\end{array}$ & $(i, j) *$ & $d_{k}$ & $\mathrm{Pk}_{\mathrm{k}}$ & $\Phi^{-1}\left(p_{k}\right)$ \\
\hline 1 & $(6,2)$ & $-1,7547$ & 0,0258 & $-1,9468$ \\
\hline 2 & $(3,1)$ & $-1,6385$ & 0,0670 & $-1,4984$ \\
\hline 3 & $(5,4)$ & $-0,9919$ & 0,1082 & $-1,2359$ \\
\hline 4 & $(4,1)$ & $-0,9363$ & 0,1495 & $-1,0386$ \\
\hline 5 & $(5,3)$ & $-0,5507$ & 0,1907 & $-0,8752$ \\
\hline 6 & $(2,4)$ & $-0,4109$ & 0,2320 & $-0,7324$ \\
\hline 7 & $(1,2)$ & $-0,3099$ & 0,2732 & $-0,6032$ \\
\hline 8 & $(3,3)$ & $-0,3082$ & 0,3144 & $-0,4833$ \\
\hline 9 & $(4,3)$ & $-0,2526$ & 0,3557 & $-0,3701$ \\
\hline 10 & $(6,4)$ & $-0,2492$ & 0,3969 & $-0,2614$ \\
\hline 11 & $(1,1)$ & $-0,0977$ & 0,4381 & $-0,1557$ \\
\hline 12 & $(2,2)$ & $-0,0775$ & 0,4794 & $-0,0517$ \\
\hline 13 & $(1,4)$ & 0,0842 & 0,5206 & 0,0517 \\
\hline 14 & $(3,3)$ & 0,1718 & 0,5618 & 0,1557 \\
\hline 15 & $(2,1)$ & 0,3166 & 0,6031 & 0,2614 \\
\hline 16 & $(1,3)$ & 0,3233 & 0,6443 & 0,3701 \\
\hline 17 & $(4,4)$ & 0,3974 & 0,6856 & 0,4833 \\
\hline 18 & $(5,2)$ & 0,5742 & 0,7268 & 0,6032 \\
\hline 19 & $(6,3)$ & 0,6164 & 0,7680 & 0,7324 \\
\hline 20 & $(3,2)$ & 0,7763 & 0,8093 & 0,8752 \\
\hline 21 & $(4,2)$ & 0,7914 & $0 \cdot, 8505$ & 1,0386 \\
\hline 22 & $(5,1)$ & 0,9683 & 0,8918 & 1,2359 \\
\hline 23 & $(3,4)$ & 1,1704 & 0,9330 & 1,4984 \\
\hline 24 & $(6,1)$ & 1,3876 & 0,9742 & 1,9468 \\
\hline
\end{tabular}

* Posição na Tabela 7: bloco i, tratamento j. 
A seguir, são apresentados os grä́icos de probabilidade normal dos residuos padronizados, em papel de probabilidade (Figura 12) e em papel comum (Figura 13). Logo, no primeiro, foram plotados $d_{k}$ contra $p_{k}$ e no segundo gräfico, $d_{k}$ contra $\Phi^{-1}\left(p_{k}\right), k=1, \ldots, n$.

A avaliação visual dos grä́ficos de probabilida de normal não sugere a presença de dados discordantes.

Calculados os valores das estatísticasteste $w$, conforme (3.2.19), e $r$, conforme $(3.2 .20)$, obteve-se $W=$ 0,9696 (n.s. conforme a Tabela A4 para $n=24$ ), e $r=0,9869$ (n.s. conforme a Tabela $A 5$ para $n=24$ ). Portanto, não há evidências que induzam à rejeição da hipótese de normalidade para os erros do ensaio nulo.

0 teste de discordancia para a observação $y_{62}$ é efetuado a seguir. A estimativa da variancia dos resíduos,

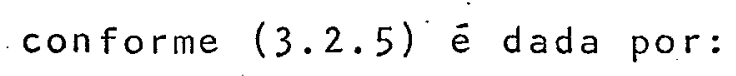

$$
\hat{v}\left(e_{i j}\right)=\frac{15}{24} \frac{3,673}{15}=0,1530
$$

logo, o maior residuo studentizado, associado à observação $y_{62}{ }^{\prime}$ é dado por

$$
\max \left|r_{i j}\right|=\frac{-0,8683}{\sqrt{0,1530}}=2,22 \text {. }
$$











Figura 13. Gráfico probabilístico normal para os residuos padronizados do ensaio 1 , em papel comum.

O valor crítico obtido da Tabela A5, para $n=24$, $p=9$ e $\alpha=0,05$, por interpolação harmônica, è igual :a, 2,748. Portanto, não se tem razões para considerar $y_{62}$ uma observação aberrante.

As estimativas das covariâncias entre residuos, usando $(3.2 .6),(3.2 .7)$ e $(3.2 .8)$ são:

$$
\operatorname{Cov}\left(e_{i j}, e_{i l}\right)=-\frac{5}{24} \cdot 0,2449=-0,0510,1 \neq j \text {, para re- }
$$
siduos associados a observações do mesmo bloco; 
$\operatorname{Cov}\left(e_{i j}, e_{k j}\right)=-\frac{3}{24} \cdot 0,2449=-0,0306, k \neq i$,para residuos de observações do mesmo tratamento;

$\operatorname{Cov}\left(e_{i j} ; e_{k l}\right)=\frac{1}{24} \cdot 0,2449=0,0102, k \neq i, 1 \neq j$, para res $i-$ duos de observações de blocos e tratamentos distintos.

As correlações entre residuos podem ser calculadas por $(3.2 .9),(3.2 .10)$ e $(3.2 .11)$. Assim:

$\rho_{\mathbf{i} \mathbf{j}, \mathbf{i} \mathbf{l}}=-1 /(4-1)=-0,333,1 \neq \mathbf{j}$, entre residuos de observa ções do mesmo bloco;

$\rho_{i j, k j}=-1 /(6-1)=-0,20, k \neq i$, entre residuos de observaçöes do mesmo tratamento;

$$
\rho_{i j, k l}=1 /(b-1)(v-1)=0,0667, k \neq i \text { e } j \neq 1 \text {, entre residuos de }
$$
observações de blocos e tratamentos distintos.

Logo, a maior correlação absoluta será.

$$
\max |\rho|=0,333
$$

que é maior que o valor crítico $g_{0.05}$ correspondente, da Tabe la $A 7$ para $n=24$ e $p=r(x)=9$.

o teste F para aditividade e o critērio de Box para homogeneidade de variâncias, aplicados ao ensaio l, leva ram aos resultados mostrados na Tabela 14. 
Tabela 14. Resultados do teste de aditividade e do teste de homogeneidade de variâncias, para o ensaio 1.

\begin{tabular}{lll}
\hline & $F_{\tilde{N} A}$ & $x^{2}$ \\
\hline Valor calculado & $0,0098 \mathrm{~ns}$ & $10,0153 \mathrm{~ns}$ \\
Valor tabelado & 0,001 (1) & 15,51 (2) \\
\hline
\end{tabular}

(1) Para $\alpha=0,05$ e $i$ e 14 graus de liberdade $(F<1)$.

(2) Para $\alpha=0,05$ e 8 graus de liberdade.

Nesse contexto, efetuou-se a anälise da variân cia, conforme consta da Tabela 15.

Tabela 15. Anâlise de variancia para o ensaio l.

\begin{tabular}{lrrrr}
\hline Causas da variação & GL & SQ & QM & F \\
\hline Mëdia & 1 & 2169,802 & & \\
Blocos & 5 & 10,692 & & \\
Tratamentos & 3 & 8,842 & 2,947 & $12,44^{* *}$ \\
Residuo & 15 & 3,673 & 0,245 & \\
\hline Total & 24 & 2193,009 & & \\
Total corrig. & 23 & 23,208 & & \\
\hline
\end{tabular}


4.2. Ensaio 2

Considere-se o ensaio em blocos casualizados, chu jos resultados estäo na Tabela 8. Na Tabela 16 tem-se a ordem de cada observação dentro do tratamento e dentro do bloco.

Tabela 16.

\section{Tratamentos}

Blocos

$\begin{array}{llll}\text { A } & \text { B } & \text { C }\end{array}$

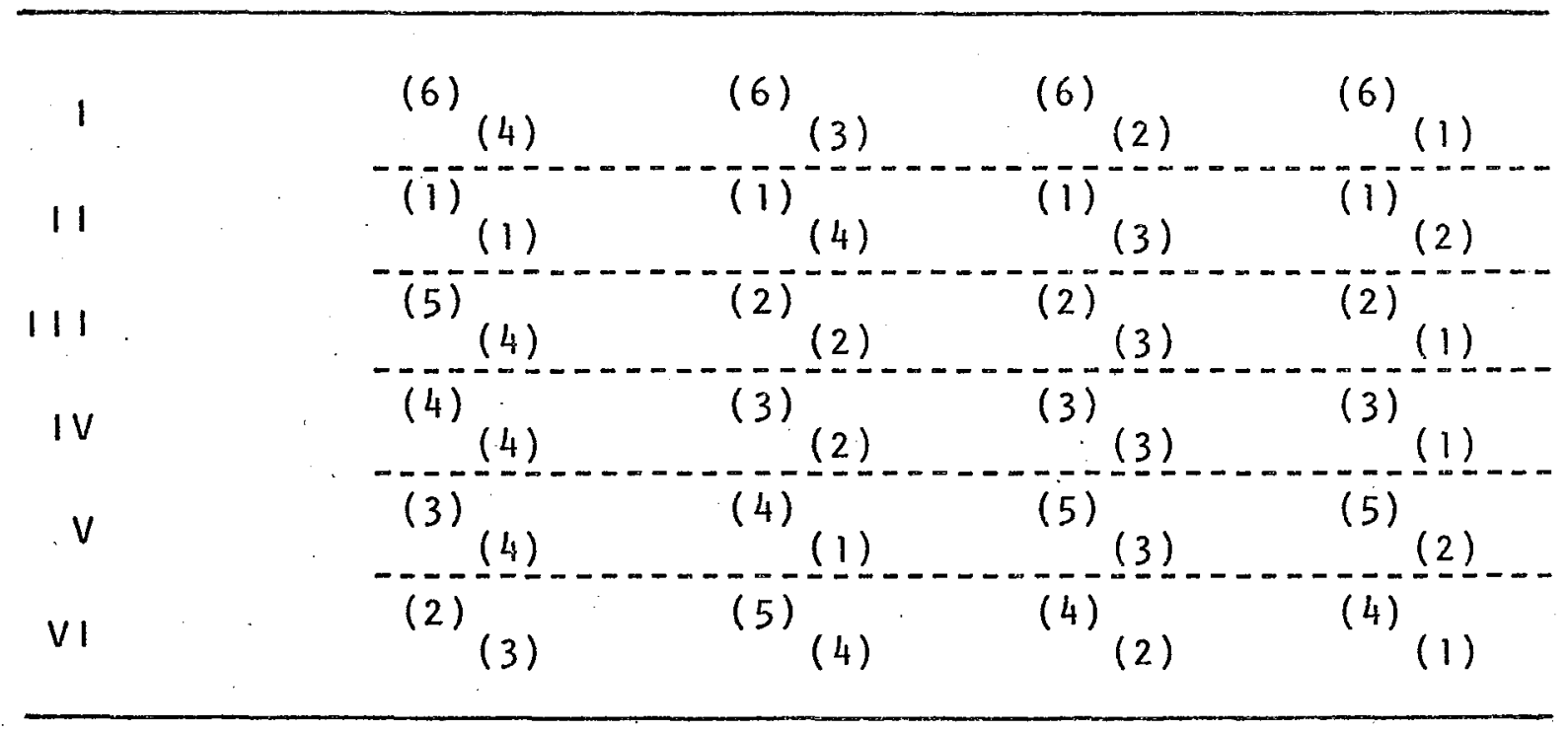

Em relação ao ensaio 1 , a ordem dos resultados dentro do tratamento Anão foi alterada. Porēm, a ordem den-. tro do bloco 2 foi modificada, alterando o padrão de colunas na Tabela 16: a observação $y_{21}=12,97$ passa a ser a mais al- 
ta do bloco 11 , enquanto, em quatroblocos; o tratamento A con tribui com a mais baixa observação (ordem (4)). As figuras 14 e 15, referem-se ao comportamento de tratamentos e de blocos, respectivamente. Pela Figura 14, nota-se um perfil do tratamento A bastante diferente dos demais marcadamente no bloco 11 .

$$
\text { De fiato, a observação } y_{21} \text {, não sō é extrema no }
$$
bloco e no tratamento respectivo, como constitui um extremo em todo o cọjunto de observações.

os residuos do ensaio 2 podem ser obtidos pelo ajuste do modelo aos dados ou pelas expressões (3.2.12) a (3.2.15). Isto é, sejam e $e_{j}$ os resíduos do ensaio 1 , então os resíduos do ensaio $2, e_{i j}^{*}$, serão

$$
\begin{aligned}
& e_{21}^{*}=e_{21}+\lambda(b-1)(v-1) / b v=0,1567+3 .(15 / 24)=2,0317 \\
& e_{2 j}^{*}=e_{2 j}-3(3 / 24), j \neq 1 \\
& e_{i 1}^{*}=e_{i 1}-3(5 / 24), i \neq 2 \quad e, \\
& e_{i j}^{*}=e_{i j}+3 / 24, i \neq 2, j \neq 1 .
\end{aligned}
$$

os residuos associados aos dados do ensaio 2 estão na Tabela 17 . 


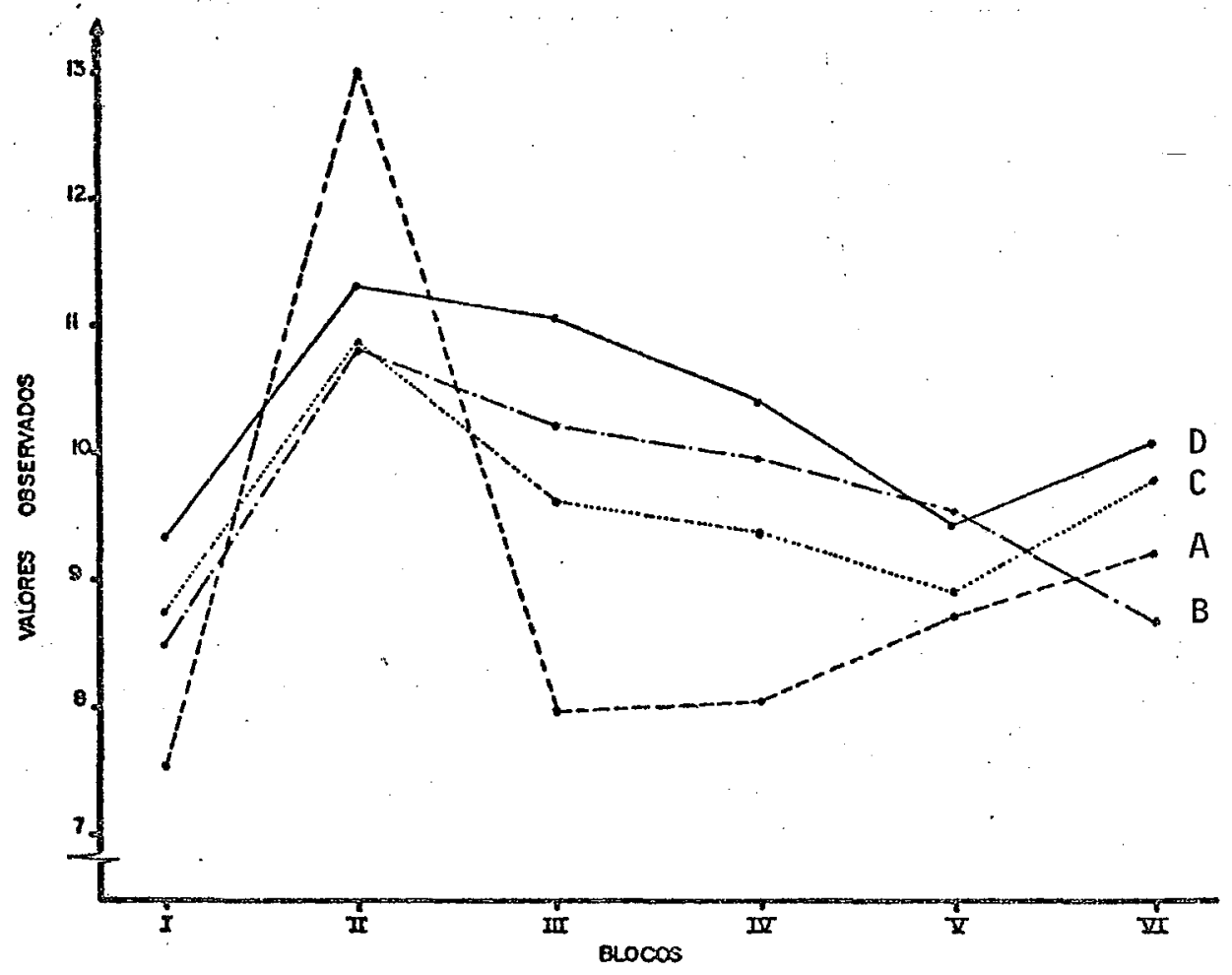

Figura 14. Perfil dos tratamentos no ensaio 2.

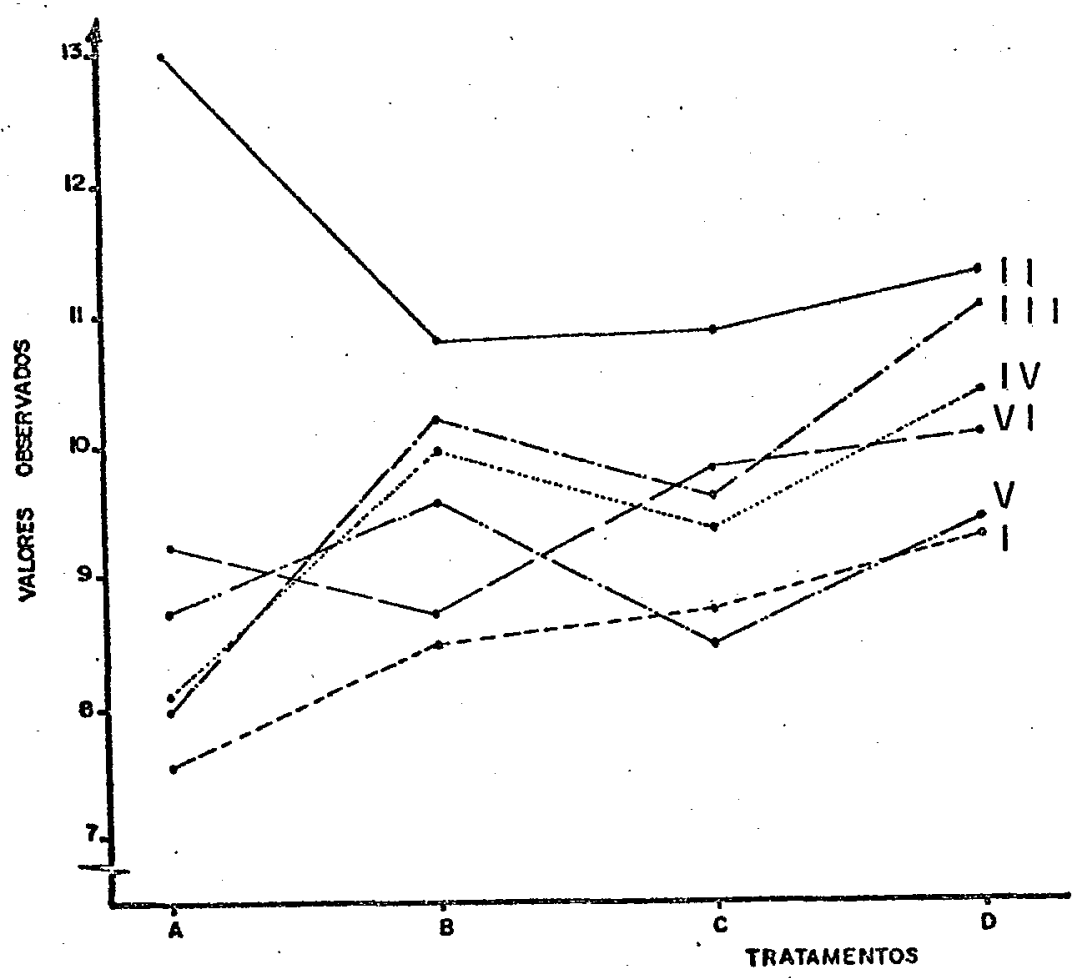

Figura 15. Perfil dos blocos no ensaio 2 . 
Tabela 17. Resíduos ordinários para o'ensaio 2.

\begin{tabular}{rrrr}
\hline$-0,4233$ & $-0,0283$ & 0,2850 & 0,1667 \\
2,0317 & $-0,6633$ & $-0,5400$ & $-0,8283$ \\
$-1,1858$ & 0,5092 & $-0,0275$ & 0,7042 \\
$-0,8383$ & 0,5167 & 0,0000 & 0,3217 \\
0,1042 & 0,4092 & $-0,1475$ & $-0,3658$ \\
0,3117 & $-0,7433$ & 0,4300 & 0,0017 \\
\hline
\end{tabular}

A soma de quadrados dos resíduos è igual a 10,238 com 15 graus de liberdade. De fato, a soma de quadrados de residuos deste ensaio (SQR*) pode ser calculada, tal como em (3.2.16), da soma de quadrados de resíduos do ensaio nulo (SQR). 0 acréscimo $S$ é dado por

$$
2 e^{\prime} \Delta+\Delta^{\prime} \Delta=0,94+5,625=6,565 \text {. }
$$

Assim, $\quad \mathrm{SQR}^{*}=3,673+6,565=10,238$

como já obtido pelo cálculo usual.

obtidos os $y_{\mathbf{i} j}$ estimados (Tabela 18)e, à partir da Tabela 17, os resíduos padronizados, constrói-se os gráficos apresentados nas Figuras 16 e 17 . 
Tabela 18. $y_{\mathbf{i j}}$ estimados para o ensaio 2.

\begin{tabular}{rrrr}
7,9633 & 8,5083 & 8,4450 & 9,1633 \\
10,9383 & 11,4833 & 11,4200 & 12,1383 \\
9,1558 & 9,7008 & 9,6375 & 10,3558 \\
8,8983 & 9,4433 & 9,3800 & 10,0983 \\
8,6058 & 9,1508 & 9,0875 & 9,8058 \\
8,8983 & 9,4433 & 9,3800 & 10,0983 \\
\hline
\end{tabular}

Nas Figuras 16 e 17 observa-se que um ponto des taca-se acima da massa de pontos formada pelos demais. Este ponto corresponde à observação $y_{21}$ que constitui, assim, um valor discordante. 0 resíduo padronizado $d_{21}=2,4592$ é 0 maior em valor absoluto, de modo que, pelo critério de INETER e WASSERMAN (1974), não hä dados aberrantes no ensaio 2.

Na Tabela 19 estão os resíduos padronizados or denados, os quais, com as correspondentes posições de "p!lot". $\mathrm{p}_{k}$, já obtidas na Tabela 13, levam ao gráfico probabilístico da Figura 18. Também da Tabela 13, tem-se os quantis normais $\Phi^{-1}\left(p_{k}\right)$, que com os residuos padronizados respectivos levam ao grä fico probabilistico da Figura 19. 




Figura 16. Gräfico de resíduos ordinärios contra y estimados, para o ensaio 2 .

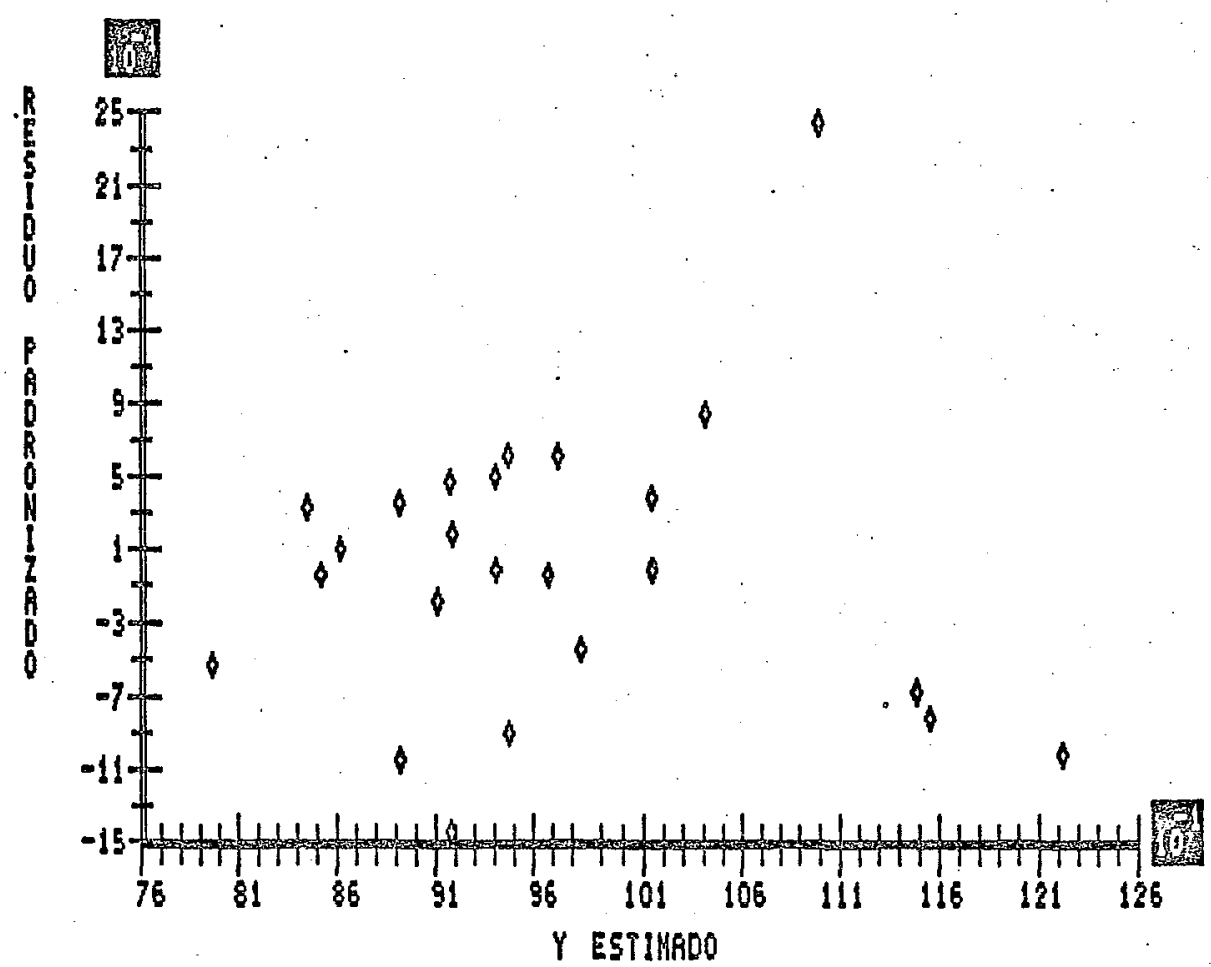

Figura 17. Gráfico de residuos padronizados contra y estima dos, para o ensaio 2 . 
Tabela 19. Resíduos padronizados ordenados para o ensaio 2.

\begin{tabular}{cccccc}
\hline $\begin{array}{l}\text { Ordem do } \\
\text { residuo }(k)\end{array}$ & $(i, j) *$ & $d_{k}$ & $\begin{array}{c}\text { Ordem do } \\
\text { residuo }(k)\end{array}$ & $(i, j)$ & $d_{k}$ \\
\hline 1 & $(3,1)$ & $-1,4354$ & 13 & $(6,4)$ & 0,0020 \\
2 & $(3,2)$ & $-1,0147$ & 14 & $(5,1)$ & 0,1261 \\
3 & $(2,4)$ & $-1,0026$ & 15 & $(1,4)$ & 0,2017 \\
4 & $(6,4)$ & $-0,8997$ & 16 & $(1,3)$ & 0,3450 \\
5 & $(2,2)$ & $-0,8029$ & 17 & $(6,1)$ & 0,3773 \\
6 & $(2,3)$ & $-0,6536$ & 18 & $(4,4)$ & 0,3894 \\
7 & $(1,1)$ & $-0,5124$ & 19 & $(5,2)$ & 0,4953 \\
8 & $(5,4)$ & $-0,4428$ & 20 & $(6,3)$ & 0,5205 \\
9 & $(5,3)$ & $-0,1785$ & 21 & $(3,2)$ & 0,6163 \\
10 & $(1,2)$ & $-0,0343$ & 22 & $(4,2)$ & 0,6254 \\
11 & $(3,3)$ & $-0,0333$ & 23 & $(3,4)$ & 0,8523 \\
12 & $(4,3)$ & 0,0 & 24 & $(2,1)$ & 2,4592 \\
\hline
\end{tabular}

*Posição na Tabela 8: bloco i, tratamento $\mathrm{j}$.

As Figuras 18 e 19 indicam o ponto discordante corresponde a $Y_{21}$. Nota-se que este ponto foge à tendência linear dos demais. Os valores calculados do teste de Shapiro-Wilk e do coeficiente de correlação são $W=0,9295$ (ns) e $r=0,9560^{*}$. Portanto, mesmo com um valor discordante, näo se pode rejeitar a hipótese de normalidade dos erros, pelo teste de Shapiro-Wilk. Porém, pelo teste do coeficiente de correlação a mesma hipōtese não é aceita, a um nível $\alpha=0,05$ de probabilidade. 
98.

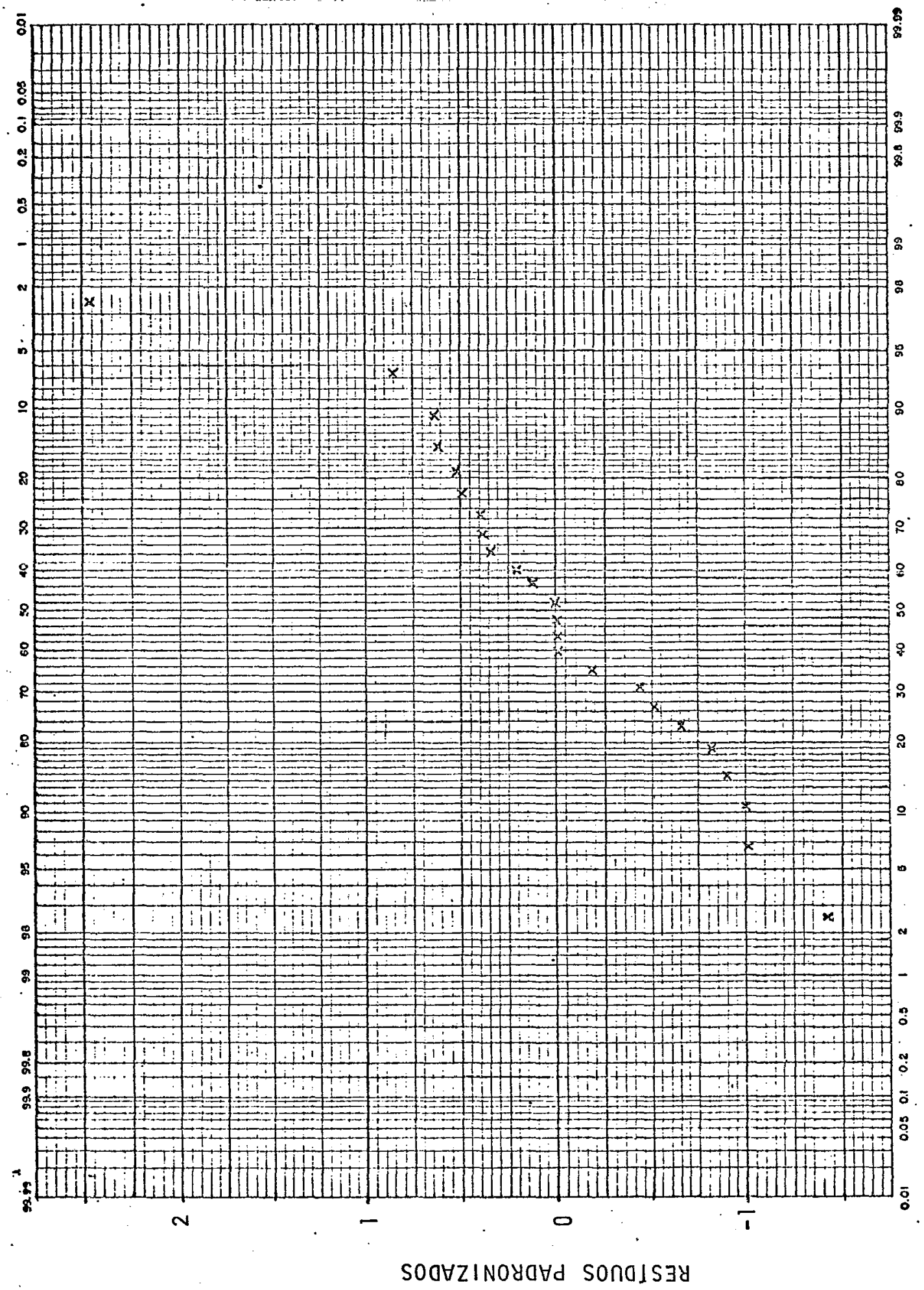






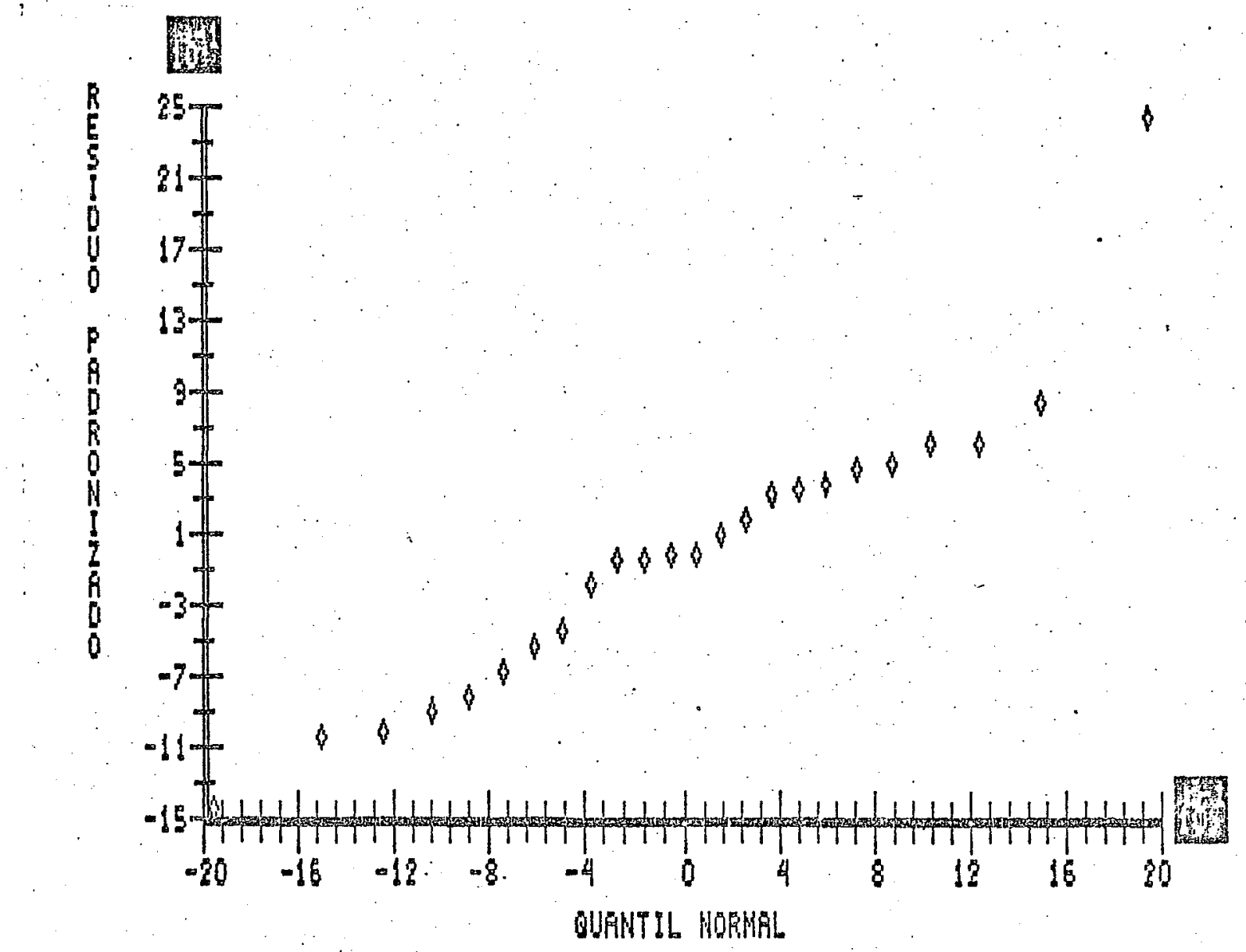

Figura 19. Gráfico probabilistico normal para residuos padronizados do ensaio 2 , em papel comum.

A estimativa da variancia dos resíduos é igual

a

$$
\hat{V}\left(e_{i j}\right)=\frac{15}{24} \cdot \frac{10,238}{15}=0,4266
$$

logo, o maior resíduo absoluto studentizado será

$$
\max \left|r_{i j}\right|=\frac{2,0317}{\sqrt{0,4266}}=3,1106 * *
$$


o valor crítico obtido da Tabela A6, por interpolação harmônica, para $n=24$ e $p=9$, a $\alpha=0,01$ é igual a 3,0. Portanto, a observação $y_{21}$ ē aberrante ao nível $\alpha=0,01$

As estimativas das covariancias entre residuos

são

$$
\begin{aligned}
& \operatorname{Cov}\left(e_{i j}, e_{i l}\right)=-(5 / 24)(0,6825)=-0,1422, \text { para } 1 \neq j ; \\
& \operatorname{Cov}\left(e_{i j}, e_{k j}\right)=-(3 / 24)(0,6825)=-0,0853, \text { para } k \neq i ; \\
& \text { e } \quad \operatorname{cov}\left(e_{i j}, e_{k l}\right)=(1 / 24)(0,6825)=0,0284, \text { para } k \neq i, 1 \neq j .
\end{aligned}
$$

As correlações entre residuos são fixas como visto em 3.2.2.2. Portanto, serão as mesmas já obtidas para o ensaio 1. Como $\max |\rho|=0,333>g_{0.05}$ (Tabela A7, para $n=24$ ), afirma-se apenas que o nível de significância para o teste de discordância é menor que 0,01 .

os resultados do teste de homogeneidade de variâncias e de aditividade são os seguintes:

Tabela 20. Resultados do teste de aditividade e de homogeneidade de variâncias, para o ensaio 2 .

$$
F_{\tilde{N} A} \quad \dot{X}^{2}
$$

$\begin{array}{lll}\text { Valor calculado } & 5,42 * & 20,51 * * \\ \text { Valor tabelado } & 4,60(1) & 20,09(2)\end{array}$

(1) Para $\alpha=0,05$ e 1 e 14 graus de 1 iberdade

(2) Para $\alpha=0,01$ e 8 graus de 1 iberdade. 
A observação discrepante $y_{21}$ alterou plenamente a aditividade e a homogeneidade de variâncias, comprometen do profundamente a validade das inferências sob o modelo adotado.

Ignorando-se as violações das pressuposições bä sicas da anālise da variância, obtēm-se o seguinte:

Tabela 21. Anālise da variância para o ensaio 2.

\begin{tabular}{lrrrr}
\hline Causas da variação & GL & SQ & QM & F \\
\hline Média & 1 & 2227,227 & & \\
Blocos & 5 & 19,987 & & \\
Tratamentos & 3 & 4,377 & 1,459 & 2,14 ns \\
Residuo & 15 & 10,238 & 0,682 & \\
\hline Total & 24 & 2261,829 & & \\
Total corrig. & 23 & 34,602 & \\
\hline
\end{tabular}

Observa-se que o teste $F$ para tratamento passou a ser não significativo. Esse resultado evidencia o fato de que a presença do "outlier" prejudicou sobremaneira a sensibilidade do teste.

Tomando-se, conforme $(3.2 .22)$, a estimativa de mínimos quadrados para a observação $y_{21}, y_{21}^{\circ}=9,72$, observase que fica retomado o padrão geral dos dados do ensaio 1 . 
Procedendo-se a uma avaliação das pressuposições de normalidade, aditividade e homogeneidade de variāncias, com $y_{21}^{0}$, obtém-se:

Tabela 22. Testes de Shapiro-Wilk $(W)$, aditividade $\left(F_{\tilde{N} A}\right)$ e ho mogeneidade de variâncias $\left(X^{2}\right), \operatorname{com} y_{21}^{0}=9,72$ no ensaio 2 .

\begin{tabular}{llll}
\hline & $W$ & $F \tilde{N A}$ & $X^{2}$ \\
\hline $\begin{array}{l}\text { Valor calculado } \\
\text { Valor tabelado }\end{array}$ & $0,9590 \mathrm{~ns}$ & $0,1668 \mathrm{~ns}$ & $8,7846 \mathrm{~ns}$ \\
& $0,916(1)$ & $0,001(2)$ & $15,51(3)$ \\
\hline
\end{tabular}

(1) Para $\alpha=0,05$ e $n=24$.

(2) Para $\alpha=0,05,1$ e i3 GL $(F<1)$.

(3) Para $\alpha=0,05$ e $8, G L$

os resultados da Tabela 22 aproximam-se dos cor respondentes para onsaio nulo.

A análise da variância utilizando a estimativa $y_{21}^{o}$ é dada a seguir. (Tabela 23 ).

A redução na soma de quadrados de resíduos obtida com a substituição do "outlier" pela estimativa de mínimos quadrados é igual a $Q_{1}=10,238-3,633=6,605$.

0 teste $F$ para tratamentos leva às mesmas conclusões que o do ensaio nulo. 
Tabela 23. Análise da variância utilizando $y_{21}^{0}=9,72$ no ensaio 2 .

\begin{tabular}{lrrrl}
\hline Causas da variação & GL & SQ & QM & F \\
\hline Média & 1 & 2165,050 & & \\
Blocos & 5 & 10,087 & & \\
Tratamentos & 3 & 9,316 & 3,105 & $11,96 * *$ \\
Residuo & 14 & 3,633 & 0,260 & \\
\hline Total & 23 & 2188,086 & & \\
Total corrig. & 22 & 23,036 & & \\
\hline
\end{tabular}

4.3. ENSAIO 3

Para os dados da Tabela 9 referentes ao ensaio 3 tem-se o seguinte padrão geral considerando-se a ordem decrescente de magnitude dentro de tratamentos e de blo$\cos ($ Tabela 24$)$.

A observação $y_{24}=7,81$ rompe mais drasticamen te do que outras caselas, tanto o padräo, na linha como na coluna: todos os demais tratamentos tem sua observação mais alta no bloco 11 , enquanto que o tratamento $D$ tem o valor mais baixo; e, ainda, a ordem da observação $y_{24}$ na linha (bloco II) é a mais baixa (ordem (4)) no tratamento $D$, enquanto que 
Tabela 24 .

\section{Tratamentos}

Blocos

\begin{tabular}{llll}
\hline$A$ & $B$ & $C$ & $D$
\end{tabular}

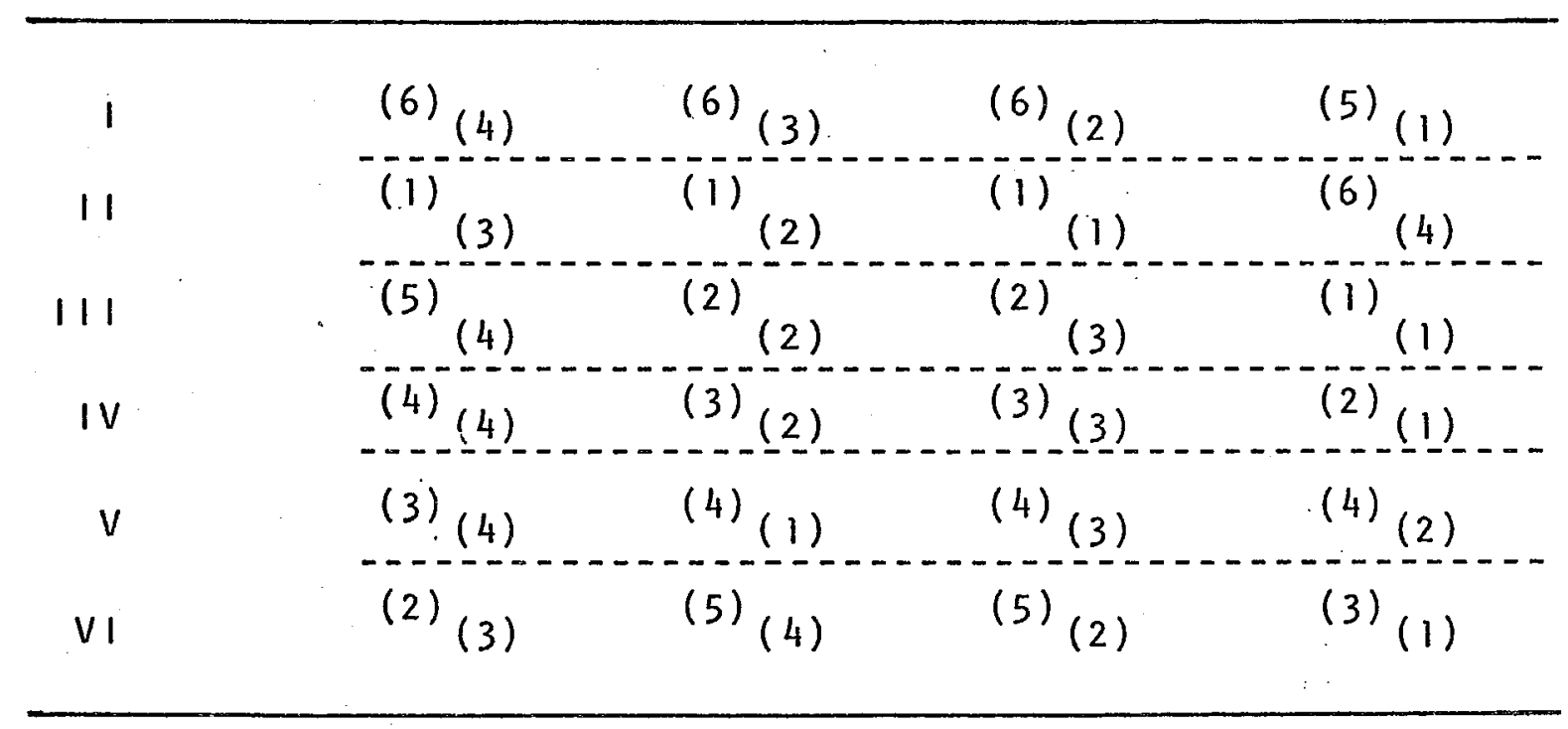

em quatro outros biocos a ordem no mesmo tratamento è a mais alta (ordem (1)).

Atravēs das Figuras 20 e 21 , visualiza-se melhor a diferença de comportamento do tratamento $D$ e do bloco 11, respectivamente. A observação $y_{24}$ não é um extremo se os dados forem considerados como uma amostra.

os resíduos ordinários para os dados. da Tabela 9 são apresentados na Tabela 25. 


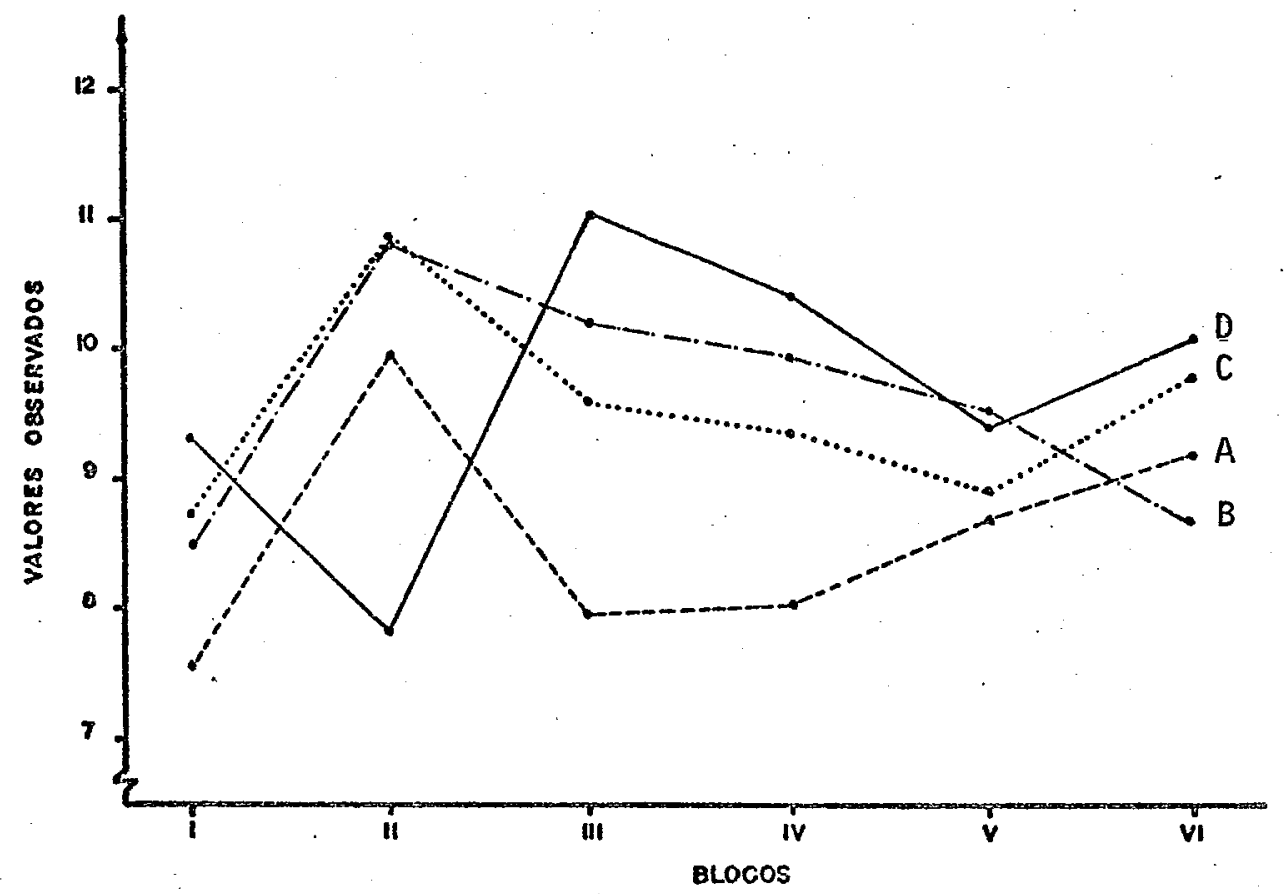

Figura 20. Perfil dos tratamentos no ensaio 3 .

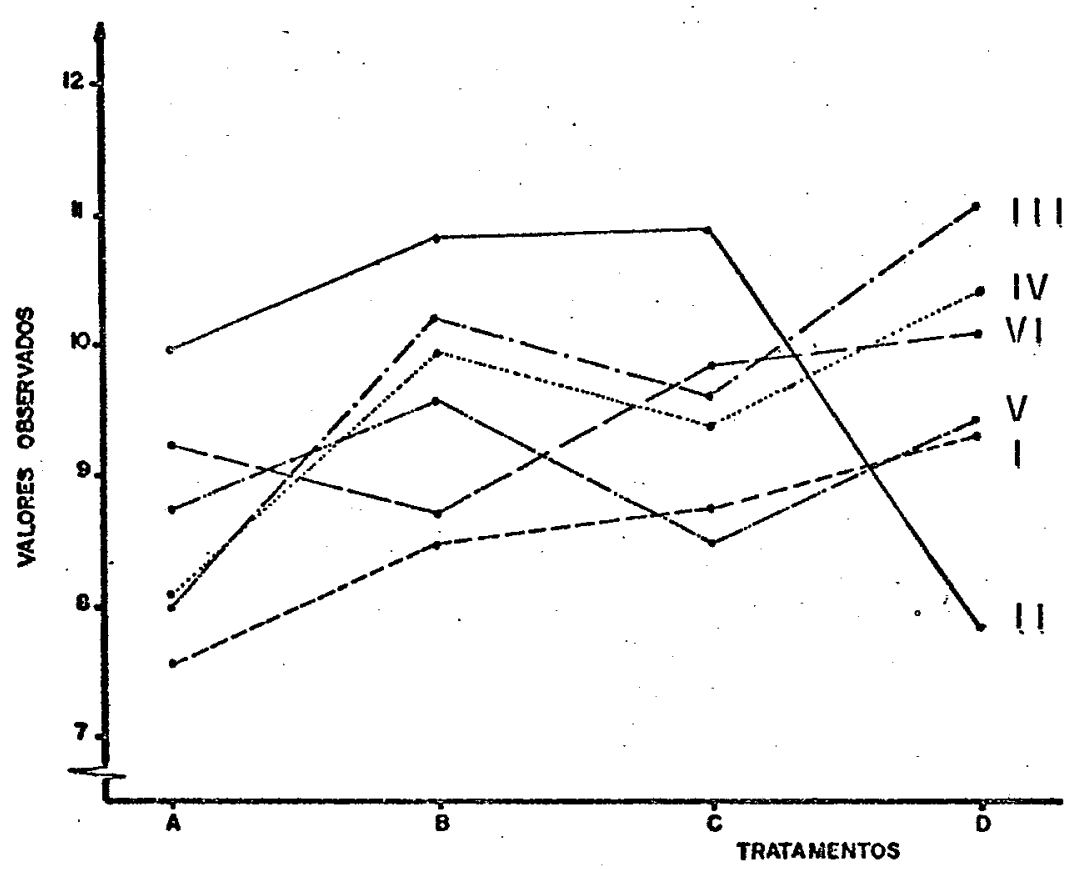

Figura 21. Perfil dos blocos no ensaio 3 . 
Tabela 25. Resíduos ordinärios para o ensaio 3.

\begin{tabular}{rrrr}
\hline$-0,1942$ & $-0,2992$ & 0,0142 & 0,4792 \\
0,8858 & 0,6908 & 0,8142 & $-2,3908$ \\
$-0,9567$ & 0,2383 & $-0,2983$ & 1,0167 \\
$-0,6092$ & 0,2458 & $-0,2708$ & 0,6342 \\
0,3333 & 0,1383 & $-0,4183$ & $-0,0533$ \\
0,5408 & $-1,0142$ & 0,1592 & 0,3142 \\
\hline
\end{tabular}

Retomando-se as expressões $(3.2 .12)$ a (3.2.15), sejam $e_{i j}$ os residuos do ensaio nulo e e $e_{i j}^{*}$ os residuos do ensaio 3 , segue que

$$
\begin{aligned}
e_{24}^{*} & =e_{24}+\lambda(b-1)(v-1) / b v \\
\therefore e_{24}^{*} & =-0,2033+(-3,5) 15 / 24=-2,3908
\end{aligned}
$$

E, de fato,

$$
\begin{aligned}
& e_{2 j}^{*}=e_{2 j}-(-3,5) 3 / 24 \text {, para } j \neq 4 \\
& e_{i 4}^{*}=e_{i 4}-(-3,5) 5 / 24, \text { para } i \neq 2 \\
& e_{i j}^{*}=e_{i j}+(-3,5) / 24, \text { para } i \neq 2 \text { e } j \neq 4 .
\end{aligned}
$$

A soma de quadrados de resíduos è igualia:12,753 com 15 graus de liberdade. Em relação a soma de quadrados de residuos do ensaio $1, S Q R=3,673$, ela foi aumentada. Verificando-se a expressão $(3.2 .16)$, tem-se que $2 \mathrm{e}^{\prime} \Delta=1,42 \mathrm{e}$ 
$\Delta^{\prime} \Delta=7,656$. Portanto, o acréscimo é de $S=1,42+7,66=9,08$, e $S Q R+S=3,673+9,079=12,753$ que corresponde à soma de quadrados de resíduos do ensaio 3 .

Tabela 26. $y_{i j}$ estimados para o ensaio 3 .

$\begin{array}{rrrr}7,7342 & 8,7792 & 8,7158 & 8,8508 \\ 9,0842 & 10,1292 & 10,0658 & 10,2008 \\ 8,9267 & 9,9717 & 9,9083 & 10,0433 \\ 8,6692 & 9,7142 & 9,6508 & 9,7858 \\ 8,3767 & 9,4217 & 9,3583 & 9,4933 \\ 8,6692 & 9,7142 & 9,6508 & 9,7858\end{array}$

Com os valores das Tabelas 25 e 26 construiuse o gräfico da Figura 22. Na Figura 23, encontra-se o gräfico equivalente, apenas utilizando-se residuos padronizados contra $y_{i j}$ estimados.

Pelas Figuras 22 e 23 , nota-se que o residuo correspondente à observação $y_{24}$ localiza-se fora da massa de pontos, o que leva à suspeita de que este pode ser um. valor aberrante. Pelo sugerido em NETER e WASSERMAN (1974), nenhum valor do ensaio é aberrante, pois todos os residuos padroniza dos incluem-se no intervalo $(-3,3)$. 
108.

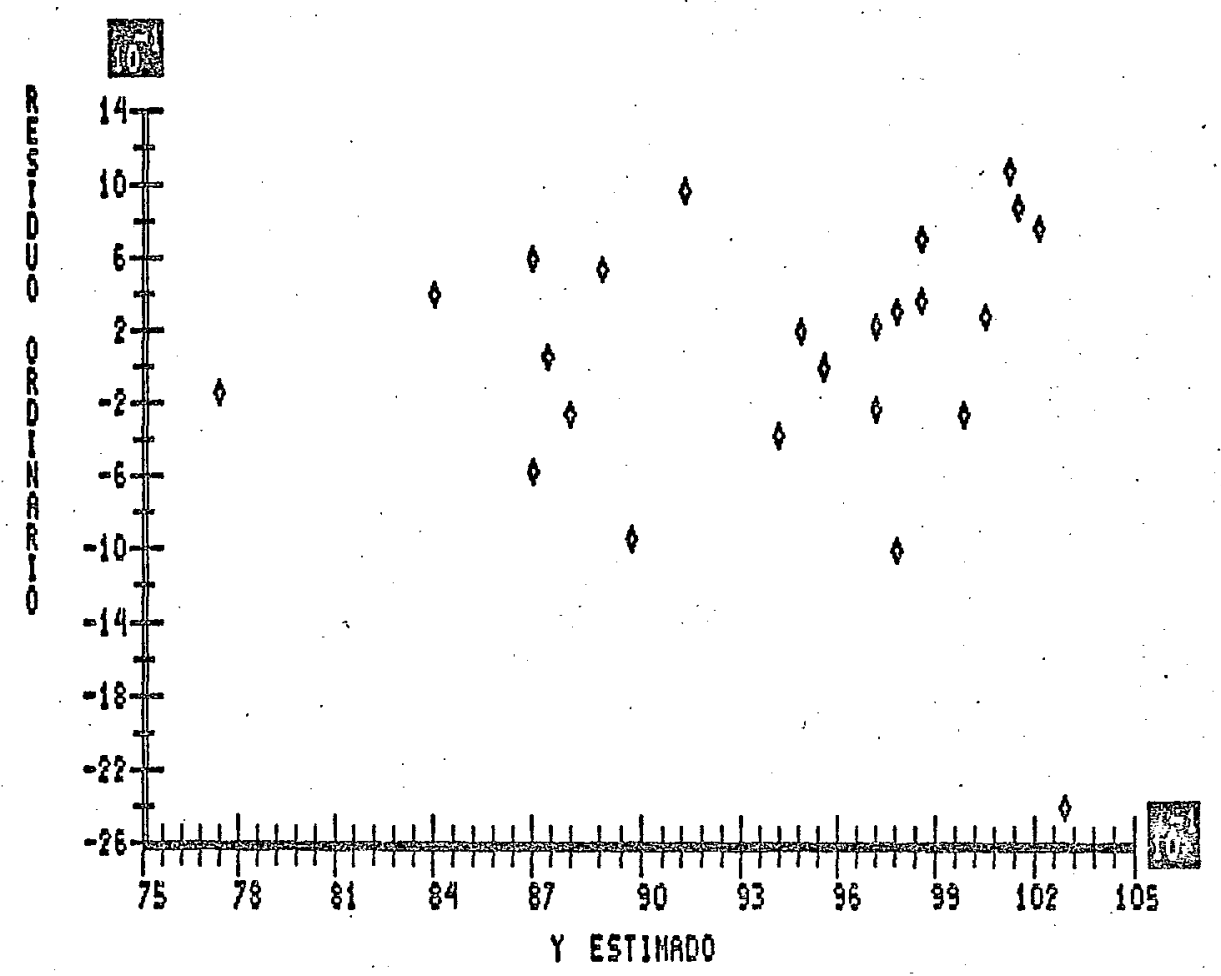

Figura 22. Gräfico de residuos ordinärios contra y estimados, para o ensaio 3 .

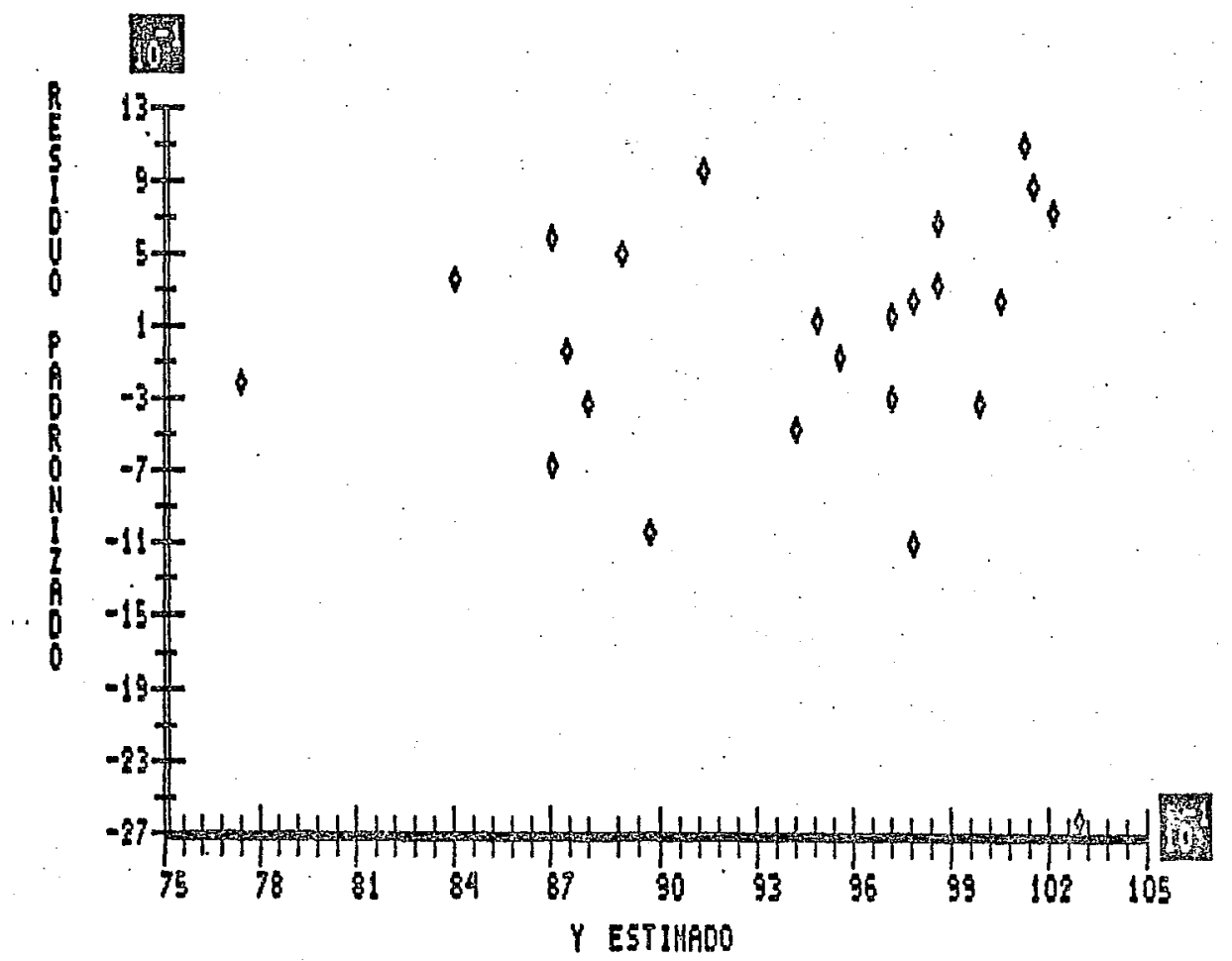

Figura 23. Grä́fico de resíduos padronizados contra y estima dos, para o ensaio 3 . 
obtidos os residuos padronizados ordenados ( $T \underline{a}$ bela 27), obtém-se os gräficos de probabilidade normal: na Fi gura 24, em papel de escala especial, portanto utilizando-se a posição de"plot" $p_{k}$ e na Figura 25 , em papel comum, utilizando se quantis normais. No canto inferior do gräfico probabilístico localiza-se, fora da tendência linear dos demais, o ponto corresponde à observação $y_{24}$.

Tabela 27. Resíduos padronizados ordenados, para o ensaio 3.

\begin{tabular}{llcccc}
\hline $\begin{array}{l}\text { Ordem do } \\
\text { residuo }(k)\end{array}$ & $(i, j) *$ & $d_{k}$ & $\begin{array}{c}\text { Ordem do } \\
\text { residuo }(k)\end{array}$ \\
\hline 1 & $(i, j)$ & $d_{k}$ \\
2 & $(2,4)$ & $-2,5929$ & 13 & $(6,3)$ & 0,1726 \\
3 & $(6,2)$ & $-1,0999$ & 14 & $(3,2)$ & 0,2585 \\
4 & $(3,1)$ & $-1,0375$ & 15 & $(4,2)$ & 0,2666 \\
5 & $(4,1)$ & $-0,6607$ & 16 & $(6,4)$ & 0,3407 \\
6 & $(5,4)$ & $-0,4537$ & 17 & $(5,1)$ & 0,3615 \\
7 & $(1,2)$ & $-0,3245$ & 18 & $(1,4)$ & 0,5197 \\
8 & $(3,3)$ & $-0,3236$ & 19 & $(6,1)$ & 0,5866 \\
9 & $(4,3)$ & $-0,2937$ & 20 & $(4,4)$ & 0,6878 \\
10 & $(1,1)$ & $-0,2106$ & 21 & $(2,2)$ & 0,7492 \\
11 & $(5,4)$ & $-0,0578$ & 22 & $(2,3)$ & 0,8830 \\
12 & $(1,3)$ & 0,0154 & 23 & $(2,1)$ & 0,9607 \\
\hline
\end{tabular}

* Posição na Tabela 9: bloco i, tratamento j. 
110.








Figura 25. Gräfico probabilístico normal para os residuos padronizados do ensaio 3 , em papel comum.

Para melhor avaliar o gráfico de probabilidade, são calculadas a estatística de Shapiro-Wilk e o coeficientede correlação, que para o ensaio 3 são $W=0,8997^{*}$ e $r=0,9422^{*}$. Portanto, conclui-se que os erros não provêm de população nor mal, com $\alpha=0,05$ de probabilidade. Pela Tabela A5, observa-se que o coeficiente de correlação calculado está abaixo do valor crítico para $\alpha=0,025$. 
Efetuando-se o teste de discordância para a ob servação $y_{24}$ obtém-se

$$
\hat{V}\left(e_{i j}\right)=\frac{15}{24} \cdot \frac{12,753}{15}=0,5314 .
$$

Portanto, a estatistica do teste, o maior resi duo absoluto studentizado, é igual a

$$
\max \left|r_{i j}\right|=\frac{2,3908}{\sqrt{0,5314}}=3,2798^{* *}
$$

- que indica que a observação $y_{24}=7,81$ é aberrante ao nivel $\alpha<0,01$.

As estimativas das covariancias entre residuos são:

$$
\begin{aligned}
& \operatorname{Cov}\left(e_{i j}, e_{i l}\right)=-(5 / 24)(0,8502)=-0,1771, \quad l \neq j ; \\
& \operatorname{Cov}\left(e_{i j}, e_{k j}\right)=-(3 / 24)(0,8502)=-0,1063, \quad k \neq i ; \\
& \operatorname{Cov}\left(e_{i j}, e_{k l}\right)=(1 / 24)(0,8502)=0,0354, k \neq i, \quad 1 \neq j .
\end{aligned}
$$

A Tabela 28 mostra os resultados do teste de homogeneidade de variancias e do teste de aditividade de Tukey.

$$
\text { Das hipōteses básicas da anālise da variância }
$$
avaliadas, tem-se duas violações: a presença de um valor aber rante e, por consequência, a ausencia de normalidade dos erros. Efetuada a anālise da variancia sem levar em conta as 
Tabela 28. Resultados dos testes de aditividade e da homogenei dade de variâncias, para o ensaio 3 .

\begin{tabular}{lll}
\hline & $F_{\tilde{N}}$ & $\ddot{X}^{2}$ \\
\hline Valor calculado & $0,1197 \mathrm{~ns}$ & $12,88 \mathrm{~ns}$ \\
Valor tabelado & $0,001(1)$ & $15,51 \quad(2)$ \\
\hline
\end{tabular}

(1) Para $\alpha=0,05$ e 1 e 14 graus de liberdade $(F<1)$.

(2) Para $\alpha=0,05$ e 8 graus de liberdade.

transgressões verificadas, encontram-se os resultados apresen tados na Tabela 29.

Tabela 29. Anālise da variància para o ensaio 3.

\begin{tabular}{lrrrr}
\hline Causas da variação & GL & SQ & QM & F \\
\hline Média & 1 & 2103,754 & & \\
Blocos & 5 & 4,588 & & \\
Tratamentos & 3 & 4,995 & 1,665 & $1,96 \mathrm{~ns}$ \\
Residuo & 15 & 12,753 & 0,850 & \\
\hline Total & & & & \\
Total corrig. & 24 & 2126,089 & & \\
\hline
\end{tabular}


114.

observa-se que no ensaio 3 , o valor aberrante afetou apenas a normalidade. No entanto, a significância do teste $F$ mudou, isto è, novamente a sensibilidade do teste foi afetada pela presença do dado aberrante.

A estimativa de minimos quadrados para a obser vação $y_{24}$ é $y_{24}^{\circ}=11,64$, conforme $(3.2 .22)$. Substituindo-se o "outlier" por esta estimativa, encontram-se os resultados da Tabela 30 , para a anālise exploratória e da Tabela 31 , para a análise de variância.

Tabela 30. Testes de Shapiro-Wilk (W), aditividade ( $\left.F_{\tilde{N} A}\right)$ e ho mogeneidade de variâncias $\left(\chi^{2}\right), \operatorname{com} \gamma_{24}^{\circ}=11,64$ no ensaio 3 .

\begin{tabular}{llll}
\hline & $W$ & $F_{\tilde{N} A}$ & $\dot{X}^{2}$ \\
\hline Valor calculado & $0,9667 n s$ & $0,1450 n s$ & $13,2764 n s$ \\
Valor tabelado & $0,916(1)$ & $0,001(2)$ & $15,51(3)$ \\
\hline
\end{tabular}

(1) Para $\alpha=0,05$ e $n=24$

(2) Para $\alpha=0,05,1$ e 13 GL $(F<1)$.

(3) Para $\alpha=0,05$ e 8 GL

A substituição do valor aberrante pela correspondente estimativa de mínimos quadrados causa uma redução acentuada na soma de quadrados de resíduos, sendo $Q_{1}=12,753-$ $3,607=9,146$. 
115.

Tabela 31. Anälise da variância utilizando $y_{24}^{0}=11,64$ no ensaio 3 .

\begin{tabular}{lrrrr}
\hline Causas da variação & $G L$ & SQ & QM & $F$ \\
\hline Média & 1 & 2176,082 & & \\
Blocos & 5 & 11,531 & & \\
Tratamentos & 3 & 9,363 & 3,121 & $12,11 * *$ \\
Resíduo & 14 & 3,607 & 0,258 & \\
\hline Total & 23 & 2200,582 & & \\
Total corrig. & 22 & 24,501 & \\
\hline
\end{tabular}

Novamente, tanto nos testes efetuados na anäli se exploratória como na anālise da variáncia, os resultados aproximam-se daqueles do ensaio nulo. 
116.

\section{CONCLUSÕES}

Face aos resultados obtidos, concluiu-se que:

a) A presença de um dado aberrante pode afetar individual ou coletivamente o conjunto de pressuposições considerado neste estudo para a análise da variancia via modelo linear ordinärio de Gauss-Markov: normalidade, homogeneidade de variancias e aditividade.

b) Quando se acrescenta um valor real $\lambda$ a uma observação $y_{i j}$, visando obter um "outlier", a aproximação de mínimos quadrados para o novo vetor y sofre a influencia de $\lambda$. Essa influência propaga-se naturalmente para o correspondente vetor de erros, alterando a soma de quadrados do resíduo. Nesse contexto, a presença do "outlier" pode alterar a sensibilidade do teste $F$ para tratamentos.

c) Os grä́ficos de residuos, usados na fase in $\underline{i}$ cial da deteç̧ão de um "outlier", bem como os perfis de blo- 
cos e tratamentos mostraram-se, nos exemplos abordados, plena mente satisfatórios e os resultados por eles sugeridos foram confirmados na fase final de identificação atravēs dos proces sos formais de inferência.

d) Os grä́ficos de probabilidade dos residuos em papel normal (utilizando a probabilidade empírica) ou em papel comum (utilizando quantis normais) foram considerados equivalentes, tanto na verificação da normalidade quanto na detecção do "outlier".

e) A substituição do valor aberrante pela correspondente estimativa de minimos quadrados mostrou-se uma me dida remediadora satisfatória para os exemplos discutidos. 
118.

\section{LITERATURA CITADA}

ANSCOMBE, F.J. e J.W. TUKEY, 1963. The examination and analy sis residuals. Technometrics. Washington, 5: 141-160.

ATKINSON, A.C., 1981. Two graphical displays for outlying and influential observations in regression. Biometrika. Cambridge, 68: 13-20.

BARNETT, V., 1978. The study of outliers: purpose and model. Applied Statistics. London, 27: 242-250:

BARNETT, V. e T. LEWIS, 1978. Outliers in Statistical Data. Belfast, John Wiley \& Sons, Inc. 365p.

BARNETT, V. e T. LEWIS, 1984. Outliers in Statistical Data. 2 a ed. Chichester, John Wiley \& Sons, Inc. 463p.

BECKMAN, R.J. e R.D. COOK, 1983. Outlier...s. Technometrics. Washington, 25: 119-163.

BOX, G.E.P., 1949. A general distribution theory for a class of likelihood criteria. Biometrika. Cambridge, 36: 317-346. 
BOX, G.E.P., 1950. Problems in the analysis of growth and wear curves. Biometrics. Washington, 6 : 362-389.

BROSS, I.D.J., 1961. Outliers in patterned experiments: a strategic appraisal. Technometrics. Washington, 3 : 91102.

COOK, R.D., 1979. Influential observations in Iinear regression. Journal of the American Statistical Association. Bos ton, 74: 169-174.

COOK, R.D. E P. PRESCOTT, 1981. On the accuracy of Bonferroni significance levels for detecting outliers in linear mo dels. Technometrics. Washington, 23: 59-63.

COOK, R.D.; N. HOLSCHUH e S. WEISBERG, 1982. A note on an alternative outlier model. Journal of the Royal Statistical Society (Series B). London, 44: 370-376.

COOK, R.D. e S. WEISBERG, 1982. Residuals and Influence in Regression. London, Chapman \& Hall. $231 \mathrm{p}$.

CUNNANE, C., 1978. Unbiased plotting positions - a review. Journal of Hydrology. Amsterdam, 37: 205-222.

DACHS, J.N.W. e J.F. CARVALHO, 1984. Diagnóstico em regressão. In: 6o Simpósio Nacional de Probabilidade e Estatistica, Rio de Janeiro. $85 \mathrm{p}$.

DANIEL, C., 1978. Patterns in residuals in the two-way layout. Technometrics. Washington, 20: 385-395.

DANIEL, C. e F.S. WOOD, 1980. Fitting Equations to Data. 2a ed. New. York, John Wiley E Sons, Inc. $458 \mathrm{p}$. 
DIXON, W.J., 1950. Analysis of extreme values. Annals of Ma thematical Statistics. Ann Arbor, 21: 489-506.

DODGE, Y., 1985. Analysis of Experiments with Missing Data. New York, Wiley. 499 p.

DOORNBOS, R., 1981. Testing for a single outlier in a linear model. Biometrics. Washington, 37: 705-712.

DRAPER, N.R. e J.A. JOHN, 1981. Influential observations and outliers in regression. Technometrics. Washington, 23 : 21-26.

DRAPER, N.R. e H. SMITH, 1966. Applied Regression Analysis. New York, John Wiley e Sons, Inc. $407 p$.

ELLENBERG, J.H., 1973. The joint distribution of the standardized least squares residuals from a general linear regression. Journal of the American Statistical Association. Boston, 68: 941-943.

ELLENBERG, J.H., 1976. Testing for a single outlier from a general linear regression. Biometrics. Washington, $32: 637$ -645 .

FILLIBEN, J.J., 1975. The probability plot correlation coef cient test for normality. Technometrics. Washington, 17: $111-117$.

GENTLEMAN, J.F,, 1980. Finding the k most likely outliers in a two-way tables. Technometrics. Washington, 22: 591600 . 
GENTLEMAN, J.F. e M.B. WILK, 1975a. Detecting outliers in a two-way table: I. Statistical behavior of residuals. Technometrics. Washington, 17: 1-14.

GENTLEMAN, J.F. e M.B. WILK, 1975b. Detecting outliers. 11. Supplementing the direct analysis of residuals. Biometrics. Washington, 31 : $387-410$.

GILL, J.L., 1978. Design and Analysis of Experiments in the Animal and Medical Sciences. Ames, $882 \mathrm{p}$.

HAN, C.P., 1969. Testing the homogenity of variances in a two-way classification. Biometrics. Washington, 25: 153158 .

HARTER, L., 1961. Expected values of normal order statistics. Biometrika. Cambridge, 48: 151-165.

HOAGLIN, D.C.; F. MOSTELLER e J.W. TUKEY, 1983. Understanding Robust and Exploratory Data Analysis. New York, Willey, 447p.

HOAGLIN, D.C. e R.E. WELSCH, 1978. The hat matrix in regression and ANOVA. The American Statistician. Washington, 32: $17-22$.

HUYHN, H. e L.S. FELDT, 1970. Conditions under which mean square ratios in repeated measurements designs have exact F-distributions. Journal of the Royal Statistical Society. London, 65: 1582-89.

IEMMA, A.F., 1985. Modelos Lineares para Experimentos com Medidas Repetidas e Covariancia Uniforme: um Enfoque através das Matrizes de Helmert. Piracicaba, ESALQ/USP, 155 p. (Tese de Livre-Docência). 
JOHN, J.A. E N.R. DRAPER, 1978. On testing for two outliers and one outlier in two-way tables. Technometrics. Washington, 20: 69-79.

KIMBALL, B.F., 1960. On the choice of plotting positions on probability paper. Journal of the American Statistical As sociation. Boston, 55: 546-560.

KIRK, R.E., 1968. Experimental Designs: Procedures for the Behavioral Sciences. Belmont, Wagsworth: $571 \mathrm{p}$.

LLOYD, E.H., 1952. Least-squares stimation of location and scale parameters using order statistics. Biometrika, Cambridge, 39: $88-95$.

LOONEY, S.W. E T.R. GULLEDGE Jr., 1985. Use of the correlation coefficient with normal probability plots. The American Statistician. Washington, 39: 75-79.

LUND, R.E., 1975. Tables for an approximate test for outliers in linear models. Technometrics. Washington, 17: 473476.

MAGE, D.T., 1982. An objective graphical method for testing normal distributional assumptions using probability plots. The American Statistician. Washington, 36: 116-120.

NETER, J. e W. WASSERMAN, 1974. Applied Linear Statistical Models - Regression, Analysis of Variance and Experimental Designs. Illinois, Richard D. Irwin. $842 p$.

QUESENBERRY, C.P. e H.A. DAVID, 1961. Some tests for outliers. Biometrika. Cambridge, 48: 379-390. 
SEBER, G.A.F., 1977. Linear Regression Analysis. New York, John Wiley \& Sons, Inc. 465p.

SHAPIRO, S.S. e M.B. WILK, 1965. An analysis of variance test for normality (complete samples). Biometrika. Cambridge, 52: $591-611$.

SoUZA, F.A.M. de, 1984. Alguns Modelos para Interação em Anā lise de Vaiância com 2 Fatores e Uma observação por. Cela. Rio de Janeiro, IMPA, 109p. (Dissertação de Mestrado).

STEFANSKY, W., 1971. Rejecting outliers by maximum normal residual. The Annals of Mathematical Statistics. Ann Arbor, 42 : $35-45$.

TIETJEN, G.L.; R.H. MOORE e R.J. BECKMAN, 1973. Testing for a single outlier in simple linear regression. Technometrics. Washington, 15: 717-721.

TUKEY, J.W., 1949. One degree of freedom for non-additivity. Biometrics. Washington, 5: 233-242.

VELLEMAN, P.F. e R.E. WELSCH, 1981. Efficient computing of regression diagnostics. The American Statistician. Washing ton, 35: 234-242.

WILK, M.B. e R. GNANADESIKAN, 1968. Probability plotting methods for the analysis of data. Biometrika. Cambridge, 55: $1-17$. 
124.

7. $A P E \bar{E} D I C E$ 
Tabela Al. Posição de "plot".

$$
p_{k}=\left\{\begin{array}{l}
1-p_{n-k+1}, \text { se } k=1, \ldots, 1[n / 2] \\
(k-0,375) /(n+0,25), \text { se } k=[n / 2], \ldots, n
\end{array}\right.
$$

\begin{tabular}{|c|c|c|c|c|c|c|c|}
\hline & 6 & 8 & 9 & 10 & 12 & 14 & 15 \\
\hline $\begin{array}{l}4 \\
5 \\
6 \\
7 \\
6 \\
9 \\
10 \\
11 \\
12 \\
13 \\
14 \\
15\end{array}$ & $\begin{array}{c}0.50000 \\
0.74000 \\
0.90000 \\
. \\
.\end{array}$ & $\begin{array}{l}0.56061 \\
0.68192 \\
0.80393 \\
0.92424\end{array}$ & $\begin{array}{l}0.50000 \\
0.60011 \\
0.71622 \\
0.82432 \\
0.93243\end{array}$ & $\begin{array}{l}0.54878 \\
0.64634 \\
0.74390 \\
0.84146 \\
0.93902\end{array}$ & $\begin{array}{l}0.54082 \\
0.62245 \\
0.70468 \\
0.78571 \\
0.86735 \\
0.94898\end{array}$ & $\begin{array}{l}0.53509 \\
0.60526 \\
0.67544 \\
0.74561 \\
0.81579 \\
0.88596 \\
0.95614\end{array}$ & $\begin{array}{l}0.50000 \\
0.56557 \\
0.63115 \\
0.69672 \\
0.76230 \\
0.82787 \\
0.89341 \\
0.95902\end{array}$ \\
\hline & 16 & 18 & 20 & 21 & 24 & 25 & 26 \\
\hline $\begin{array}{l}9 \\
10 \\
11 \\
12 \\
13 \\
14 \\
15 \\
16 \\
17 \\
18 \\
19 \\
20 \\
21 \\
22 \\
23 \\
24 \\
25 \\
26\end{array}$ & $\begin{array}{l}0.53077 \\
0.59231 \\
0.65385 \\
0.71538 \\
0.77692 \\
0.83846 \\
0.90060 \\
0.96154\end{array}$ & $\begin{array}{l}0.52740 \\
0.58219 \\
0.63699 \\
0.69178 \\
0.71658 \\
0.80137 \\
0.85616 \\
0.91096 \\
0.96575\end{array}$ & $\begin{array}{l}0.52469 \\
0.57467 \\
0.62346 \\
0.67284 \\
0.72222 \\
0.77160 \\
0.82099 \\
0.87037 \\
0.91975 \\
0.96914\end{array}$ & $\begin{array}{l}0.50000 \\
0.54706 \\
0.59412 \\
0.64118 \\
0.68824 \\
0.73529 \\
0.78235 \\
0.82941 \\
0.87647 \\
0.92353 \\
0.97059\end{array}$ & $\begin{array}{l}0.52062 \\
0.56186 \\
0.60309 \\
0.64433 \\
0.68557 \\
0.72630 \\
0.76804 \\
0.80928 \\
0.85052 \\
0.89175 \\
0.93299 \\
0.97423\end{array}$ & $\begin{array}{l}0.50000 \\
0.53960 \\
0.57921 \\
0.61881 \\
0.05842 \\
0.69802 \\
0.73762 \\
0.77723 \\
0.81683 \\
0.85644 \\
0.89604 \\
0.93564 \\
0.97525\end{array}$ & $\begin{array}{l}0.51905 \\
0.55714 \\
0.59524 \\
0.63333 \\
0.67143 \\
0.70952 \\
0.74762 \\
0.78571 \\
0.82381 \\
0.86190 \\
0.90000 \\
0.93810 \\
0.97619\end{array}$ \\
\hline & 27 & .28 & 30 & 32 & 33. & 35 & 36 \\
\hline $\begin{array}{l}14 \\
15 \\
16 \\
17 \\
18 \\
19 \\
20 \\
21 \\
22 \\
23 \\
24 \\
25 \\
26 \\
27 \\
28 \\
29 \\
30 \\
31 \\
32 \\
33 \\
34 \\
35 \\
36\end{array}$ & $\begin{array}{l}0.50000 \\
0.53670 \\
0.57339 \\
0.61009 \\
0.64679 \\
0.68349 \\
0.72018 \\
0.75688 \\
0.79358 \\
0.83028 \\
0.86697 \\
0.90367 \\
0.94037 \\
0.57706\end{array}$ & $\begin{array}{l}0.51770 \\
0.55310 \\
0.58850 \\
0.62389 \\
0.65929 \\
0.69469 \\
0.73099 \\
0.76549 \\
0.80088 \\
0.83628 \\
0.87168 \\
0.94708 \\
0.94248 \\
0.97788\end{array}$ & $\begin{array}{l}0.51653 \\
0.54959 \\
0.58264 \\
0.61570 \\
0.64876 \\
0.68182 \\
0.71483 \\
0.74793 \\
0.73097 \\
0.81405 \\
0.34711 \\
0.88017 \\
0.91322 \\
0.94629 \\
0.97934\end{array}$ & $\begin{array}{l}0.51550 \\
0.54651 \\
0.57752 \\
0.66853 \\
0.63953 \\
0.67054 \\
0.70155 \\
0.73256 \\
0.76357 \\
0.79457 \\
0.82558 \\
0.05659 \\
0.89760 \\
0.91860 \\
0.94961 \\
0.99062\end{array}$ & $\begin{array}{l}0.50000 \\
0.53600 \\
0.56015 \\
0.59023 \\
0.62030 \\
0.65039 \\
0.68045 \\
0.71053 \\
0.74060 \\
0.77060 \\
0.80075 \\
0.83083 \\
0.86090 \\
0.89098 \\
0.92165 \\
0.95113 \\
0.98120\end{array}$ & $\begin{array}{l}0.50000 \\
0.52837 \\
0.55674 \\
0.58511 \\
0.61348 \\
0.64184 \\
0.67021 \\
0.69858 \\
0.72675 \\
0.75532 \\
0.79357 \\
0.81206 \\
0.84043 \\
0.86879 \\
0.59710 \\
0.92553 \\
0.95390 \\
0.98227\end{array}$ & $\begin{array}{l} \\
0.51379 \\
0.54138 \\
0.56897 \\
0.59655 \\
0.62414 \\
0.65172 \\
0.67931 \\
0.70690 \\
0.73448 \\
0.76207 \\
0.78966 \\
0.81724 \\
0.84483 \\
0.67241 \\
0.90000 \\
0.92759 \\
0.95517 \\
0.98276\end{array}$ \\
\hline
\end{tabular}


Tabela Al. Continuação.

\begin{tabular}{|c|c|c|c|c|c|c|c|}
\hline$k$ & 40 & 42 & 44 & 45 & 48 & 49 & 50 \\
\hline $\begin{array}{l}21 \\
22 \\
23 \\
24 \\
25 \\
26 \\
27 \\
28 \\
29 \\
30 \\
31 \\
32 \\
33 \\
34 \\
35 \\
36 \\
37 \\
38 \\
39 \\
40 \\
41 \\
42 \\
43 \\
44 \\
45 \\
46 \\
47 \\
48 \\
49 \\
50\end{array}$ & $\begin{array}{l}0.51242 \\
0.53727 \\
0.56211 \\
0.58696 \\
0.61180 \\
0.63665 \\
0.661 .49 \\
0.68634 \\
0.71118 \\
0.73602 \\
0.76097 \\
0.78571 \\
0.81056 \\
0.83540 \\
0.86025 \\
0.88509 \\
0.90994 \\
0.93478 \\
0.95963 \\
0.98447\end{array}$ & $\begin{array}{l}0.51183 \\
0.53550 \\
0.55517 \\
0.58284 \\
0.60651 \\
0.63018 \\
0.65385 \\
0.67751 \\
0.70118 \\
0.72485 \\
0.74355 \\
0.77219 \\
0.79580 \\
0.81953 \\
0.84320 \\
0.86684 \\
0.89053 \\
0.91420 \\
0.93787 \\
0.96154 \\
0.98521\end{array}$ & $\begin{array}{l}0.51130 \\
0.53390 \\
0.55650 \\
0.57910 \\
0.69169 \\
0.62429 \\
0.64689 \\
0.66949 \\
0.69209 \\
0.71469 \\
0.73729 \\
0.75989 \\
0.78249 \\
0.80508 \\
0.82768 \\
0.85028 \\
0.87288 \\
0.89548 \\
0.91808 \\
0.94068 \\
0.96328 \\
0.98588\end{array}$ & $\begin{array}{l}0.50000 \\
0.52210 \\
0.54420 \\
0.5630 \\
0.58340 \\
0.61050 \\
0.63230 \\
0.65470 \\
0.67690 \\
0.69890 \\
0.72099 \\
0.74309 \\
0.78519 \\
0.78729 \\
0.80939 \\
0.83149 \\
0.85359 \\
0.87569 \\
0.89779 \\
0.91989 \\
0.943 .99 \\
0.96409 \\
0.98619\end{array}$ & $\begin{array}{l}0.51036 \\
0.53109 \\
0.55181 \\
0.57254 \\
0.59326 \\
0.61399 \\
0.63472 \\
0.65544 \\
0.67617 \\
0.69689 \\
0.71762 \\
0.73834 \\
0.75907 \\
0.77979 \\
0.80052 \\
0.82124 \\
0.84197 \\
0.86269 \\
0.88342 \\
0.90415 \\
0.92487 \\
0.94560 \\
0.96632 \\
0.98705\end{array}$ & $\begin{array}{l} \\
0.50000 \\
0.52030 \\
0.54061 \\
0.56091 \\
0.58122 \\
0.60152 \\
0.62183 \\
0.64213 \\
0.66244 \\
0.68274 \\
0.70305 \\
0.72335 \\
0.74365 \\
0.76396 \\
0.78426 \\
0.80457 \\
0.82487 \\
0.84518 \\
0.86548 \\
0.88579 \\
0.90609 \\
0.92640 \\
0.94670 \\
0.96701 \\
0.98731\end{array}$ & $\begin{array}{l} \\
\\
0.59995 \\
0.52985 \\
0.54975 \\
0.56965 \\
0.58955 \\
0.60945 \\
0.62935 \\
0.64925 \\
0.66915 \\
0.68945 \\
0.70896 \\
0.72886 \\
0.74876 \\
0.76866 \\
0.78356 \\
0.80846 \\
0.82836 \\
0.84926 \\
0.86816 \\
0.88906 \\
0.90796 \\
0.92786 \\
0.94776 \\
0.96766 \\
0.98756\end{array}$ \\
\hline
\end{tabular}


Tabela A2. Quantis normais

$$
\Phi^{-1}\left(p_{k}\right)=\left\{\begin{array}{l}
-_{\Phi}^{-1}\left(p_{n-k+1)}, \text { se } k=1, \ldots,[n / 2] ;\right. \\
\Phi^{-1}(k-0,375) /(n+0,25), \text { se } k=[n / 2], \ldots, n .
\end{array}\right.
$$

\begin{tabular}{|c|c|c|c|c|c|c|c|}
\hline & 6 & 8 & 9 & 10 & 12 & 14 & 15 \\
\hline $\begin{array}{r}4 \\
5 \\
6 \\
7 \\
8 \\
9 \\
10 \\
11 \\
12 \\
13 \\
14 \\
15\end{array}$ & $\begin{array}{l}0.2019 \\
0.6433 \\
1.2816\end{array}$ & $\begin{array}{c}0.1525 \\
0.4728 \\
0.8525 \\
1.4342 \\
=\end{array}$ & $\begin{array}{l}0.0000 \\
0.2744 \\
0.5717 \\
0.9320 \\
1.4942\end{array}$ & $\begin{array}{l}0.1226 \\
0.3755 \\
0.6554 \\
1.0005 \\
1.5467\end{array}$ & $\begin{array}{l}0.1025 \\
0.3119 \\
0.5362 \\
0.7917 \\
1.1140 \\
1.6350 \\
.\end{array}$ & $\begin{array}{l}0.0881 \\
0.2670 \\
0.4550 \\
0.6608 \\
0.8994 \\
1.2053 \\
1.7075\end{array}$ & $\begin{array}{l}0.0000 \\
0.1651 \\
0.3349 \\
0.5150 \\
0.7137 \\
0.9458 \\
1.2451 \\
1.7394\end{array}$ \\
\hline & 16 & 18 & 20 & $21 !$ & 24 & 25 & $26^{\circ}$ \\
\hline $\begin{array}{l}9 \\
10 \\
11 \\
12 \\
13 \\
14 \\
15 \\
16 \\
17 \\
18 \\
19 \\
20 \\
21 \\
22 \\
23 \\
24 \\
25 \\
26\end{array}$ & $\begin{array}{l}0.0772 \\
0.2335 \\
0.3957 \\
0.5692 \\
0.7619 \\
0.9881 \\
1.2816 \\
1.7687\end{array}$ & $\begin{array}{l}0.0687 \\
0.2075 \\
0.3504 \\
0.5009 \\
0.6638 \\
0.8465 \\
1.0633 \\
1.3467 \\
1.8217\end{array}$ & $\begin{array}{l}0.0620 \\
0.1868 \\
0.3146 \\
0.4478 \\
0.5894 \\
0.7441 \\
0.9191 \\
1.1281 \\
1.4034 \\
1.8683\end{array}$ & $\begin{array}{c}. \\
0.0000 \\
0.1183 \\
0.2382 \\
0.3616 \\
0.4909 \\
0.6289 \\
0.7802 \\
0.9518 \\
1.1575 \\
1.4292 \\
1.8895 \\
.\end{array}$ & $\begin{array}{l}0.0517 \\
0.1557 \\
0.2614 \\
0.3701 \\
0.4833 \\
0.6032 \\
0.7324 \\
0.8752 \\
1.0386 \\
1.2359 \\
1.4984 \\
1.9468\end{array}$ & $\begin{array}{l}. \\
0.0000 \\
0.0994 \\
0.1998 \\
0.3024 \\
0.4081 \\
0.5187 \\
0.6360 \\
0.7628 \\
0.9034 \\
1.0644 \\
1.2592 \\
1.5192 \\
1.9642\end{array}$ & $\begin{array}{l}0.0478 \\
0.1437 \\
0.2410 \\
0.3407 \\
0.4439 \\
0.5520 \\
0.6670 \\
0.7917 \\
0.9360 \\
1.0890 \\
1.2816 \\
1.5390 \\
1.9808\end{array}$ \\
\hline & 27 & 28 & 30 & 32. & 33 & 35 & 36 \\
\hline $\begin{array}{l}14 \\
15 \\
16 \\
17 \\
19 \\
19 \\
20 \\
21 \\
22 \\
23 \\
24 \\
25 \\
26 \\
27 \\
28 \\
29 \\
30 \\
31 \\
32 \\
33 \\
34 \\
35 \\
36\end{array}$ & $\begin{array}{l}0.0000 \\
0.0921 \\
0.1850 \\
0.2796 \\
0.3766 \\
0.4775 \\
0.5834 \\
0.6963 \\
0.8189 \\
0.9552 \\
1.1122 \\
1.3058 \\
1.5579 \\
1.9966\end{array}$ & $\begin{array}{l}0.0144 \\
0.1335 \\
0.2237 \\
0.3157 \\
0.4105 \\
0.5092 \\
0.6131 \\
0.7240 \\
0.8448 \\
0.9793 \\
1.1344 \\
1.3230 \\
1.5760 \\
2.0117\end{array}$ & $\begin{array}{l}0.0414 \\
0.1246 \\
0.2087 \\
0.2942 \\
0.3820 \\
0.4728 \\
0.5677 \\
0.6680 \\
0.7755 \\
0.8929 \\
1.0241 \\
1.1759 \\
1.3609 \\
1.6098 \\
2.0407\end{array}$ & $\begin{array}{l}0.0389 \\
0.1169 \\
0.1955 \\
0.2755 \\
0.3572 \\
0.4414 \\
0.5289 \\
0.3206 \\
0.7178 \\
0.8224 \\
0.9368 \\
1.0551 \\
1.2138 \\
1.3958 \\
1.6412 \\
2.0669\end{array}$ & $\begin{array}{l}0.00010 \\
0.0755 \\
0.1513 \\
0.2281 \\
0.3063 \\
0.3863 \\
0.4690 \\
0.5549 \\
0.6452 \\
0.7411 \\
0.8443 \\
0.9574 \\
1.0844 \\
1.2318 \\
1.4122 \\
1.6559 \\
2.0793 \\
.\end{array}$ & $\begin{array}{l}0.0000 \\
0.0712 \\
0.1427 \\
0.2150 \\
0.2884 \\
0.3634 \\
0.4405 \\
0.5203 \\
0.6253 \\
0.6913 \\
0.7947 \\
0.8855 \\
0.9962 \\
1.1207 \\
1.2655 \\
1.4433 \\
1.6837 \\
2.1033\end{array}$ & $\begin{array}{l}0.0346 \\
0.1039 \\
0.1738 \\
0.2444 \\
0.3164 \\
0.3900 \\
0.4658 \\
0.5443 \\
0.5264 \\
0.7130 \\
0.8052 \\
0.9049 \\
1.0145 \\
1.1379 \\
1.2816 \\
1.2580 \\
1.6972 \\
2.1142\end{array}$ \\
\hline
\end{tabular}


Tabela A2. Continuação.

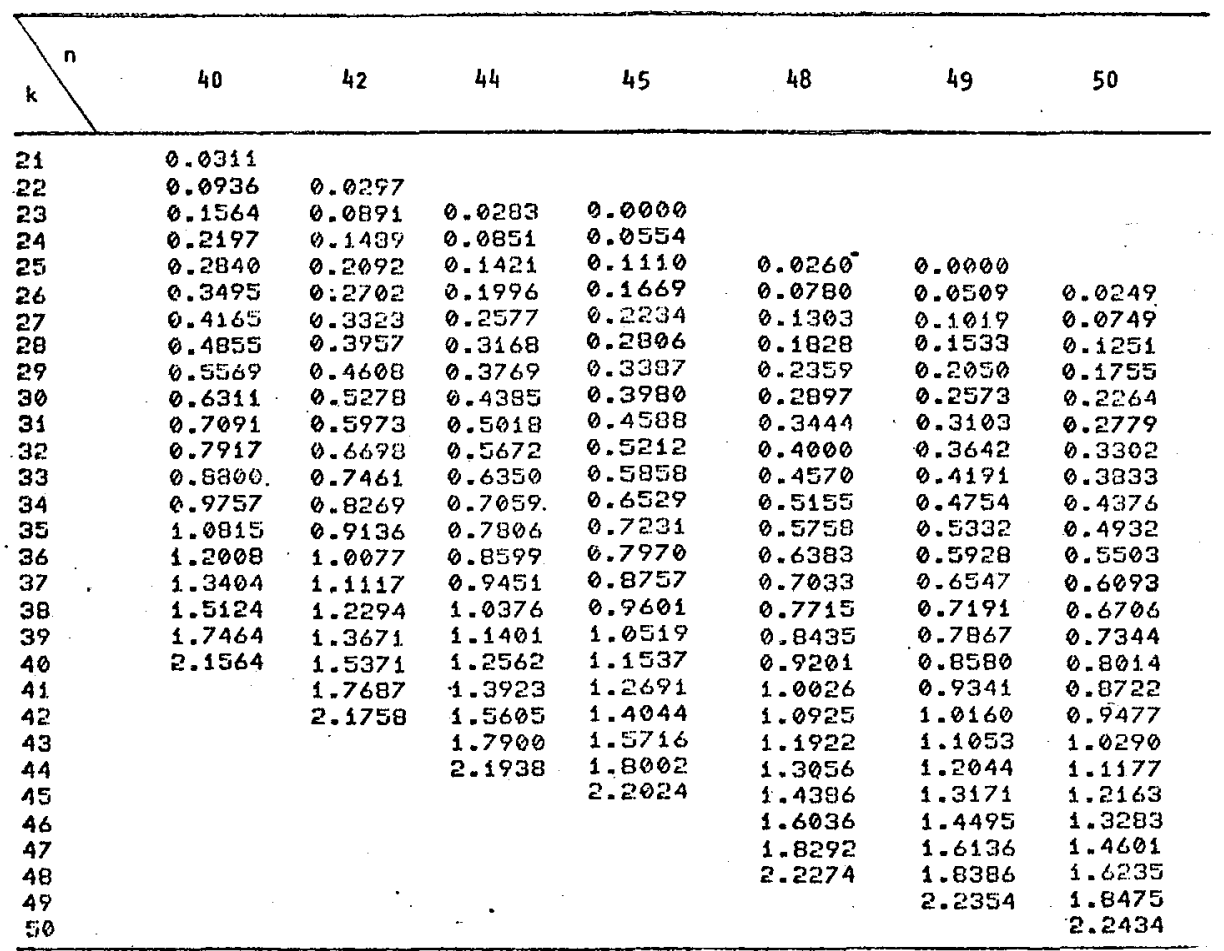


Tabela A3. Valores das constantes $n-t+1$

requeridas para o cálculo da estatística $W$ de Shapiro-Wilk.

\begin{tabular}{|c|c|c|c|c|c|c|c|c|c|c|}
\hline$k$ & 1 & 2 & 3 & 4 & 5 & 6 & 7 & 8 & 9 & 10 \\
\hline 3 & 0.7071 & & & & & & & & & \\
\hline 4 & 0.6872 & 0.1677 & . & & & . & & & & \\
\hline 5 & 0.6646 & 0.2413 & & & & & & & & \\
\hline 6 & 0.6431 & 0.2806 & 0.0875 & & & & & & & \\
\hline 7 & 0.6233 & 0.3031 & 0.1401 & & & & & & & \\
\hline 8 & 0.6052 & 0.3164 & 0.1743 & 0.0561 & & & & & & \\
\hline 9 & 0.5888 & 0.3244 & 0.1976 & 0.0947 & & & & & & \\
\hline 10 & 0.5739 & 0.3291 & 0.2141 & 0.1224 & 0.0399 & & & & & \\
\hline 12 & 0.5475 & 0.3325 & 0.2347 & 0.1586 & 0.0922 & 0.0303 & & & & \\
\hline 14 & 0.5251 & 0.3318 & 0.2460 & 0.1802 & 0.1240 & 0.0727 & 0.0240 & & & \\
\hline 16 & 0.5056 & 0.3290 & 0.2521 & 0.1939 & 0.1447 & 0.1005 & 0.0593 & 0.0196 & & \\
\hline 18 & 0.4886 & 0.3253 & 0.2553 & 0.2027 & 0.1587 & 0.1197 & 0.0837 & 0.0496 & 0.0163 & \\
\hline 20 & 0.4734 & 0.3211 & 0.2565 & 0.2085 & 0.1686 & 0.1334 & 0.1013 & 0.0711 & 0.0422 & 0.0140 \\
\hline 25 & 0.4450 & 0.3069 & 0.2543 & 0.2148 & 0.1822 & 0.1539 & 0.1283 & 0.1046 & 0.0823 & 0.0610 \\
\hline 30 & 0.4254 & 0.2944 & 0.2487 & 0.2148 & 0.1870 & 0.1630 & 0.1415 & 0.1219 & 0.1036 & 0.0862 \\
\hline 35 & 0.4096 & 0.2834 & 0.2427 & 0.2127 & 0.1883 & 0.1673 & 0.1487 & 0.1317 & 0.1160 & 0.1013 \\
\hline 40 & 0.3964 & 0.2737 & 0.2368 & 0.2098 & 0.1878 & 0.1691 & 0.1526 & 0.1376 & 0.1237 & 0.1108 \\
\hline 45 & 0.3850 & 0.2651 & 0.2313 & 0.2065 & 0.1865 & 0.1695 & 0.1545 & 0.1410 & 0.1286 & 0.1170 \\
\hline 50 & 0.3751 & 0.2574 & 0.2260 & 0.2032 & 0.1847 & 0.1691 & 0.1554 & 0.1430 & 0.1317 & 0.1212 \\
\hline
\end{tabular}

\begin{tabular}{c|cccccccccc}
\hline$k$ & 11 & 12 & 13 & 14 & 15 & 16 & 17 & 18 & 19 & 20 \\
\hline 25 & 0.0403 & 0.0200 & & & & & & & & \\
30 & 0.0697 & 0.0537 & 0.0381 & 0.0227 & 0.0076 & & & & & \\
35 & 0.0873 & 0.0739 & 0.0610 & 0.0484 & 0.0361 & 0.0239 & 0.0119 & & & \\
40 & 0.0986 & 0.0870 & 0.0759 & 0.0651 & 0.0546 & 0.0444 & 0.0343 & 0.0244 & 0.0146 & 0.0049 \\
45 & 0.1062 & 0.0959 & 0.0860 & 0.0765 & 0.0673 & 0.0584 & 0.0497 & 0.0412 & 0.0328 & 0.0245 \\
50 & 0.1113 & 0.1020 & 0.0932 & 0.0846 & 0.0764 & 0.0685 & 0.0608 & 0.0532 & 0.0459 & 0.0386 \\
\hline
\end{tabular}

\begin{tabular}{l|ccccc}
\hline$k$ & 21 & 22 & 23 & 24 & 25 \\
$n$ & & $\cdot$ & & & \\
\hline 45 & 0.0163 & 0.0081 & & & \\
50 & 0.0314 & 0.0244 & 0.0174 & 0.0104 & 0.0035 \\
\hline
\end{tabular}

$\mathrm{n}=$ nümero de observações.

Fonte: BARNETT e LEWIS (1984). 
Tabela A4. Valores críticos para a estatística $W$ de Shapiro-Wilk para $\alpha=0,05$ e 0,01 .

\begin{tabular}{ccc}
\hline & \multicolumn{2}{c}{$\alpha$} \\
\cline { 3 - 3 }$n$ & $5 \%$ & $1 \%$ \\
\hline 3 & 0.767 & 0.753 \\
4 & 0.748 & 0.687 \\
5 & 0.762 & 0.686 \\
6 & 0.788 & 0.713 \\
7 & 0.803 & 0.730 \\
8 & 0.818 & 0.749 \\
9 & 0.829 & 0.764 \\
10 & 0.842 & 0.781 \\
12 & 0.859 & 0.805 \\
14 & 0.874 & 0.825 \\
16 & 0.887 & 0.844 \\
18 & 0.897 & 0.858 \\
20 & 0.905 & 0.868 \\
25 & 0.918 & 0.888 \\
30 & 0.927 & 0.900 \\
35 & 0.934 & 0.910 \\
40 & 0.940 & 0.919 \\
45 & 0.945 & 0.926 \\
50 & 0.947 & 0.930 \\
\hline
\end{tabular}

$\mathrm{n}=$ nūmero de observações.

Fonte: BARNETT e LEWIS (1984). 
Tabela A5. Valores críticos para o teste do coeficiente de correlação ba seado na posição de "plot" $p_{k}=(k-0,375) /(n+0,25)$.

\begin{tabular}{|c|c|c|c|c|c|c|c|c|c|c|c|c|c|c|}
\hline$n$ & .000 & .005 & .010 & .025 & .050 & .100 & .250 & .500 & .750 & .900 & .950 & .975 & .990 & .995 \\
\hline 3 & .866 & .867 & .869 & .872 & .879 & .891 & .924 & .966 & .992 & .999 & .9997 & .9999 & 1.000 & 1.000 \\
\hline 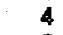 & .785 & .813 & .824 & .846 & .868 & .894 & .931 & .958 & .979 & .992 & .996 & .998 & .999 & 1.000 \\
\hline 5 & .729 & .807 & .826 & .856 & .880 & .903 & .934 & .960 & .977 & .988 & .992 & .995 & .997 & .998 \\
\hline & .686 & .820 & .838 & .866 & .888 & .910 & .939 & .962 & .977 & .986 & .990 & .993 & .996 & .997 \\
\hline 7 & .651 & .828 & .850 & .877 & .898 & .918 & .944 & .964 & .978 & .986 & .990 & .992 & .995 & .996 \\
\hline & .623 & .840 & .861 & .887 & .906 & .924 & .948 & .966 & .978 & .986 & .990 & .992 & .994 & .995 \\
\hline & .599 & .854 & .871 & .894 & .912 & .930 & .952 & .968 & .980 & .986 & .990 & .992 & .994 & .995 \\
\hline 10 & .578 & .862 & .879 & .901 & .918 & .934 & .954 & .970 & .980 & .987 & .990 & .992 & .994 & .995 \\
\hline 11 & .560 & .870 & .886 & .907 & .923 & .938 & .957 & .972 & .981 & .987 & .990 & .992 & .994 & .995 \\
\hline 12 & .544 & .876 & .892 & .912 & .928 & .942 & .960 & .973 & .982 & .983 & .990 & .992 & .994 & .995 \\
\hline 13 & .529 & .885 & .899 & .918 & .932 & .945 & .962 & .974 & .983 & .988 & .991 & .992 & .994 & .995 \\
\hline 14 & .516 & .890 & .905 & .923 & .935 & .948 & .964 . & .976 & .984 & .989 & .991 & .992 & .994 & .995 \\
\hline 15 & .504 & .896 & .910 & .927 & .939 & .951 & .965 & .977 & .984 & .989 & .991 & .993 & .994 & .995 \\
\hline .16 & .493 & .899 & .913 & .929 & .941 & .953 & .967 & .978 & .985 & .989 & .991 & .993 & .994 & .995 \\
\hline 17 & .483 & .905 & .917 & .932 & .944 & .954 & .968 & .979 & .986 & .990 & .992 & .993 & .994 & .995 \\
\hline 18 & .473 & .908 & .920 & .935 & .946 & .957 & .970 & .979 & .986 & .990 & .992 & .993 & .9945 & .9952 \\
\hline 19 & .465 & .914 & .924 & .938 & .949 & .958 & .971 & .980 & .987 & .990 & .992 & .993 & .9946 & .9953 \\
\hline 20 & .457 & .916 & .926 & .940 & .951 & .960 & .972 & .981 & .987 & - .991 & .992 & .894 & .9947 & .9954 \\
\hline 21 & .449 & .918 & .930 & .943 & .952 & .961 & .973 & .982 & .987 & .991 & .993 & .994 & .995 & .996 \\
\hline 22 & .442 & .923 & .933 & .945 & .954 & .963 & .974 & .982 & .988 & .991 & .993 & .994 & .995 & .996 \\
\hline 23 & .435 & .925 & .935 & .947 & .956 & .864 & .975 & .983 & .988 & .991 & .993 & .994 & .995 & .996 \\
\hline 24 & .429 & .927 & .937 & .949 & .957 & .965 & .976 & .983 & .988 & .992 & .993 & .994 & .995 & .996 \\
\hline 25 & .422 & .929 & .939 & .951 & .959 & .966 & .976 & .984 & .989 & .992 & .993 & .994 & .995 & .996 \\
\hline 26 & .417 & .932 & .941 & .952 & .960 & .967 & .977 & .984 & .989 & .992 & .993 & .994 & .995 & .996 \\
\hline 27 & .411 & .934 & .943 & .953 & .961 & .968 & .978 & .985 & .989 & .992 & .994 & .995 & .9955 & .9960 \\
\hline 28 & .408 & .938 & .944 & .955 & .962 & .968 & .978 & .985 & .990 & .992 & .994 & .995 & .9955 & .9960 \\
\hline 29 & .401 & .939 & .946 & .956 & .963 & .970 & .979 & .985 & .990 & .993 & .994 & .995 & .9956 & .9961 \\
\hline 30 & .396 & .939 & .947 & .957 & .964 & .971 & .979 & .986 & .990 & .993 & .994 & .995 & .9957 & .9962 \\
\hline 31 & .392 & .942 & .950 & .958 & .965 & .972 & .980 & .986 & .990 & .993 & .994 & .995 & .9957 & .9962 \\
\hline 32 & .387 & .943 & .950 & .959 & .966 & .972 & .980 & .987 & .991 & .993 & .994 & .995 & .9958 & .9963 \\
\hline 33 & .383 & .944 & .951 & .961 & .967 & .973 & .981 & .987 & .991 & .993 & .994 & .995 & .9959 & .9963 \\
\hline 34 & .379 & .946 & .953 & .962 & .968 & .974 & .981 & .987 & .991 & .993 & .994 & .995 & .996 & .997 \\
\hline 35 & .375 & .947 & .954 & .962 & .969 & .974 & .982 & .987 & .991 & .994 & .9945 & .9953 & .99 & .997 \\
\hline 36 & .371 & .948 & .955 & .963 & .969 & .975 & .982 & .988 & .991 & .994 & .9946 & .9954 & .996 & .997 \\
\hline 37 & .368 & .950 & .956 & .964 & .970 & .976 & .983 & .988 & .991 & .994 & .995 & .9955 & .9962 & .997 \\
\hline 38 & .364 & .951 & .957 & .965 & .971 & .976 & .983 & .988 & .992 & .994 & .995 & .9956 & .99 & .997 \\
\hline 39 & .361 & .951 & .958 & .966 & .971 & .977 & .983 & .988 & .992 & .994 & .995 & .9957 & .9963 & .997 \\
\hline 40 & .358 & .953 & .959 & .966 & .972 & .977 & .984 & .989 & .992 & .994 & .995 & .9957 & .9964 & .997 \\
\hline 41 & .354 & .953 & .960 & .967 & .973 & .377 & .984 & .989 & .95 & .994 & .9 & .996 & .9965 & .9968 \\
\hline 42 & .351 & .954 & .961 & .968 & .973 & .978 & .984 & .989 & .992 & .994 & .995 & .996 & .9965 & .9969 \\
\hline 43 & .348 & .956 & .961 & .968 & .974 & .978 & .984 & .989 & .992 & .994 & .99 & .996 & .99 & .9969 \\
\hline 44 & .346 & .957 & .962 & .969 & .974 & .979 & .985 & .989 & .993 & .9945 & .9953 & .996 & .9966 & .9970 \\
\hline 4 & .34 & .957 & .963 & .969 & .974 & .979 & .985 & .990 & .993 & .9945 & .9954 & .996 & .9966 & .9970 \\
\hline 46 & .340 & .958 & .963 & 970 & .975 & .980 & .985 & .990 & .99 & .995 & .9955 & .9961 & .99 & .9971 \\
\hline 47 & .337 & .959 & .965 & .971 & .976 & .980 & .986 & .990 & .993 & .995 & .9956 & .9962 & .9968 & .9972 \\
\hline 48 & .335 & .959 & .965 & .971 & .976 & .980 & .986 & .990 & .99 & .995 & .9956 & .9962 & .9968 & .9972 \\
\hline 49 & .332 & .961 & .966 & .972 & .976 & .981 & .986 & .990 & .993 & .995 & .9957 & .9963 & .9968 & .9972 \\
\hline 50 & .330 & .961 & .966 & .972 & .977 & .981 & .986 & .990 & .993 & .99 & .9957 & .9963 & .9969 & .9972 \\
\hline 55 & .319 & .965 & .969 & .974 & .979 & .982 & .987 & .991 & .994 & .99 & .996 & .9966 & .9971 & .9974 \\
\hline$\sigma$ & .309 & .967 & .971 & .976 & .980 & .984 & .988 & .992 & .994 & .9956 & .9963 & .9968 & 9973 & .9975 \\
\hline .65 & .300 & .969 & .973 & .978 & .981 & .985 & .989 & .992 & .994 & .996 & .9965 & .9969 & .9974 & .9977 \\
\hline 70 & .292 & .971 & .975 & .979 & .983 & .986 & .990 & .993 & .995 & .99 & .9966 & .9971 & .9975 & .9978 \\
\hline 75 & .28 & .973 & .976 & .981 & .984 & .987 & .990 & .993 & .995 & .99 & .9968 & .9972 & .9976 & .9979 \\
\hline 80 & .277 & .975 & .978 & .982 & .985 & .987 & .991 & .993 & .995 & .99 & .9970 & .9974 & .9978 & .9980 \\
\hline 85 & .271 &. .976 & .979 & .983 & .985 & .988 & .991 & .994 & .996 & .9966 & .9971 & .9975 & .9979 & .9981 \\
\hline 90 & .266 & .977 & .980 & .984 & .986 & .988 & .992 & .994 & .996 & .9967 & .9972 & .9976 & .9979 & .9981 \\
\hline 95 & .260 & .979 & .981 & .984 & .987 & .989 & .992 & .994 & .996 & . 9969 & .9973 & .9977 & .9980 & .9982 \\
\hline 100 & .255 & .979 & .982 & .985 & .987 . & .989 & .992 & .995 & .996 & .9970 & .9974 & .9979 & .9981 & .9983 \\
\hline
\end{tabular}

$n=$ nümero de observações.

Fonte: LOONEY e GULLEDGE (1985). 
Tabela A6. Valores críticos superiores para resíduos studentizados.

\begin{tabular}{|c|c|c|c|c|c|c|c|c|c|c|}
\hline \multirow{2}{*}{$\mathbf{n}$} & \multicolumn{9}{|c|}{$p$} & \multirow[b]{2}{*}{25} \\
\hline & 1 & 2 & 3 & 4 & 5 & 6 & 8 & 10 & 15 & \\
\hline 5 & .1 .92 & & & & ${ }^{\prime}$ & $\therefore$ & r. & & & \\
\hline 6 & 2.07 & 1.93 & & • & & & & & & \\
\hline 7 & 2.19 & 2.08 & 1.94 & & & & & & & \\
\hline 8 & 2.28 & 2.20 & 2.10 & 1.94 & & & & & & \\
\hline 9 & 2.35 & 2.29 & 2.21 & -2.10 & 1.95 & & & & & \\
\hline .10 & 2.42 & 2.37 & 2.31 & 2.22 & 2.11 & 1.95 & & & & \\
\hline 12 & 2.52 & 2.49 & 2.45 & 2.39 & 2.33 & 2.24 & 1.96 & & & . \\
\hline 14 & 2.61 & 2.58 & 2.55 & 2.51 & 2.47 & 2.41 & 2.25 & 1.96 & & \\
\hline 16 & 2.68 & 2.66 & 2.63 & 2.60 & 2.57 & 2.53 & 2.43 & 2.26 & & \\
\hline 18 & 2.73 & 2.72 & 2.70 & 2.68 & 2.65 & 2.62 & 2.55 & 2.44 & & \\
\hline 20 & 2.78 & 2.77 & 2.76 & 2.74 & 2.72 & 2.70 & 2.64 & 2.57 & 2.15 & \\
\hline $25^{\circ}$ & 2.89 & 2.88 & 2.87 & $2.86^{\circ}$ & 2.84 & 2.83 & 2.80 & 2.76 & 2.60 & \\
\hline 30 & 2.96 & 2.96 & 2.95 & 2.94 & 2.93 & 2.93 & 2.90 & 2.88 & 2.79 & 2.17 \\
\hline 35 & 3.03 & 3.02 & 3.02 & 3.01 & 3.00 & 3.00 & 2.98 & 2.97 & 2.91 & 2.64 \\
\hline 40 & 3.08 & 3.08 & 3.07 & 3.07 & 3.06 & 3.06 & 3.05 & 3.03 & 3.00 & 2.84 \\
\hline 45 & 3.13 & 3.12 & 3.12 & 3.12 & 3.11 & 3.11 & 3.10 & 3.09 & 3.06 & 2.96 \\
\hline 50 & 3.17 & 3.16 & .3 .16 & 3.16 & 3.15 & 3.15 & 3.14 & 3.14 & 3.11 & 3.04 \\
\hline 60 & 3.23 & 3.23 & 3.23 & 3.23 & 3.22 & 3.22 & 3.22 & 3.21 & 3.20 & 3.15 \\
\hline 70 & 3.29 & 3.29 & 3.28 & 3.28 & 3.28 & 3.28 & 3.27 & 3.27 & 3.26 & 3.23 \\
\hline 80 & 3.33 & 3.33 & 3.33 & 3.33 & 3.33 & 3.33 & 3.32 & 3.32 & 3.31 & 3.29 \\
\hline 90 & 3.37 & 3.37 & 3.37 & 3.37 & 3.37 & 3.37 & 3.36 & 3.36 & 3.36 & 3.34 \\
\hline 100 & 3.41 & 3.41 & 3.40 & 3.40 & 3.40 & 3.40 & 3.40 & 3.40 & 3.39 & 3.38 \\
\hline
\end{tabular}


Tabela A6. Continuação.

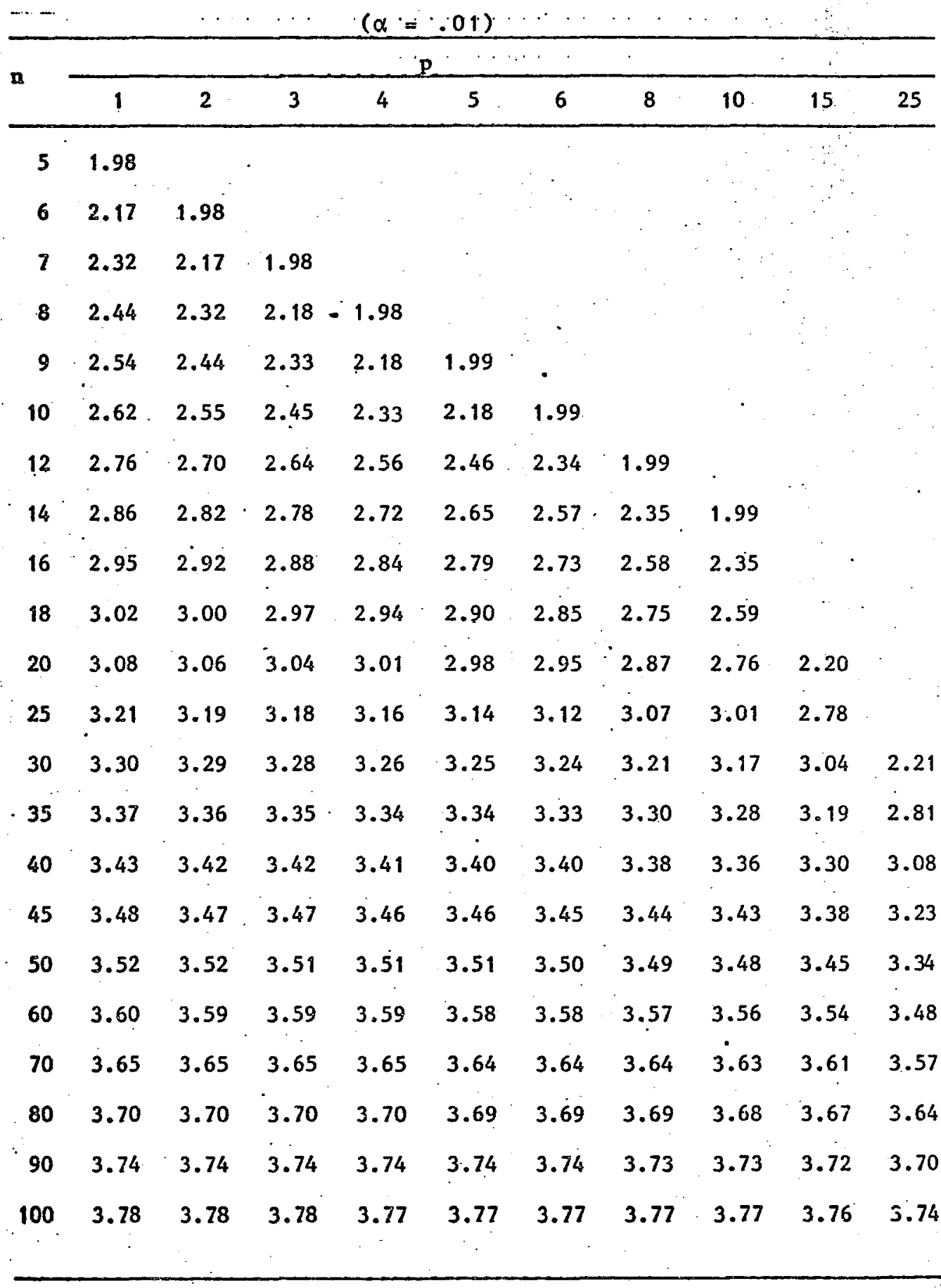

$n=$ nümero de observaçōes; $p=r[X]$.

Fonte; LUND (1975). 
Tabela A7. Limite superior, $g_{\alpha}$, para o coeficiente de correlação mínimo, $\alpha=0,05$.

\begin{tabular}{|c|c|c|c|c|c|c|c|c|c|c|}
\hline \multirow[t]{2}{*}{$\mathbf{n}$} & & \multicolumn{8}{|c|}{$\mathrm{p}$} & \multirow[b]{2}{*}{15} \\
\hline & & 1 & 2 & 3 & 4 & 5 & 6 & 8 & 10 & \\
\hline $\begin{array}{l}5 \\
6 \\
7 \\
8 \\
9 \\
10 \\
12 \\
14 \\
16 \\
18 \\
20 \\
25 \\
30 \\
35 \\
40 \\
50\end{array}$ & $\therefore$ & $\begin{array}{l}.744 \\
.624 \\
.542 \\
.481 \\
.434 \\
.397 \\
.340 \\
.298 \\
.266 \\
.241 \\
.220 \\
.183 \\
.157 \\
.137 \\
.123 \\
.102\end{array}$ & $\begin{array}{l}.923 \\
.768 \\
.645 \\
.559 \\
.495 \\
.445 \\
.373 \\
.323 \\
.285 \\
.256 \\
.233 \\
.191 \\
.162 \\
.142 \\
.126 \\
.104\end{array}$ & $\begin{array}{l}.936 \\
.787 \\
.663 \\
.573 \\
.506 \\
.414 \\
.352 \\
.307 \\
.273 \\
.246 \\
.199 \\
.168 \\
.146 \\
.130 \\
.106\end{array}$ & $\begin{array}{l}.944 \\
.803 \\
.678 \\
.586 \\
.464 \\
.386 \\
.332 \\
.293 \\
.262 \\
.209 \\
.175 \\
.151 \\
.133 \\
.108\end{array}$ & $\begin{array}{l}.951 \\
.816 \\
.690 \\
.526 \\
.428 \\
.362 \\
.315 \\
.279 \\
.219 \\
.182 \\
.156 \\
.137 \\
.111\end{array}$ & $\begin{array}{l}.957 \\
.827 \\
.607 \\
.479 \\
.398 \\
.341 \\
.299 \\
.231 \\
.190 \\
.161 \\
.141 \\
.113\end{array}$ & $\begin{array}{l}. \\
.845 \\
.624 \\
.492 \\
.408 \\
.349 \\
.258 \\
.207 \\
.174 \\
.150 \\
.119\end{array}$ & $\begin{array}{l}.858 \\
.639 \\
.504 \\
.416 \\
.293 \\
.228 \\
.188 \\
.160 \\
.125\end{array}$ & $\begin{array}{r}.978 \\
.765 \\
.435 \\
.304 \\
.235 \\
.192 \\
.143\end{array}$ \\
\hline
\end{tabular}

$\mathrm{n}=$ nümero de observações; $\mathrm{p}=\mathrm{r}[\mathrm{X}]$.

Fonte: DOORNBOS (1981). 